UNIVERSIDADE DE SÃO PAULO

FACULDADE DE ODONTOLOGIA DE BAURU

ALINE DUARTE DA CRUZ

Esforço auditivo e fadiga em adolescentes com deficiência auditiva - Uso do Sistema FM

BAURU

2018 



\section{Esforço auditivo e fadiga em adolescentes com deficiência auditiva - Uso do Sistema FM}

Tese apresentada à Faculdade de Odontologia de Bauru da Universidade de São Paulo para obtenção do título de Doutor em Ciências no Programa de Fonoaudiologia, na área de concentração Processos e Distúrbios da Comunicação

Orientadora: Profa. Dra. Regina Tangerino de Souza Jacob

Coorientador: Prof. Dr. Jean-Pierre Gagné

\section{Versão corrigida}

\section{BAURU}




\begin{tabular}{|c|c|}
\hline & Cruz, Aline Duarte da Cruz \\
\hline C889e & $\begin{array}{l}\text { Esforço auditivo e fadiga em adolescentes com } \\
\text { deficiência auditiva - Uso do Sistema FM / Aline Duarte } \\
\text { da Cruz. - Bauru, } 2018 \text {. }\end{array}$ \\
\hline & 128 p. : il. ; 31cm. \\
\hline & $\begin{array}{l}\text { Tese (Doutorado) - Faculdade de Odontologia de } \\
\text { Bauru. Universidade de São Paulo }\end{array}$ \\
\hline & $\begin{array}{l}\text { Orientadora: Profa. Dra. Regina Tangerino de } \\
\text { Souza Jacob }\end{array}$ \\
\hline & Coorientador: Prof. Dr. Jean-Pierre Gagné \\
\hline
\end{tabular}

Nota: A versão original desta tese encontra-se disponível no Serviço de Biblioteca e Documentação da Faculdade de Odontologia de Bauru - FOB/USP.

Autorizo, exclusivamente para fins acadêmicos e científicos, a reprodução total ou parcial desta dissertação/tese, por processos fotocopiadores e outros meios eletrônicos.

Assinatura:

Comitê de Ética da FOB-USP

Protocolo no: $1.074 .623 / 2015$

Data: $22 / 05 / 2015$ 
FOLHA DE APROVAÇÃO 



\section{DEDICATÓRIA}

Aos meu pais, Júlia e Gercio, que sempre me deram a oportunidade de escolher os caminhos e sempre me apoiaram para continuar caminhando em frente. Obrigada pelas palavras de incentivo e pela maneira com que me ensinam a superar cada obstáculo em meu caminho e a perseguir meus ideais com dedicação e coragem, sem nunca desistir.

A vocês dedico este trabalho e todo o meu amor. 



\section{AGRADECIMENTOS}

A Deus, por estar sempre comigo, me guiando, iluminado meu caminho em todos os momentos da minha vida.

A minha família, pelo incentivo, paciência e carinho.

A minha orientadora, Profa. Dra. Regina Tangerino de Souza Jacob, pela oportunidade de desenvolver essa pesquisa. Por compartilhar seus conhecimentos, pela confiança e dedicação com que me orientou. Obrigada por todos os ensinamentos, apoio, oportunidades e por fazer parte do meu crescimento profissional.

Ao meu co-orientador, Prof. Dr. Jean-Pierre Gagné, por compartilhar seus conhecimentos, por ter me dado a oportunidade de realizar um estágio em seu laboratório no Institut Universitaire de Gériatrie de Montréal, e viabilizar minha experiência do doutorado sanduíche, proporcionando-me imenso aprendizado profissional e pessoal.

Ao Prof. Dr. Seiji Isotani e Ms. Doutorando Wilmax Marreiro Cruz do Departamento de Sistemas de Computação do Instituto de Ciências Matemáticas e de Computação da Universidade de São Paulo pela parceria e desenvolvimento da plataforma para auxiliar a execução de testes de dupla tarefa, denominada PALETA.

Aos adolescentes, sem os quais seria impossível a realização deste trabalho. Obrigada pela confiança e colaboração.

As professoras Dra. Adriane Lima Mortari Moret, Dra. Natália Barreto Frederigue Lopes e Dra. Erika Cristina Bucuvic, pelas valiosas contribuições e participação na banca de qualificação.

Às Fga. Dra. Erika Cristina Bucuvic, Fga. Dra. Ticiana Cristina de Freitas Zambonato e Fga. Ms. Patrícia Graciano Vicci Araújo por terem me acolhido na DSA-HRAC e por compartilharem comigo todos os seus conhecimentos sobre o Sistema FM, e à Aline Martins de Oliveira por todo o auxílio com o agendamento dos pacientes. 

As professoras Dra. Maria Fernanda Capoani Garcia Mondelli, Dra. Ticiana Cristina de Freitas Zambonato, Dra. Eliane Maria Carrit Delgado-Pinheiro por aceitarem o convite para serem membro titular da banca examinadora da minha tese. Muito obrigada pela disponibilidade e por suas valiosas contribuições e considerações que enriqueceram este trabalho.

À Designer Camila Medina, por todo capricho e dedicação com o tutorial da PALETA.

À Tradutora Amanda Salimon, por toda ajuda e auxílio.

A Leslie Gauthier, pela ajuda na realização da análise estatística e por auxiliar sempre nos momentos do trabalho em Montréal. Obrigada pelo carinho e amizade.

Ao Departamento de Fonoaudiologia e seus funcionários por toda a ajuda.

Aos meus amigos, próximos e distantes, pela alegria de fazerem parte da minha vida e por estarem sempre ao meu lado, me apoiando e torcendo por mim. Obrigada pela amizade.

Aos meus amigos e a minha família canadense, que tive a oportunidade de conhecer em Montréal. Obrigada pelo acolhimento e suporte que me deram, e por todos os momentos inesquecíveis.

A Coordenação de Aperfeiçoamento de Pessoal de Nível Superior (CAPES), pelo apoio financeiro à pesquisa, pela bolsa de doutorado e a pela bolsa do Programa de Doutorado Sanduíche no Exterior (Processo No: 88881.132744/2016-01).

A todos que direta ou indiretamente contribuíram para a realização deste trabalho e me ajudaram a chegar até aqui. 

"O futuro não é um lugar aonde estamos indo, mas um lugar que estamos criando. O caminho para ele não é encontrado, mas construído." 



\section{RESUMO}

O esforço auditivo é definido como o esforço cognitivo e de atenção necessários para compreender a fala em ambiente ruidoso. Este estudo teve como objetivo analisar o esforço auditivo e fadiga em adolescentes com deficiência auditiva, usuários de aparelho de amplificação sonora individual (AASI), sem e com sistema de frequência modulada (FM), e comparar com adolescentes com audição normal, por meio do desenvolvimento de uma plataforma para execução da tarefa secundária em teste de dupla tarefa; analisar o impacto do ruído na aprendizagem pela perspectiva dos participantes; e investigar a opinião dos usuários sobre o impacto do uso do sistema FM na sala de aula. Participaram 18 adolescentes com audição normal e 13 adolescentes com deficiência auditiva sensorioneural, bilateralmente, de grau moderado e severo usuários de AASI e sistema FM, com média de idade de 14 anos. O esforço auditivo foi avaliado por meio do paradigma da dupla tarefa, a fadiga por meio de escala, o impacto do ruído na aprendizagem por meio de uma questão e foi aplicado um questionário sobre o uso do sistema FM em ambiente educacional. Foram utilizados para análise dos resultados o teste $T(p<0,01)$, Anova, qui-quadrado de Pearson $(p<0,05)$ e análise descritiva. Foi elaborada uma plataforma para auxiliar a execução do teste de dupla tarefa, denominada PALETA, com um teste de memória de reconhecimento de cores. A diferença do esforço auditivo com base no número de respostas corretas foi estatisticamente significativa entre os participantes do grupo com audição normal e os participantes do grupo com deficiência auditiva na condição apenas com AASI, o que não ocorreu quando analisado o tempo de resposta. Os resultados sugerem que o desempenho do grupo com audição normal foi próximo ao do grupo com deficiência auditiva na condição com AASI e sistema FM, sendo que na condição de uso apenas do AASI apresentou um esforço auditivo maior. Os resultados obtidos na escala de avaliação da fadiga não revelaram diferenças estatisticamente significativas entre nenhum dos grupos. Sobre o impacto no ruído na sala de aula, os resultados revelaram que o grupo usuário de AASI e sistema FM relataram menor queixa quanto ao ruído interferir na aprendizagem do que seus pares ouvintes e na condição apenas com seus AASI. O questionário aplicado forneceu informações sobre as perspectivas do usuário de sistema FM, que em sua maioria encontravam-se 

satisfeitos e faziam o uso efetivo de seus dispositivos em sala de aula. Conclui-se que a PALETA é considerada uma ferramenta efetiva para auxiliar na cução de teste de dupla tarefa quando considerado o número de respostas corretas; o uso do sistema FM foi efetivo para reduzir o esforço auditivo; não foram encontradas diferenças significativas entre os grupos quanto à fadiga; a queixa dos adolescentes com deficiência auditiva quanto ao impacto do ruído na aprendizagem diminui significativamente com o uso do sistema FM, e a maioria dos adolescentes usuários de sistema FM encontravam-se satisfeitos e faziam o uso efetivo de seus dispositivos em sala de aula.

Palavras-chave: Adolescente. Perda Auditiva. Auxiliares de Audição. Relação SinalRuído. Ruído. Fadiga. Teste de Esforço. 



\section{ABSTRACT \\ Listening effort and fatigue in hearing impaired adolescents - The use of FM systems}

Listening effort is defined as the cognitive effort and the attention required to understand speech in a noisy environment. This study aims to analyze listening effort and fatigue in hearing impaired adolescents, users of HA, with and without a FM system, and to compare them with adolescents with normal hearing, through development of a platform for performing the secondary task in a dual-task test; analyze the impact of noise on learning from the participants' perspective; and investigate users' opinions on the impact of using the FM system in the classroom. A total of 31 adolescents participated in this study: 18 with normal hearing and 13 with moderate to severe bilateral sensorineural hearing loss, users of HA and FM system. The mean age of the adolescents was 14 years. Listening effort was evaluated using dual task paradigm; fatigue, using a scale; the impact of noise on learning, using a question; and the use of the FM system in an educational environment, using a questionnaire. The results were statistically analyzed using t-test $(p<0.01)$, Anova, chisquare of Pearson $(p<0.05)$ and descriptive analysis. A platform was developed to assist in the execution of the dual task test. The platform was named PALETA and consisted of color recognition memory test. Based on the number of correct responses, the difference in listening effort was statistically significant between the participants of the normal hearing group and the participants of the hearing-impaired group when these participants were using $\mathrm{HA}$; but the difference was not statistically significant when comparing response times. The results suggest that the performance of the normal hearing group was similar to the hearing-impaired group when these participants were using a HA and a FM system. When the participants of the hearingimpaired group were using only the HA, the results showed a greater listening effort. The results obtained in the fatigue assessment scale did not reveal statistically significant differences in any of the groups. On the impact of noise in the classroom, the results revealed that the hearing-impaired group users of hearing aid and FM system reported less complaints about noise interfering in learning than their normal hearing peers and in the condition only with their HA. The questionnaire applied 

provided information on the user's perspectives of FM system, which showed that the users were mostly satisfied and made effective use of their devices in the classroom. It is concluded that PALETA is considered an effective tool to assist in the execution of dual task test when considering the number of correct answers; the use of the FM system was effective in reducing listening effort; no significant differences were found between the groups regarding fatigue; the complaint of adolescents with hearing loss about the impact of noise on learning diminishes significantly with the use of the FM system; and the majority of adolescents using FM systems were satisfied and made effective use of their devices in the classroom.

Key words: Adolescent. Hearing Loss. Hearing Aids. Signal-To-Noise Ratio. Noise. Fatigue. Exercise Test 



\section{LISTA DE ILUSTRAÇÕES}

\section{- FIGURAS}

Figura 1 - Modelo de relação entre a perda auditiva, a fadiga e o desempenho escolar.

Figura 2 - Critérios de exclusão dos estudos identificados 36

Figura 3 - Ambiente do procedimento.

Figura 4 - As médias das relações sinal/ruído no teste HINT ( \pm 1 SD) para a tarefa única (barras cinza) e dupla tarefa (barra preta) são plotadas como função das condições experimentais para o grupo com audição normal (G1) e o grupo com deficiência auditiva (G2) sob as condições de amplificação (AASI e AASI + sistema FM)

Figura 5 - As médias dos tempos de respostas em segundos ( $\pm 1 \mathrm{SD}$ ) para a tarefa de memória de reconhecimento de cores para as condições de tarefa única (barras cinza) e de dupla tarefa (barra preta) são plotadas para as condições de escuta para o grupo com audição normal (G1) e o grupo com deficiência auditiva (G2) nas condições de amplificação (AASI e AASI + sistema FM)

Figura 6 - Média do esforço auditivo com base nos dados dos tempos de respostas em segundos ( $\pm 1 \mathrm{SD}$ ) para a tarefa de memória de reconhecimento de cores para o grupo com audição normal (G1) e o grupo com deficiência auditiva (G2- AASI e G2- AASI + sistema FM)

Figura 7 - Média do número de respostas corretas na tarefa de memória de reconhecimento de cores ( $\pm 1 \mathrm{SD}$ ) para o grupo com audição normal (G1) e o grupo com deficiência auditiva (G2) em ambas as condições de amplificação (AASI e AASI + sistema FM) 

Figura 8 - Média do esforço auditivo com base no número de respostas corretas na tarefa de memória de reconhecimento de cores ( $\pm 1 \mathrm{SD}$ ) para o grupo com audição normal (G1) e o grupo com deficiência (G2) em ambas as condições de amplificação (AASI e AASI + sistema FM)

Figura 9 - Escores médios obtidos para a escala de fadiga ( \pm 1 SD) para o grupo com audição normal (G1) e o grupo de participantes com deficiência auditiva (G2) que preencheram o questionário para duas condições de audição: AASI e AASI + sistema FM

Figura 10 - Percentual das respostas obtidas na questão 1 (escala LERI) para o grupo com audição normal (G1) e o grupo com deficiência auditiva (G2) que responderam à questão para duas condições de audição: AASI e AASI + Sistema FM 65

- QUADROS

Quadro 1 - Design do Quadrado Latino - G2 52

Quadro 2 - Design do Quadrado Latino- G1. 53

Quadro 3 - Síntese dos resultados significativos entre os grupos 63 



\section{LISTA DE TABELAS}

Tabela 1 - Estratégias de busca para consultas e número de artigos encontrados nas bases de dados de acordo com os descritores...... 36

Tabela 2 - Dados demográficos dos participantes do G2 (n=13) 48

Tabela 3 - Síntese dos modelos e marcas dos sistemas FM utilizados pelos participantes $(n=13)$.

Tabela 4 - Condições de apresentações das tarefas 52

Tabela 5 - Questionário de Avaliação do Sistema FM: Perspectiva do Usuário 66 



\section{LISTA DE ABREVIATURA E SIGLAS}

AASI Aparelho de Amplificação Sonora Individual

ABNT Associação Brasileira de Normas Técnicas

AN

Audição Normal

ANSI

American National Standard Institute

ASA

Acoustical Society of American

BVS Biblioteca Virtual em Saúde

CEP Comitê de Ética em Pesquisa

DA Deficiência Auditiva

$\mathrm{dB} \quad$ Decibel

DECS Descritores em Ciências da Saúde

DSA Divisão de Saúde Auditiva

DT

Dupla Tarefa

ECA Estatuto da Criança e do Adolescente

EVA Escala Visual Analógica

FM Frequência Modulada

FOB Faculdade de Odontologia de Bauru

G1

Grupo 1

G2

Grupo 2

G2AASI Grupo 2 - Aparelho de Amplificação Sonora Individual

G2FM Grupo 2 - Aparelho de Amplificação Sonora Individual e Sistema de Frequência Modulada

HRAC Hospital de Reabilitação de Anomalias Craniofaciais

HINT Hearing in Noise Test

IC Implante Coclear

IPRF I Índice Percentual de Reconhecimento de Fala

LDV Limiar de Detecção de Voz 



$\begin{array}{ll}\text { LERI } & \text { Learning Effort-Reward Imbalance } \\ \text { LIBRAS } & \text { Língua Brasileira de Sinais } \\ \text { LRS } & \text { Limiar de Reconhecimento de Sentenças } \\ \text { MEG } & \text { Magnetoencefalografia } \\ \text { NBR } & \text { Norma Brasileira } \\ \text { NRC } & \text { Número de Respostas Corretas } \\ \text { OPM } & \text { Órteses, Próteses e Materiais Especiais } \\ \text { PedsQL MFS } & \text { Pediatric Quality of Life Inventory - Multidimensional Fatigue Scale } \\ \text { PDT } & \text { Paradigma da dupla tarefa } \\ \text { S/R } & \text { Sinal/Ruído } \\ \text { SSQ } & \text { Speech, Spatial and Qualities } \\ \text { SUS } & \text { Sistema Único de Saúde } \\ \text { TA } & \text { Tecnologia Assistiva } \\ \text { TP } & \text { Tarefa primária } \\ \text { TR } & \text { Tempo de Resposta } \\ \text { TS } & \text { Tarefa secundária } \\ \text { USP } & \text { Universidade de São Paulo }\end{array}$





\section{SUMÁRIO}

1 INTRODUÇÃO

2 REVISÃO DE LITERATURA

2.1 ADOLESCÊNCIA - DESAFIOS DO ADOLESCENTE COM

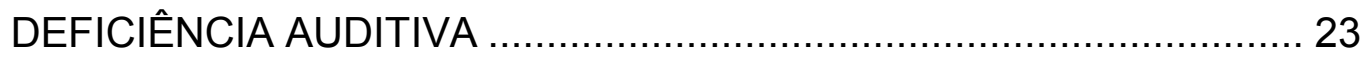

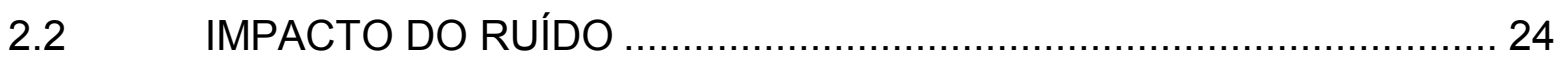

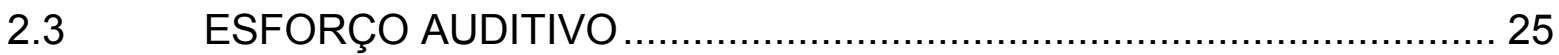

2.4 SISTEMA DE FREQUÊNCIA MODULADA (FM) ............................. 33

2.4.1 Esforço auditivo e o uso do sistema FM em adolescentes: revisão sistemática de literatura

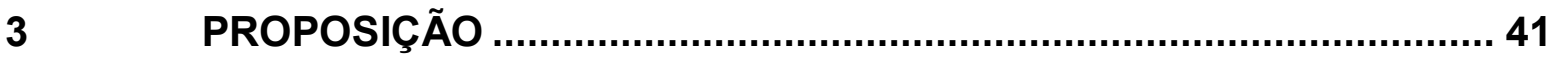

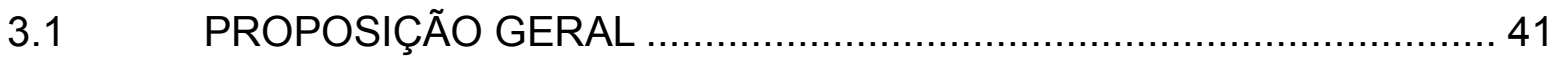

3.2 PROPOSIÇÕES ESPECÍFICAS ……….................................... 41

$4 \quad$ MATERIAL E MÉTODOS................................................................ 45

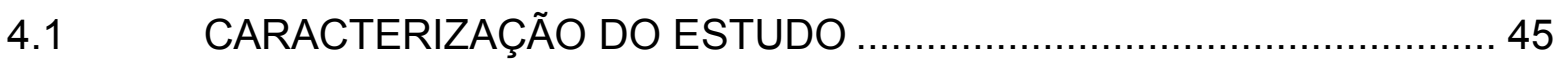

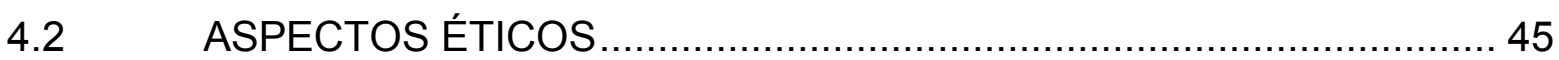

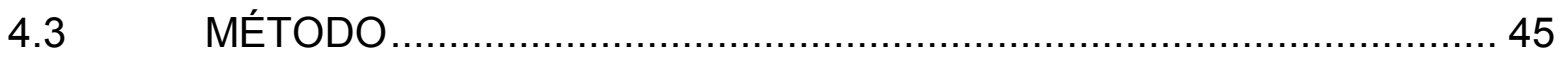

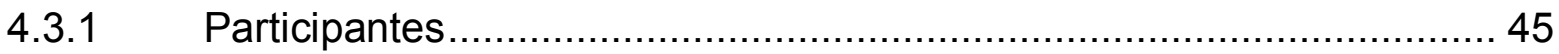

4.3.1.1 Recrutamento e seleção dos participantes.......................................... 46

4.3.1.2 Descrição dos participantes.............................................................. 47

4.3.2 Instrumentos e procedimentos ..................................................... 49

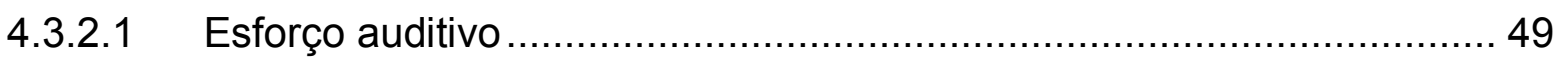

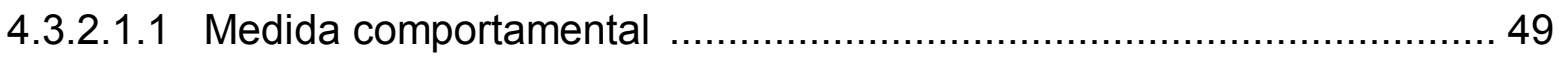

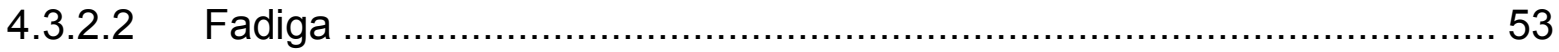

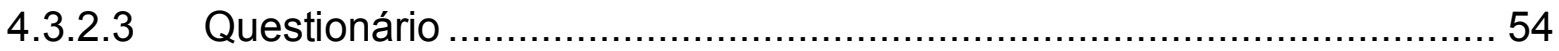

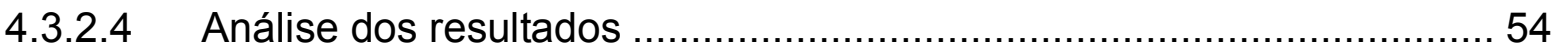

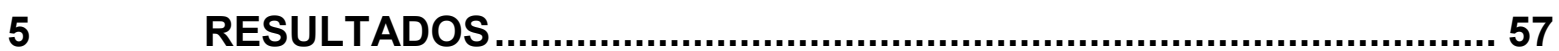

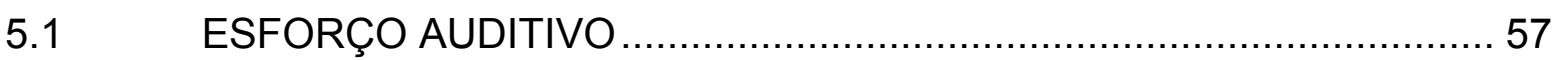





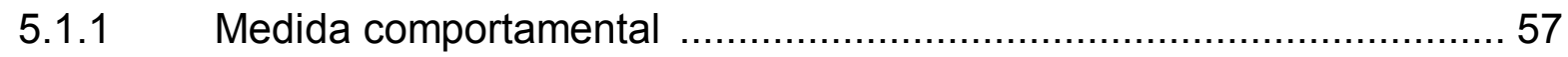

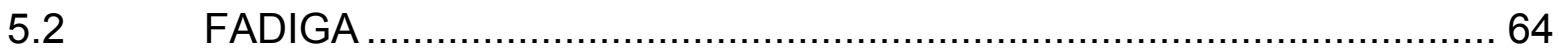

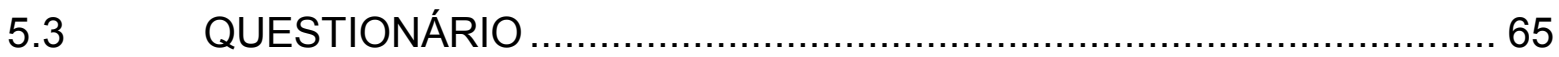

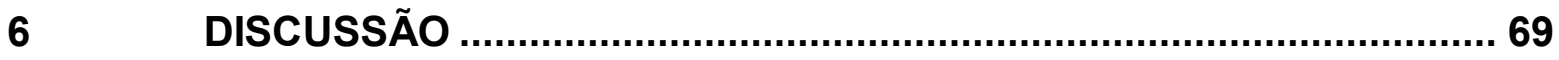

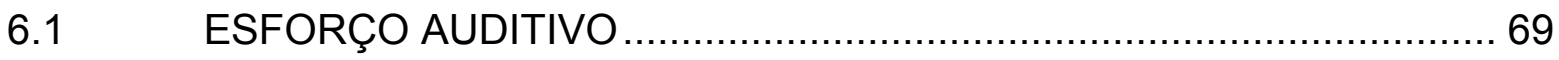

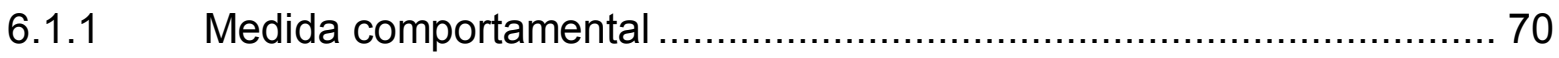

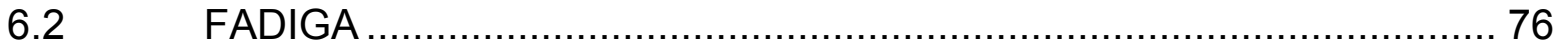

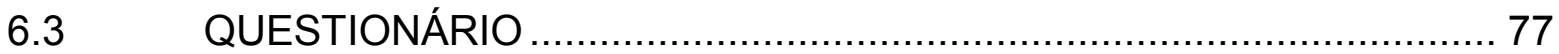

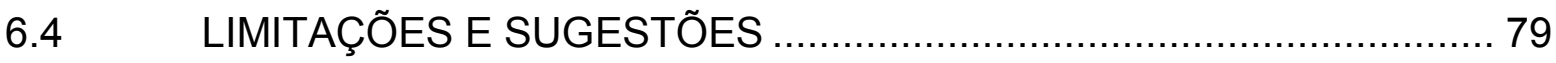

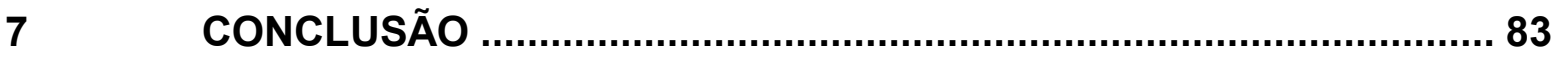

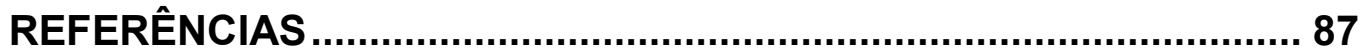

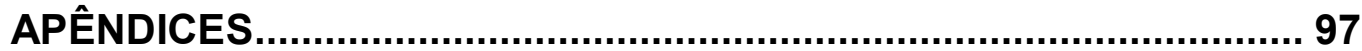

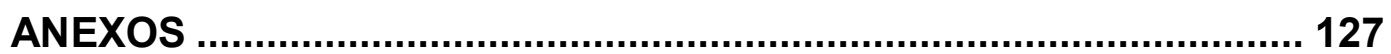



1 INTRODUÇÃO 



\section{INTRODUÇÃO}

Nas salas de aula os níveis de ruído geralmente são elevados, com impacto direto no esforço auditivo. O esforço auditivo é definido como os esforços cognitivos e de atenção que são necessários para a compreensão do sinal de fala na presença de ruído de fundo (HICKS; THARPE, 2002; GOSSELIN; GAGNÉ, 2010).

Os problemas relacionados ao esforço auditivo e fadiga em indivíduos com deficiência auditiva (DA) podem ser minimizados por meio da utilização do aparelho de amplificação sonora individual (AASI) e/ou do implante coclear (IC). No entanto, a maior queixa dos indivíduos com DA ainda é a dificuldade de entender a fala em ambientes com ruído competitivo, mesmo com a utilização do AASI e/ou IC (KOCHKIN, 2011).

A mensuração do esforço auditivo pode ser realizada por meio de medidas de autoavaliação, fisiológicas e/ou comportamentais. Embora na literatura não haja consenso acerca de qual é a melhor medida a ser utilizada para mensurar o esforço auditivo, estudos apontam que todas são válidas (MCGARRIGLE et al., 2014, GAGNÉ et al., 2017).

As medidas de autoavaliação geralmente incluem escalas ou questionários que mensuram o esforço auditivo por meio do uso de escala visual analógica (EVA) (RUDNER et al., 2012; MCGARRIGLE et al., 2014; BESS; HORNSBY, 2014; GATEHOUSE; NOBLE, 2004).

As medidas fisiológicas, por sua vez, podem incluir as seguintes mensurações: dilatação da pupila (ZEKVELD; KRAMER; FESTEN, 2011); nível de cortisol (HICKS; THARPE, 2002); mudanças na frequência cardíaca (MACKERSIE; CONES, 2011); condutividade dérmica ou eletromiografia de superfície (MACKERSIE; CONES, 2011); e magnetoencefalografia (MEG) (OBLESER et al., 2012).

As medidas comportamentais incluem o uso do paradigma de tarefa simples (HOUBEN; DOORN-BIERMAN; DRESCHLER, 2013) e/ou do paradigma da dupla tarefa (PDT) (HICKS; THARPE, 2002; HORNSBY, 2013; STELMACHOWICZ et al., 2007).

Estudos internacionais utilizam o PDT para fornecer uma medida comportamental do esforço auditivo. O PDT é uma avaliação composta por um teste 
de fala no ruído (tarefa primária - TP), que é apresentado juntamente com outra tarefa, como por exemplo, uma tarefa de memória (tarefa secundária - TS). Nessa tarefa o paciente deve ser orientado que o reconhecimento da fala é a principal tarefa em que ele deve focar sua atenção, e que qualquer outra tarefa é secundária (GOSSELIN; GAGNÉ, 2011; HORNSBY, 2013).

O PDT está relacionado à execução eficiente de várias operações mentais simultâneas, como o que acontece no ambiente de aprendizagem. Um exemplo é quando em aula se exige que os alunos acompanhem atentamente a fala contínua do professor, enquanto fazem suas anotações (HOWARD; MUNRO; PLACK, 2010). As consequências mais comuns do esforço auditivo são o aumento do stress e da fadiga (HORNSBY et al., 2014).

$\mathrm{Na}$ literatura não foram encontrados estudos que investigassem e correlacionassem o impacto do esforço auditivo e da fadiga em adolescentes com DA usuários de sistema de frequência modulada (FM). Considerando que esses fatores podem comprometer o aprendizado do indivíduo em ambiente de sala de aula ruidosa, acredita-se que seja de extrema importância a realização de que estudos que tenham como objetivo mensurar o esforço auditivo e a fadiga em adolescentes com DA, incluindo os usuários de sistema FM, a fim de desenvolver instrumentos visando a padronização da avaliação do esforço auditivo por meio do paradigma da dupla tarefa. 
2 REVISÃo DE LITERATURA 



\section{REVISÃO DE LITERATURA}

\subsection{ADOLESCÊNCIA - DESAFIOS DO ADOLESCENTE COM DEFICIÊNCIA AUDITIVA}

De acordo com o Estatuto da Criança e do Adolescente (ECA) Lei 8.069/90, considera-se criança a pessoa até os doze anos de idade incompletos, e adolescente aquela entre 12 e 18 anos de idade (BRASIL, 1990).

Segundo Lobo (2016) a adolescência é um período transitório entre a infância e a vida adulta. Trata-se de uma fase de modificações e conflitos pessoais.

A literatura aponta que se trata de uma fase crítica por si só. Portanto, os adolescentes com DA, além de lidarem com as mudanças típicas da puberdade, personalidade-busca pela identidade e ambiente, precisam lidar com a sua DA e suas limitações que representam um fator de diferenciação (LOBO, 2016).

Zugliani, Motti e Castanho (2007) destacam que nessa fase pode haver um agravamento da ansiedade e tensões, porque a DA afeta a comunicação e entendimento com o seu ambiente, que em geral é composto por indivíduos ouvintes. Devido a isso, o adolescente precisa formar sua identidade como sendo uma pessoa que possui uma DA.

Embora a DA não seja visível de imediato, o uso do AASI e/ou IC faz com que ela seja notada. Desta forma, a aceitação da DA soma-se à necessidade de aceitação do uso do recurso de amplificação sonora (ZUGLIANI; MOTTI; CASTANHO, 2007). Nesse sentido, Fonseca (2001) relatam que os dispositivos são a marca da deficiência, despertam curiosidade e colocam o usuário em evidência.

Durante o processo de reabilitação da criança ou adolescente, o envolvimento familiar é de extrema importância, assim como, o acesso a atendimento especializados (fonoaudiólogos, médicos, psicólogos, entre outros) e da escola (MIGUEL; NOVAES, 2013).

$\mathrm{Na}$ fase da adolescência, a experiência clínica nos atendimentos dos pacientes com DA tem mostrado que o uso do AASI pode ser muitas vezes interrompido ou não usado efetivamente. Levando em consideração que os adolescentes com DA passam a maior parte do tempo na escola, o uso efetivo do AASI e/ou IC é de extrema 
importância, visto que a maior queixa dos indivíduos com DA ainda é a dificuldade de entender a fala em ambientes com ruído competitivo, mesmo com a utilização do AASI e/ou IC (KOCHKIN, 2011).

\subsection{IMPACTO DO RUÍDO}

Em um ambiente com presença de ruído de fundo, a compreensão do sinal de fala pode ser prejudicada, o que pode levar à perda ou distorção da mensagem recebida (RUDNER et al., 2011).

Nas salas de aula, os níveis de ruído geralmente excedem os valores recomendados (CRUZ, 2016; FIDÊNCIO, 2014) pela Associação Brasileira de Normas Técnicas (ABNT) por meio da norma NBR 10.152 de 1987 e pela American National Standard Institute (ANSI, 2010). A norma brasileira (NBR) 10.152 de 1987 da ABNT regulariza os níveis de ruído recomendados para salas de aula que considera 40 decibel (dB) como o maior nível sonoro para conforto e $50 \mathrm{~dB}$ o maior valor aceitável para o ambiente escolar. Já as recomendações da ANSI (2010) especificam que o nível máximo de ruído em uma sala de aula não deve exceder $35 \mathrm{~dB}$. A diferença entre o nível do sinal de fala e o nível do ruído é expressa em dB por meio da relação sinal/ruído (S/R). Uma relação positiva significa que a intensidade do sinal de fala está acima do ruído, e uma relação negativa indica que a intensidade do ruído está acima da intensidade do sinal de fala. A ANSI (2010) recomenda que a relação S/R para o aluno com DA deve ser de pelo menos $+15 \mathrm{~dB}$.

$\mathrm{Na}$ sala de aula, o ruído pode fazer com que o aluno deixe de prestar atenção ou tenha de exercer um esforço substancial para ouvir as informações fornecidas pelo professor ou outros colegas de classe. Isso pode ter um efeito deletério sobre a capacidade do aluno de realizar outras tarefas secundárias, tais como: fazer anotações, responder perguntas e, memorizar a sequência de instruções. $\mathrm{O}$ ambiente ruidoso em sala de aula pode ter um impacto negativo na aprendizagem e interferir no desempenho acadêmico do aluno (CRANDELL; SMALDINO, 2000; HICKS; THARPE, 2002; SHIELD; DOCKRELL, 2003). 


\subsection{ESFORÇO AUDITIVO}

O esforço auditivo pode ser definido como os recursos cognitivos e de atenção que são necessários para compreender a fala em situações desfavoráveis, como, por exemplo, ambiente ruidoso (HICKS; THARPE, 2002; SHIELD; DOCKRELL, 2003; MCGARRIGLE et al., 2014; GAGNÉ et al., 2017). Geralmente, uma relação S/R favorável ajuda a reduzir o esforço auditivo, especialmente em indivíduos com DA (HICKS; THARPE, 2002). Na ocorrência de altos níveis de esforço para ouvir, o processamento da fala no ruído pode prejudicar outras habilidades cognitivas, além de causar fadiga e estresse (HICKS; THARPE, 2002; KOCHKIN, 2011; KRAMER et al., 2016). A sala de aula é um exemplo clássico de uma situação em que crianças e adolescentes estão expostos ao ruído (HOWARD et al., 2010; BESS; HORNSBY, 2014; BESS; GUSTAFSON; HORNSBY, 2014).

McGarrigle et al. (2014) salientam que houve um aumento na quantidade de pesquisas realizadas que abordam o tema esforço auditivo e fadiga. A fadiga é caracterizada por sentimento de cansaço, exaustão, dificuldades de concentração, aumento da distração, alteração de humor, diminuição da energia ou da eficiência mental (BOKSEM; TOPS 2008). A fadiga pode levar ao estresse. O estresse é uma reação do corpo a uma alteração que requer um ajuste físico, mental ou emocional. $O$ estresse crônico pode ser considerado como uma fonte de ameaça ou perturbação, que por sua vez, pode ocasionar os sentimentos de cansaço, irritabilidade e falta de energia (HOCKEY, 2013).

Bess e Hornsby (2014) elaboraram um modelo conceitual que descreve o esforço auditivo, a fadiga, o estresse e o desempenho escolar relacionados ao indivíduo com DA em ambientes ruidosos (Figura 1). 


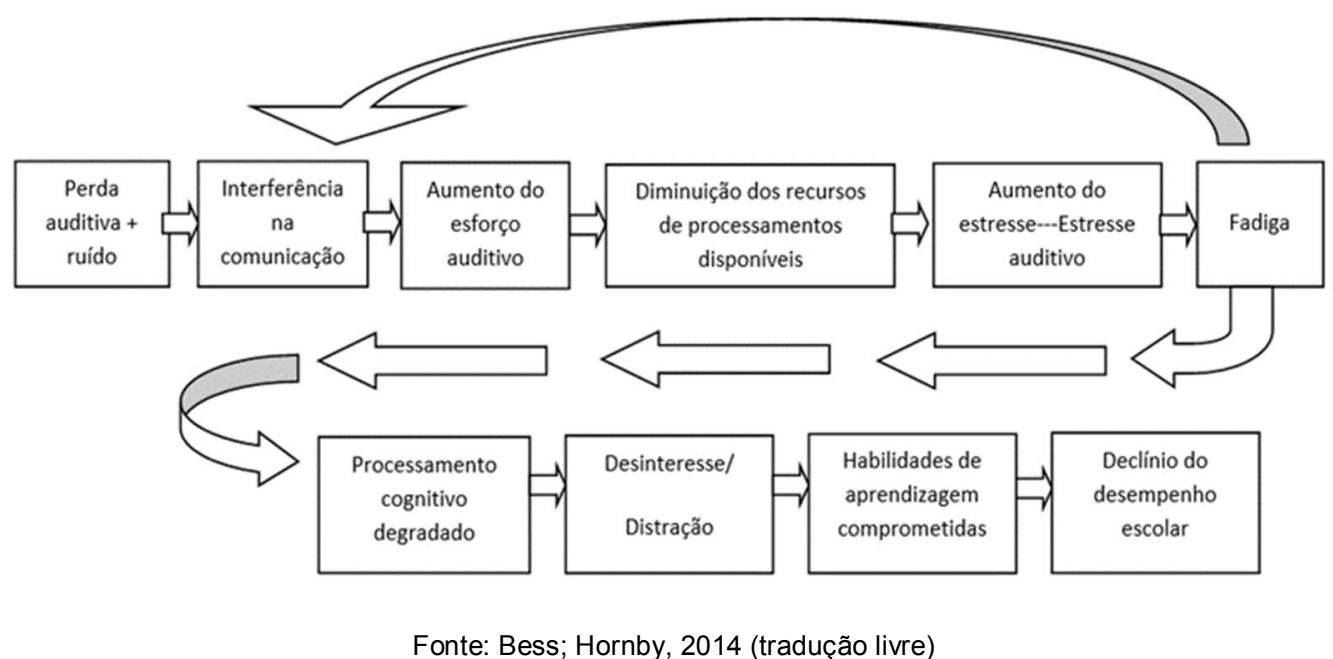

Figura 1 - Modelo de relação entre a perda auditiva, a fadiga e o desempenho escolar

O esforço auditivo pode ser medido por meio de medidas de autoavaliação, fisiológicas e/ou comportamentais (GOSSELIN; GAGNÉ, 2011; RUDNER et al., 2012; MCGARRIGLE et al., 2014).

As medidas de autoavaliação são os questionários, escalas ou relatos referentes ao esforço auditivo. Um dos exemplos citados na literatura para mensurar o esforço auditivo na população adulta é o questionário Speech, Spatial and Qualities (SSQ) que avalia aspectos dinâmicos e estáticos relacionados à audição. As questões 14, 18 e 19 desse questionário abordam o esforço auditivo (GATEHOUSE; NOBLE, 2004; GONSALEZ; ALMEIDA, 2015).

As medidas de autoavaliação são consideradas como uma maneira rápida e fácil de medir o esforço auditivo e fadiga, entretanto McGarrigle et al. (2014) afirmam que podem incorporar algumas desvantagens, como inconsistência de escala, ou falta de atenção, ou cooperação do participante durante a coleta de dados. Hicks e Tharpe (2002) enfatizam que as escalas ou questionários não devem ser a única medida utilizada para avaliar o esforço auditivo e a fadiga, porque às vezes pode haver uma discrepância entre as medidas de autoavaliação quando comparadas as medidas fisiológicas ou comportamentais.

As medidas fisiológicas se baseiam nas mudanças que ocorrem no organismo quando é apresentada uma tarefa de escuta simultaneamente. As medidas encontradas na literatura para essa mensuração são: dilatação da pupila - é a medida 
do diâmetro da pupila, conforme aumenta o esforço auditivo a pupila se dilata (ZEKVELD; KRAMER; FESTEN, 2011; STEEL; PAPSIN; GORDON, 2015; KRAMER; TEUNISSEN; ZEKVELD, 2016); nível de cortisol - é mensurado por meio da análise da saliva do indivíduo, uma vez que a situação de estresse faz com que o hipotálamo aumente a produção de cortisol (HICKS; THARPE, 2002; KRAMER; TEUNISSEN; ZEKVELD, 2016); frequência cardíaca - por meio da medida dos batimentos cardíacos por minuto (MACKERSIE; CONES, 2011); temperatura da pele - é monitorada por meio da temperatura da mão utilizando eletrodos que são posicionado entre os dedos, durante uma atividade de escrita (MACKERSIE; CONES, 2011); condutividade dérmica - é monitorada por meio da transpiração da palma da mão utilizando eletrodos que são posicionado no músculo tenar e hipotenar, durante uma atividade de escrita (MACKERSIE; CONES, 2011); eletromiografia de superfície - é calculada por meio da musculatura frontal da face (MACKERSIE; CONES, 2011); MEG - é a análise do domínio tempo-frequência (OBLESER et al., 2012); e, sincronização da onda $\mathrm{N} 1$ e calculada por meio da avaliação da onda N1 (BERNARDING et al., 2013). Diferente das medidas de autoavaliação, as medidas fisiológicas não dependem da resposta do paciente, entretanto uma desvantagem é que requerem equipamentos específicos e treinamento, por isso não são comuns na prática clínica.

As medidas comportamentais incluem o uso do paradigma de tarefa simples (HOUBEN; DOORN-BIERMAN; DRESCHLER, 2013; MACPHERSON; AKEROYD, 2013) e/ou do PDT (FRASER et al., 2010; GOSSELIN; GAGNÉ, 2011; HICKS; THARPE, 2002; HORNSBY, 2013; SARAMPALIS et al., 2009; STELMACHOWICZ et al., 2007).

O PDT envolve a administração de duas tarefas, uma tarefa primária (TP) e uma tarefa secundária (TS). Neste paradigma experimental, a TP e a TS são administradas sozinhas e simultaneamente, ou seja, o participante deve executar as tarefas primária e secundária ao mesmo tempo. A TP geralmente envolve 0 reconhecimento da fala (palavras ou frases) apresentadas em diferentes relações $S / R$. A TS pode envolver uma tarefa de reconhecimento de sinal visual, de resposta motora ou de memória (GAGNÉ et al., 2017). O declínio no desempenho na TS quando ambas as tarefas são apresentadas simultaneamente (ou em estreita proximidade 
temporal) é a métrica que quantifica o esforço auditivo (GOSSELIN; GAGNÉ, 2011; FRASER et al., 2010; GAGNÉ et al., 2017).

Há uma vasta literatura sobre o uso de paradigmas de tarefa dupla para medir o esforço auditivo entre adultos e idosos com DA (DOWNS, 1982; HORNSBY, 2013; DESJARDINS; DOHERTY, 2013, 2014; NEHER; GRIMM; HOHMANN, 2014; WU et al., 2014; PICOU; RICKETTS, 2014; PICOU; ASPELL; RICKETTS, 2014; PICOU; RICKETTS; HORNSBY, 2013; TUN; MCCOY; WINGFIELD, 2009), porém não foram encontrados trabalhos com adolescentes com deficiência auditiva usuários de AASI.

Downs (1982) examinou os efeitos do uso do AASI no esforço auditivo em adultos com DA por meio do PDT. A tarefa principal era o reconhecimento de palavras sem e com AASI. A TS consistia em pressionar o botão sempre que uma luz acendesse, mensurando o tempo de resposta (TR). Os resultados mostraram reconhecimento de palavras e TR melhores quando os indivíduos utilizaram os AASI. A melhora no TR foi tomada como evidência da redução do esforço auditivo ao usar AASI.

Tun, McCoy e Wingfield (2009) e Desjardins e Doherty (2013) tiveram como objetivo avaliar o esforço auditivo em adultos e idosos encontrando que os idosos apresentam maior esforço auditivo em entender a fala no ruído e exigem mais recursos cognitivos do que os adultos.

Hornsby (2013) mediu a velocidade de processamento cognitivo (tempo para responder a um estímulo visual) em adultos com DA, enquanto realizavam o PDT. Os participantes foram testados sem e com AASI, sendo que a velocidade de processamento diminuiu sistematicamente ao longo do tempo sem o uso do AASI, sendo considerada uma indicação objetiva de fadiga. Já com o uso do AASI, a velocidade de processamento manteve-se estável durante a mesma tarefa, destacando os benefícios potenciais da amplificação para reduzir os efeitos da fadiga.

Picou, Ricketts e Hornsby (2013) investigaram os fatores que influenciam o esforço auditivo em adultos com DA, por meio do PDT, o qual foi apresentado nas condições apenas via auditiva e audiovisual, os resultados indicaram que o ruído de fundo aumenta o esforço auditivo, e os aparelhos auditivos auxiliam a reduzir o esforço auditivo, enquanto pistas visuais não influenciaram no esforço auditivo.

Desjardins e Doherty (2014), em seu estudo utilizaram o PDT para avaliar adultos usuários de AASI com algoritmo de redutor do ruído e destacam que o redutor 
de ruído reduziu o esforço auditivo. Resultados semelhantes também foram encontrados no estudo de Neher, Grimm e Hohmann (2014) realizado em idosos com DA.

Continuando com os estudos realizados na população adulta com DA, encontra-se o estudo de Wu et al (2014) que investigaram o impacto do AASI e do AASI com tecnologia direcional no esforço auditivo. Os autores referem que o AASI com tecnologia direcional reduz significativamente o esforço auditivo. Picou, Aspell e Ricketts (2014) avaliaram o esforço auditivo em usuários de AASI com três tipos de processamento direcional e os resultados mostraram que não houve diferenças significativas no esforço auditivo.

Picou e Ricketts (2014), avaliaram o efeito da mudança na TS no PDT, sendo realizado em quatro situações: apenas via auditiva (silêncio e ruído) e audiovisual (silêncio e ruído). Participaram adultos com audição normal (AN) e com DA, e os resultados mostraram que a pista visual não influenciou no esforço auditivo, assim como a alteração da complexidade da TS não alterou a sensibilidade do paradigma da DT e, nas situações com ruído de fundo, todos os participantes apresentaram maior esforço auditivo comparado com as situações apresentadas no silêncio.

Em relação a população infantil e adolescentes, os estudos são escassos. Há referências ao uso de medida comportamental por meio do paradigma de DT para investigar o esforço auditivo em crianças com DA usuárias de AASI (HICKS; THARPE, 2002; STELMACHOWICZ et al., 2007; MCFADDEN; PITTMAN, 2008), e em adolescentes com IC (HUGHES; GALVIN, 2013); por meio da auto avaliação (HICKS; THARPE; 2002; HORNSBY et al. 2014) e medidas fisiológicas (HICKS; THARPE, 2002; STEEL, PAPSIN; GORDON, 2015; BESS et al.,2016). Vale ressaltar que estudo de Hicks e Tharpe (2002) foi a única investigação na qual utilizaram a três medidas: comportamental, fisiológica e autoavaliação, para investigar o esforço auditivo em crianças.

Hicks e Tharpe (2002) utilizaram a medida comportamental (PDT) para avaliar o esforço auditivo em 28 crianças de seis a 12 anos, divididas igualmente em dois grupos. Na DT, a tarefa principal consistiu em uma tarefa de reconhecimento de palavras administrada em três relações de $S / R$ diferentes, que foram $+20 \mathrm{~dB},+15 \mathrm{~dB}$ e $+10 \mathrm{~dB}$. Não houve diferença significativa entre os dois grupos nas tarefas de reconhecimento de fala. Com relação à TS (estímulo visual de luzes), os TR obtidos 
sob a condição de DT mostraram que as crianças com DA apresentam um maior esforço auditivo quando comparado as crianças com AN. Destas, 20 participaram da avaliação dos níveis de cortisol divididas em dois grupos: crianças com DA e AN. À medida que a relação $S / R$ diminuiu, o nível de cortisol diminuiu, em todas as crianças, este resultado foi atribuído ao cansaço/fadiga. No entanto, não foram observadas diferenças significativas entre os grupos, os autores sugeriram que o uso de amplificação adequada das crianças com DA pode ter auxiliado na redução da fadiga ou o estresse relacionado à escuta e que a mensuração do nível de cortisol na saliva pode não ser suficientemente sensível para mensurar a fadiga ou o estresse relacionado à escuta. As mesmas 20 crianças responderam ao Dartmouth Primary Care Cooperative Information Project Scales (COOP), uma escala composta por questões que visam avaliar a percepção de uma criança nas áreas de aptidão física, sentimentos emocionais, escola, comunicação familiar, hábitos de saúde e apoio social - a escala gera uma pontuação que varia entre um e cinco. Não foram observadas diferenças entre os grupos. Os autores enfatizaram que as pode existir discrepância entre as medidas de auto avaliação e comportamental na mensuração do esforço auditivo.

Stelmachowicz et al. (2007) usaram um paradigma de DT para avaliar o esforço auditivo em crianças. Participaram do estudo 56 crianças, entre sete e 14 anos de idade, divididas em dois grupos: 24 com DA e 32 com AN. A tarefa principal consistiu em palavras com relação $S / R$ de $+8 \mathrm{~dB}$ apresentadas por meio de um filtro de $5 \mathrm{KHz}$ e de $10 \mathrm{KHz}$. A TS consistiu na tarefa de memorização de dígitos. Os resultados revelaram que as crianças mostraram melhores resultados na compreensão de fala nas palavras apresentadas por meio da condição de fala do filtro $10 \mathrm{kHz}$ do que a condição de 5kHz.Para ambos os grupos, o desempenho na TS condição de tarefa única (TU) foi relativamente melhor do que nas condições de DT. Os pesquisadores relataram que a falta de efeito significativo para a TS era semelhante aos resultados relatados anteriormente por Hicks e Tharpe (2002).

McFadden e Pittman (2008) também usaram o PDT para avaliar o esforço auditivo em crianças. A TP consistiu em palavras administradas em silêncio e nas relações $S / R$ de $+6 d B$ e $0 d B$. A TS envolveu estimulação visual (jogos de ligar pontos). Participaram desta investigação 21 crianças (dez crianças com DA (cinco usavam AASI bilateral; duas AASI unilateral; e três sem adaptação) e 11 crianças com 
AN) com idade entre oito e 12 anos. Neste estudo, os resultados sugeriram que as crianças com DA leve apresentaram uma queda significativa no desempenho do teste de percepção de fala em condição de DT em ambas as condições de relação $S / R$, o que não foi observado nas crianças com AN. Os autores concluíram que ambos os grupos apresentaram melhor desempenho na TS quando foi administrada sob a condição de TU, do que quando na condição de DT.

Hughes e Galvin (2013) usaram um PDT para avaliar o esforço auditivo em 16 adolescentes com idades entre dez e 22 anos de idade. A população foi composta por dois grupos: adolescentes com DA usuários de IC bilateralmente e adolescentes com AN. A tarefa principal consistiu em uma tarefa de reconhecimento de palavras apresentada em várias relações $S / R$, nos dois grupos. Para o grupo com $D A$, a relação $S / R$ variou de $+10 a+15 d B$, e para os adolescentes com $A N$ a relação $S / R$ variou de 0 a $-2 d B$. A TS consistiu em uma tarefa de correspondência visual de elementos geométricos. Os resultados indicaram que o uso de IC bilateral reduziu o esforço auditivo quando comparado ao uso de apenas um IC. Os autores apontaram que o esforço auditivo desenvolvido pelos adolescentes que utilizaram IC bilateral foi semelhante ao esforço desenvolvido pelo grupo com AN.

Steel, Papsin e Gordon (2015) utilizaram como medida fisiológica a pupilometria para avaliar o esforço auditivo. Participaram do estudo, 25 crianças usuárias de IC bilateral e 24 crianças com AN, com idade entre 11 a 12 anos. Os resultados revelaram que as crianças usuárias de IC apresentaram maior esforço auditivo do que as crianças com AN, sendo observado por meio do aumento significativo do TR desses indivíduos quando comparado as crianças com $A N$, e também pelas maiores diferenças da dilatação da pupila. Os autores concluíram que as mudanças no diâmetro da pupila podem ser usadas para quantificar o esforço auditivo em crianças usuárias de IC bilateral. No entanto, eles declararam que há necessidade de pesquisas adicionais com esta metodologia, especialmente estudos que incluam uma amostra maior.

Bess et al. (2016) utilizaram uma medida fisiológica de análise do nível de cortisol por meio da saliva para mensurar o esforço auditivo em crianças entre seis e 12 anos de idade. Participaram deste estudo 28 crianças com AN e 32 com DA usuárias de AASI bilateral, não houve diferença significativa no nível de cortisol entre os dois grupos de crianças, porém, os níveis mais elevados de cortisol foram 
encontrados apenas nas crianças mais velhas com DA. Os autores argumentaram que, embora os resultados não revelassem diferença significativa entre os grupos, as crianças com DA apresentaram maior vigilância e precisaram mobilizar mais energia diária do que as com AN, indicado pelo aumento do nível de cortisol ao longo do dia, especialmente após o acordar. Esse aumento de energia na manhã pode indicar que as crianças com DA estão em maior risco de fadiga.

Os autores apontaram ainda algumas limitações relacionadas à abordagem experimental que utilizaram. Dentre elas estão: custo e tempo para análises laboratoriais; necessidade de controlar fatores que possam influenciar na resposta do cortisol, como, por exemplo: alimentos, bebidas, emoções, medicamentos, entre outros fatores; necessidade de monitorar os protocolos experimentais para evitar que as amostras de cortisol se contaminem; e, a necessidade de várias medidas diárias para melhor conclusão dos resultados (BESS et al.,2016). A necessidade de equipamentos específicos e treinamento que acabam dificultando o uso de medidas fisiológicas para avaliar o esforço auditivo na prática clínica também foram apontadas por McGarrigle et al. (2014) como uma limitação dessa metodologia.

Hornsby et al. (2014) examinou o efeito da DA em relatos de fadiga. Participaram crianças entre seis a 12 anos de idade, divididas em dois grupos: dez crianças com DA (cinco usavam AASI bilateral, uma com AASI unilateral e quatro com IC) e dez crianças com AN. O estudo foi considerado preliminar, por abordar uma pequena amostra. Os autores obtiveram classificações subjetivas de fadiga por meio da utilização do instrumento Pediatric Quality of Life Inventory - Multidimensional Fatigue Scale (PedsQL MFS) validado para crianças entre cinco e 18 anos de idade, que consiste em três subescalas: Fadiga Física, Fadiga Sono/Repouso e Fadiga Cognitiva, sendo a pontuação total igual à soma de todas as três subescalas. Os resultados mostraram que houve aumento da fadiga em crianças com DA, com resultados mais baixos em todas as áreas da escala, quando comparado a crianças com AN. Os autores observam que a escala PedsQL MFS não foi desenvolvida para crianças com DA, portanto, não inclui itens específicos sobre dificuldades relacionadas à audição.

Além disso, Hornsby et al. (2014) e Bess et al. (2016) enfatizaram a importância de investigar a fadiga em escolares, porque ela pode estar associada a consequências acadêmicas e psicossociais negativas. Segundo Bess e Hornsby (2014) o esforço 
auditivo e a fadiga são fatores que podem comprometer a aprendizagem dos alunos com DA. Os autores destacam a necessidade de pesquisas envolvendo essa temática, a fim de compreender melhor o esforço auditivo e a fadiga, e como elas impactam o desempenho acadêmico dos alunos com DA, contribuindo no desenvolvimento de estratégias de intervenção mais eficazes para essa população.

Diante disso, são necessárias mais pesquisas para: determinar os mecanismos subjacentes responsáveis pelo esforço auditivo e fadiga; investigar o impacto de fatores como o grau de perda auditiva e/ou o tipo de amplificação como fatores de risco para a fadiga e, explorar o impacto do esforço auditivo e da fadiga nas habilidades acadêmicas e no processo de aprendizagem.

\subsection{SISTEMA DE FREQUÊNCIA MODULADA (FM)}

O sistema FM é uma tecnologia assistiva (TA) que tem como objetivo melhorar a relação $S / R$ em ambiente ruidoso, e diminuir os efeitos da reverberação e da distância da fonte sonora (interlocutor).

[...] O dispositivo é composto por um transmissor e um receptor. O transmissor é responsável por captar a fonte sonora, por exemplo, a voz do professor, por meio de um microfone. O sinal é enviado diretamente para o receptor, que recebe e converte o sinal em energia elétrica. O microfone do AASI permanece ativo, na configuração denominada padrão $\mathrm{FM}+\mathrm{M}$ (microfone do sistema FM funciona juntamente com o microfone do AASI), assim o aluno ouve o professor e também as demais informações auditivas do ambiente. O sistema FM pode ser classificado com relação ao modo de utilização do receptor, sendo como, pessoal ou em campo livre. No sistema FM pessoal o receptor é acoplado ao AASI do usuário, ou posicionado por meio do colar de indução magnética. No caso do sistema FM em campo livre, o(s) receptor(es) são posicionados em alto falantes na sala de aula (JACOB; QUEIROZ-ZATTONI, 2015).

O sistema FM foi incluído na Tabela de Procedimentos, Medicamentos, Órteses, Próteses e Materiais Especiais (OPM) do Sistema Único de Saúde (SUS) pela Portaria MS-SCTIE n²1 de 07/05/2013. A portaria contempla crianças e adolescentes, na faixa etária entre cinco e 17 anos de idade (BRASIL, 2013). As 
normas publicadas na portaria MS-SCTIE n²1 - BRASIL (2013) descrevem que os critérios para indicação do dispositivo são:

[...] ser usuário de AASI e/ou IC; possuir domínio da linguagem oral ou estar em fase de desenvolvimento; estar matriculado no Ensino Fundamental I ou II e/ou Ensino Médio; apresentar desempenho em avaliação de habilidades de reconhecimento de fala no silêncio (Índice Percentual de reconhecimento de Fala (IPRF) melhor que $30 \%$, e em caso de crianças em fase de desenvolvimento de linguagem oral, quando não for possível a realização do IPRF, ou a utilização de testes com palavras devido à idade, deve ser considerado o limiar de detecção de Voz (LDV) igual ou inferior a 40 (com AASI ou IC).

A indicação do sistema FM é imprescindível para melhorar a relação $S / R$, e consequentemente, melhorar a compreensão do sinal de fala para estudantes com DA (BERTACHINI et al., 2015; JACOB; QUEIROZ-ZATTONI, 2015; THIBODEAU; SCHAPER, 2014; THIBODEAU; WALLACE, 2014).

Gustafson et al (2013) observaram 26 crianças com DA, usuárias de AASI e sistema FM. Os autores concluíram que crianças entre sete e dez anos de idade são usuárias mais consistentes dos AASI e do sistema FM no ambiente escolar do que as crianças entre 11 a 12 anos, independentemente da severidade da DA.

Apesar da importância do uso efetivo e dos benefícios que o sistema FM pode proporcionar aos usuários ser conhecida e comprovada pela literatura, Johnson (2014) destaca que no caso dos adolescentes, o estigma social e o desejo de serem como seus pares podem influenciar no uso adequado desta TA. Ainda segundo o autor, isso ocorre mesmo quando o sistema FM está bem adaptado.

\subsubsection{Esforço auditivo e o uso do sistema FM em adolescentes: revisão} sistemática de literatura

Em consonância ao exposto, foi realizada uma revisão sistemática de literatura com objetivo de responder a seguinte pergunta de investigação: "Em adolescentes usuários de AASI e/ou IC, o uso do sistema FM diminui o esforço auditivo e a fadiga em situações ruidosas?" 
A metodologia foi baseada nas diretrizes dispostas no Cochrane Handbook, produzido pela Colaboração Cochrane (HIGGINS; GREEN, 2011).

A estratégia de busca da revisão sistemática de literatura foi realizada por meio da combinação entre cinco descritores indexados nos Descritores em Ciências da Saúde (DecS) e também foram utilizadas palavras-chaves relacionadas ao tema para auxiliar no levantamento bibliográfico. Todos os descritores foram empregados em grupos compostos por, no mínimo, duas palavras-chaves (Tabela 1). A pesquisa foi realizada com a estratégia de busca em Português e Inglês.

As bases de dados científicas pesquisadas foram: Biblioteca Virtual em Saúde (BVS) - engloba as bases de dados LILACS, MEDLINE, SciELO e IBECS; e, a base de dado Web of Science. Foi também utilizado o processo de busca manual a fim de encontrar referências que não constaram na busca das bases eletrônicas (Tabela 1). Para seleção dos artigos os critérios de inclusão adotados foram: participantes $(P)$ adolescentes com DA usuários de AASI e/ou IC; intervenção (I) - uso do sistema FM; desfechos mensurados (O) - testes de percepção da fala no ruído e escalas/questionários que avaliassem o esforço auditivo e a fadiga; tipos de estudo artigos publicados em revistas indexadas com nível de evidência utilizando a classificação do Oxford Centre for Evidence-Based Medicine (2009). Além disso, não houve restrição quanto ao idioma e a data de publicação, sendo analisados todos os artigos publicados até a data da busca (março de 2017).

A seleção dos artigos foi realizada por meio de três etapas. Na primeira etapa, todos os estudos identificados após a combinação entre descritores nas bases de dados foram analisados por dois revisores, por meio da análise do título do estudo, com o intuito de selecionar os artigos que atendiam aos critérios de elegibilidade. Ainda nessa etapa foi realizada a busca manual dos artigos que não constaram nas bases de dados. Na segunda etapa, para seleção dos artigos, foi verificado o corpo dos resumos com o intuito de obter informações sobre a utilização de instrumentos para avaliar o esforço auditivo. Foram levantados os textos na íntegra nos casos em que o título ou o resumo deixaram margens de dúvidas. Os principais dados de cada artigo selecionados foram detalhadamente coletados por meio de uma ficha protocolar padronizada para esse estudo. Portanto, na etapa três, os artigos foram lidos na íntegra. A análise descritiva dos artigos selecionados foi realizada de acordo com o 
objetivo da revisão. Foram identificados 153 artigos em todas as bases de dados e buscas manuais (Tabela 1 ).

Tabela 1 - Estratégias de busca para consultas e número de artigos encontrados nas bases de dados de acordo com os descritores

\begin{tabular}{|c|c|c|c|c|}
\hline Estratégia de busca & BVS & $\begin{array}{l}\text { Web of } \\
\text { Science }\end{array}$ & $\begin{array}{l}\text { Busca } \\
\text { Manual }\end{array}$ & Total \\
\hline 1."Adolescent" AND "Hearing Loss" AND "Fatigue" & 69 & 9 & - & 78 \\
\hline 2."Adolescent" AND "Hearing Aids" AND " Cochlear & 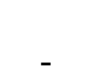 & - & - & 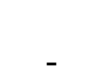 \\
\hline 3."Adolescent" AND "Hearing Loss" AND "Fatigue" & & & - & \\
\hline AND "Hearing Aids" AND “ Cochlear Implantation” & - & - & & - \\
\hline $\begin{array}{l}\text { 4."Adolescente" AND "Perda Auditiva" AND "Fadiga" } \\
\text { 5."Adolescente" AND "Auxiliares de Audição" AND }\end{array}$ & 36 & - & - & 36 \\
\hline $\begin{array}{l}\text { "Implante Coclear" AND "Fadiga" } \\
\text { 6."Adolescente" AND "Perda Auditiva" AND "Fadiga" }\end{array}$ & - & - & - & - \\
\hline AND "Auxiliares de Audição" AND "Implante Coclear" & - & - & & - \\
\hline 7.“Listening Effort” AND “Dual-Task Paradigm” & 15 & 21 & - & 36 \\
\hline 8.“FM System” AND “Listening Effort” & - & 3 & - & 3 \\
\hline Total & 120 & 33 & - & 153 \\
\hline
\end{tabular}

Em uma pré-seleção dessas citações, foram excluídas publicações duplicadas e que não continham conteúdo correspondente ao objetivo proposto. Ao final do levantamento, nenhum artigo atendeu aos critérios de inclusão (Figura 2).

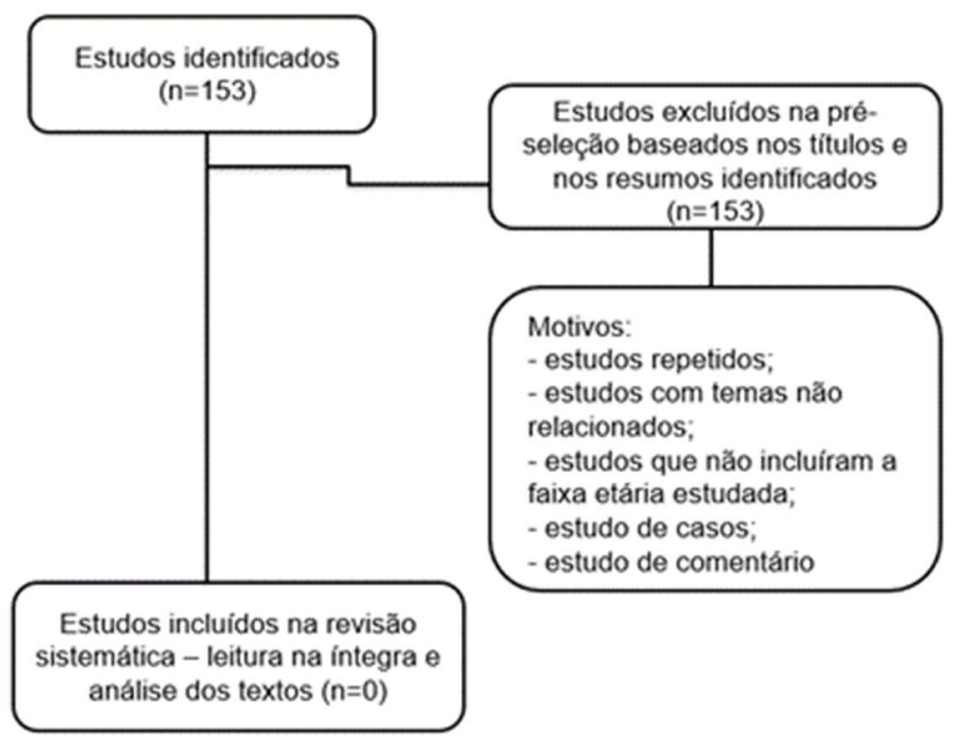

Legenda: $n=$ número de estudos

Figura 2 - Critérios de exclusão dos estudos identificados 
Enfim, na revisão sistemática não foram encontrados estudos que mensurassem o esforço auditivo em adolescentes com DA usuários de AASI e/ou IC e sistema FM.

O processo de uma revisão sistemática facilita a síntese da evidência de temas específicos. Dessa forma, a revisão sistemática vazia indicou que ainda existe uma lacuna quanto à avaliação do impacto do sistema FM no esforço auditivo e na fadiga em situações ruidosas, como em sala de aula. Apesar do processo de aprendizagem ser um fenômeno multifatorial, fica o questionamento do quão prejudicial o esforço auditivo e a fadiga podem ser para o desempenho acadêmico do estudante com DA e na aceitação do uso deste dispositivo.

As conclusões acima levam a inferência de que é importante realizar mais pesquisas para desenvolver um consenso com base em evidências científicas confiáveis, e desenvolver um método padronizado válido para avaliar o esforço auditivo e a fadiga nessa população. 

3 PROPOSIÇÃO 



\section{PROPOSIÇÃO}

\subsection{PROPOSIÇÃO GERAL}

Analisar o esforço auditivo e a fadiga em adolescentes com DA, usuários de AASI, sem e com sistema FM, e comparar com adolescentes com AN.

\subsection{PROPOSIÇÕES ESPECÍFICAS}

- Elaborar e desenvolver uma TS para o teste de DT;

- Analisar e comparar o esforço auditivo em adolescentes com DA, usuários de AASI, sem e com sistema FM, com adolescentes com AN por meio do PDT;

- Analisar e comparar a fadiga em adolescentes com DA, usuários de AASI, sem e com sistema FM, com adolescentes com AN por meio de questionário.

- Analisar o impacto do ruído na aprendizagem pela perspectiva dos adolescentes com DA, usuários de AASI, sem e com sistema FM, e dos adolescentes com AN.

- Investigar a opinião dos participantes com DA sobre o impacto do uso do sistema FM na sala de aula. 

4 MATERIAL e MÉtodos 



\section{MATERIAL E MÉTODOS}

\subsection{CARACTERIZAÇÃO DO ESTUDO}

Trata-se de um estudo de coorte transversal.

\subsection{ASPECTOS ÉTICOS}

O estudo foi aprovado pelo Comitê de Ética em Pesquisa (CEP) da Faculdade de Odontologia de Bauru da Universidade de São Paulo (FOB/USP) Campus Bauru, sob protocolo $n^{\circ}$ 1.074.623/2015 (Anexo A).

Os responsáveis e os adolescentes participantes da pesquisa, após terem entendido e concordado com os propósitos do estudo, assinaram o Termo de Consentimento Livre e Esclarecido (Apêndice A) e o Termo de Assentimento (Apêndice B) atestando sua permissão para a participação no trabalho e publicação dos dados obtidos. $O$ anonimato e a liberdade de retirar seu consentimento a qualquer momento foi garantido aos responsáveis e participantes.

A coleta dos dados ocorreu no período de Janeiro a Junho de 2017. O estudo foi realizado em uma sala da Clínica de Fonoaudiologia da FOB/USP.

\subsection{MÉTODO}

\subsubsection{Participantes}

Para compor os grupos, foram elaborados os seguintes critérios de seleção dos participantes.

Critério de inclusão do Grupo 1 (G1): apresentar audição dentro dos padrões de normalidade; ausência de alterações motoras e visuais; faixa etária entre 12 a 18 anos de idade (BRASIL, 1990); estar matriculado no ensino fundamental, médio ou superior de ensino regular. 
Critério de inclusão do Grupo 2 (G2): apresentar DA sensorioneural, bilateralmente, de grau moderado, severo e/ou profundo; ausência de alterações associadas à DA que impeçam o desenvolvimento global; ausência de alterações motoras e visuais; faixa etária entre 12 a 18 anos de idade (BRASIL, 1990); fazer uso efetivo do AASI; estar adaptado com sistema FM pessoal; estar matriculado no ensino fundamental, médio ou superior de ensino regular.

\subsubsection{Recrutamento e seleção dos participantes}

A composição da casuística do $\mathrm{G} 1$ foi realizada por recrutamento na comunidade por meio de contato aleatório com adolescentes conhecidos da pesquisadora. O grupo foi composto por 18 adolescentes com audição dentro dos padrões de normalidade.

Para avaliação da audição dos adolescentes do G1 foi realizada a pesquisa das emissões otoacústicas por estímulo transiente com o equipamento Otoport Lite/Interacoustics (pesquisadas as bandas de frequência de 1000, 1500, 2000, 3000 e $4000 \mathrm{~Hz}$, sendo utilizado como critério para passa-falha a presença de EOAt em no mínimo três bandas) e, a pesquisa do reflexo acústico ipsilateral por meio do equipamento Titan/Interacoustics. O procedimento foi realizado em uma sala silenciosa na Clínica de Fonoaudiologia da FOB/USP. Todos os adolescentes apresentaram emissões otoacústicas por estímulo transiente e reflexo acústico ipsilateral presentes bilateralmente.

Para seleção dos adolescentes com DA (G2), foram recrutados os pacientes matriculados na Clínica de Fonoaudiologia FOB/USP e na Divisão de Saúde Auditiva (DSA) do Hospital de Reabilitação de Anomalias Craniofaciais (HRAC) da USP, campus de Bauru.

Para compor o G2 foram avaliados 90 prontuários de adolescentes com DA, destes 77 foram excluídos pelos seguintes motivos: 24 por não conseguirem repetir listas de sentenças e/ou apresentarem muitas trocas articulatórias; cinco por fazerem uso de leitura orofacial; quatro por se comunicarem por LIBRAS (Língua Brasileira de Sinais) e não por comunicação oral; um não usa o sistema FM porque o receptor/transmissor está quebrado; 18 por não usarem o sistema FM, sendo um por vergonha ou não sentirem necessidade; dois não usam o sistema FM porque os 
professores gritam muito; cinco devolveram o sistema FM por não quererem usar; três por alterações neurológicas; um por estar aguardando a cirurgia de IC; um por alterações motoras; cinco pelo AASI estarem quebrados; quatro por alteração visual; e quatro por não terem disponibilidade para participar.

Dessa forma, foram selecionados para compor o G2 13 adolescentes de ambos os sexos com DA usuários de AASI e sistema FM pessoal, com os dispositivos funcionando adequadamente.

\subsubsection{Descrição dos participantes}

O G1 foi composto por adolescentes com audição dentro dos padrões de normalidade, sendo dez participantes do sexo masculino e oito do sexo feminino, com idade entre 12 anos e 17 anos e oito meses, sendo a média de 14 anos e oito meses. O nível de escolaridade dos adolescentes variou entre $7^{\circ}$ ano do ensino fundamental a $1^{\circ}$ ano do ensino superior.

O G2 foi composto por 11 participantes do sexo masculino e dois do sexo feminino, com idade entre 12 anos e 17 anos e quatro meses, sendo a média de 14 anos e seis meses. O nível de escolaridade dos adolescentes variou entre $7^{\circ}$ ano do ensino fundamental a $1^{\circ}$ ano do ensino médio.

Os adolescentes do G2 apresentavam DA sensorioneural bilateral de grau moderado $(n=12)$ e severo $(n=1)$. Segundo dados coletados nos prontuários dos participantes, verificou-se que a média da idade de realização do diagnóstico destes foi de cinco anos e três meses, e a média da idade de adaptação dos AASI foi de cinco anos e oito meses. Todos estavam adaptados bilateralmente com AASI e sistema FM. A média da idade dos adolescentes com DA na adaptação do sistema FM foi de 11 anos e 7 meses. Os dados demográficos dos participantes são apresentados na Tabela 2. Na Tabela 3 é apresentada a síntese dos modelos do sistema FM adaptados. 
Tabela 2 - Dados demográficos dos participantes do $G 2(n=13)$

\begin{tabular}{|c|c|c|c|c|c|c|c|}
\hline $\begin{array}{l}\text { Participantes } \\
\qquad(n=13)\end{array}$ & $\begin{array}{l}\text { Idade } \\
\text { atual }\end{array}$ & $\begin{array}{c}\text { Grau da } \\
\text { perda } \\
\text { auditiva }\end{array}$ & $\begin{array}{c}\text { Idade no } \\
\text { diagnóstico }\end{array}$ & $\begin{array}{c}\text { Idade na } \\
\text { adaptação } \\
\text { do AASI }\end{array}$ & $\begin{array}{c}\text { Idade na } \\
\text { adaptação } \\
\text { do Sistema } \\
\text { FM }\end{array}$ & \multicolumn{2}{|c|}{$\begin{array}{c}\text { Sistema FM } \\
\text { Marca } \\
\text { Transmissor/ } \\
\text { receptor }\end{array}$} \\
\hline 1 & $12 \mathrm{a}, 9 \mathrm{~m}$ & Moderado & $5 a, 8 m$ & $5 a, 8 m$ & $12 a, 9 m$ & Oticon & $\begin{array}{l}\text { Amigo } \\
(\mathrm{ACR})\end{array}$ \\
\hline 2 & $13 a, 11 \mathrm{~m}$ & Moderado & $2 a$. & $7 a$. & $11 a, 7 m$ & Starkey & $\begin{array}{c}\text { Comfort } \\
\text { Audio DM10 } \\
\text { (DH10) }\end{array}$ \\
\hline 3 & $17 \mathrm{a}, 1 \mathrm{~m}$ & Severo & $4 a, 3 m$ & $4 a, 7 m$ & $13 a, 9 m$ & Phonak & $\begin{array}{c}\text { Smartlink } \\
\text { (Mlxi) }\end{array}$ \\
\hline 4 & $12 a$. & Moderado & $7 a, 4 m$ & $7 a, 4 m$ & $9 a, 7 m$ & Oticon & $\begin{array}{l}\text { Amigo T31 } \\
\text { (R12) }\end{array}$ \\
\hline 5 & $11 \mathrm{a}, 11 \mathrm{~m}$ & Moderado & $5 \mathrm{a}, 11 \mathrm{~m}$ & $6 a, 3 m$ & $9 a, 3 m$ & Phonak & $\begin{array}{c}\text { Smartlink } \\
\text { (Mylink) }\end{array}$ \\
\hline 6 & $17 a, 4 m$ & Moderado & $11 a, 3 m$ & $11 a, 6 m$ & $14 a, 4 m$ & Phonak & $\begin{array}{l}\text { Smartlink } \\
\text { (Mlxi) }\end{array}$ \\
\hline 7 & $13 a, 3 m$ & Moderado & $3 a, 8 m$ & $3 a, 8 m$ & $10 a, 4 m$ & Phonak & Inspiro(MLi) \\
\hline 8 & $16 a, 9 m$ & Moderado & $3 a, 3 m$ & $3 a, 6 m$ & 14a. & Phonak & $\begin{array}{l}\text { Smartlink } \\
\text { (Mylink) }\end{array}$ \\
\hline 9 & $14 a, 8 m$ & Moderado & $6 a, 7 m$ & $6 a, 8 m$ & $12 a, 8 m$ & Oticon & $\begin{array}{l}\text { Amigo T31 } \\
\text { (R12) }\end{array}$ \\
\hline 10 & $16 a, 4 m$ & Moderado & $5 a, 7 m$ & $6 a, 2 m$ & $13 a, 5 m$ & Phonak & $\begin{array}{l}\text { Smartlink } \\
\text { (ML9i) }\end{array}$ \\
\hline 11 & 13a,10m & Moderado & $6 a, 2 m$ & $6 a, 2 m$ & $13 a, 2 m$ & Phonak & $\begin{array}{l}\text { Smartlink } \\
\text { (Mylink) }\end{array}$ \\
\hline 12 & $13 a, 8 m$ & Moderado & $2 \mathrm{a}, 10 \mathrm{~m}$ & $2 \mathrm{a}, 10 \mathrm{~m}$ & $9 a, 11 m$ & Oticon & $\begin{array}{l}\text { Amigo } \\
\text { (ACR) }\end{array}$ \\
\hline 13 & $15 a, 1 m$ & Moderado & $9 a, 9 m$ & $9 a, 11 m$ & $12 a, 4 m$ & Phonak & $\begin{array}{c}\text { Smartlink } \\
\text { (ML9i) }\end{array}$ \\
\hline
\end{tabular}

Legenda: a(anos); m(meses) 
Tabela 3 - Síntese dos modelos e marcas dos sistemas FM utilizados pelos participantes ( $n=13$ )

\begin{tabular}{ccc}
\hline Marca & $\begin{array}{c}\text { Sistema FM } \\
\text { Transmissor/receptor }\end{array}$ & $\begin{array}{c}\text { Usuários } \\
\text { N (\%) }\end{array}$ \\
\hline Phonak & Smartlink (Mlxi, ML9i) & $4(30,8)$ \\
& Smartlink Mylink & $3(23,0)$ \\
Oticon & Inspiro(MLi) & $1(7,7)$ \\
& Amigo T31 (R12) & $2(15,4)$ \\
Starkey & Amigo ACR & $2(15,4)$ \\
Legenda: \%=porcentagem & $1(7,7)$ \\
\hline
\end{tabular}

\subsubsection{Instrumentos e procedimentos}

\subsubsection{Esforço auditivo}

\subsection{Medida comportamental}

A medida comportamental utilizada nesta pesquisa foi o PDT, constituído por uma TP e uma TS.

A TP envolveu a percepção da fala no ruído (repetir as listas de sentenças). Nesta pesquisa foi utilizada a versão em português do Hearing in Noise Test (HINT), adaptada por Bevilacqua et al. (2008). O HINT consiste em 12 listas com 20 sentenças cada, que são registradas por um falante masculino nativo. Foi aplicado pelo equipamento HINTPro 7.2 Audiometric System, e a seleção da lista e realizada de forma aleatória pelo próprio software. O teste foi administrado em campo livre. $O$ ruído (mascaramento de ruído estacionário - ruído branco) foi apresentado com uma intensidade fixa de $65 \mathrm{~dB}$ nível de pressão sonora (NPS). O HINT requer um reconhecimento de fala em conjunto aberto.

O HINT está disponível em diversas línguas, e a similaridade do procedimento e resultados torna-os comparável entre as mesmas. Soli e Wong (2008) reforçam que o objetivo do HINT é avaliar a inteligibilidade de fala no ruído, e pode ser comparado de duas formas: intra-sujeitos, que é a comparação do mesmo sujeito entre duas ou mais condições, e entre os sujeitos, que se refere à comparação dele com a média encontrada por seus pares com AN 
O HINT Brasil utiliza a técnica ascendente-descendente proposta por Levitt e Rabiner (1967). A intensidade das sentenças é modificada adaptativamente, para mais ou para menos, conforme a reposta do participante. Os resultados do HINT são expressos em dB pelos valores do limiar de reconhecimento de sentenças (LRS) que corresponde à relação $S / R$ em que o indivíduo apresentou $50 \%$ de reconhecimento das sentenças (LEVITT; RABINER, 1967). A relação S/R positiva é quando o sinal de fala está acima do sinal do ruído, e a relação negativa é quando o sinal do ruído está acima do sinal de fala (WEISS; DEMPSEY, 2008).

As caixas de som foram posicionadas a um metro de distância da cabeça do ouvinte em $0^{\circ}$. azimute para o estímulo de fala e em $180^{\circ}$. azimute para o ruído, conforme recomendação da American Academy of Audiology (2008, 2011). Esta configuração foi selecionada porque simula um ambiente de sala de aula típico. Nas avaliações com o sistema FM, o microfone do transmissor foi posicionado a $6 \mathrm{~cm}$ de distância da caixa de som a $0^{\circ}$. azimute.

Os participantes foram orientados a repetir as sentenças que ouviram. Foram aceitas como resposta correta quando o indivíduo repetia corretamente todas as palavras das sentenças.

A TS consistiu em uma tarefa de memória de reconhecimento de cores projetada especificamente para este estudo. Foi elaborada uma plataforma para auxiliar a execução de testes de DT. A plataforma foi desenvolvida em parceria com o Departamento de Sistemas de Computação do Instituto de Ciências Matemáticas e de Computação da USP.

O material desenvolvido foi denominado PALETA - Plataforma para Auxiliar de Execução de Testes de Dupla Tarefa. O teste pode ser administrado em celular, tablet e em computadores, sendo que neste estudo foi utilizado um tablet (Samsung Galaxy Tab A - 8"). Especificamente, após cada apresentação, o participante teve que se lembrar e reproduzir uma sequência de quatro cores aleatórias. Nesta tarefa, era possível que a mesma cor aparecesse mais de uma vez dentro de uma apresentação. A resposta foi considerada correta somente quando o participante acertou todas as quatro cores na mesma ordem que a gerada pela plataforma. No total foram 20 apresentações, selecionadas de acordo com a TP, visto que o HINT é composto por 20 sentenças. A plataforma permite que o fonoaudiólogo selecione o número e o tempo de apresentações dos estímulos, ajustando de acordo com a TP utilizada. O 
número de respostas corretas (NRC) obtidas e o TR total necessário para completar a tarefa de memória de cores são registrados na plataforma. Sob a condição de DT, a tarefa de reconhecimento de fala no ruído e a tarefa de memória de reconhecimento de cores foram administradas simultaneamente.

Os participantes foram submetidos a uma sessão de treino (TP, TS e DT) para garantir que tinham compreendido o teste. O participante foi orientado que iria realizar três testes: o primeiro era composto de sentenças que deveriam ser repetidas, 0 segundo por um teste de memória e o terceiro era a aplicação dos dois juntos. TP: Foram orientados a escutar as sentenças e repeti-las. TS: Foram orientados que deveriam memorizar e repetir a sequência de cores visualizada. DT: foram orientados a memorizar as cores enquanto escutavam a frase, e então deveriam repetir a sentença e ao mesmo tempo repetirem a sequência de cores memorizada. Nesta tarefa, os pacientes foram orientados que quando ouvissem o ruído deveriam apertar a seta branca para iniciar o teste.

A Figura 3 representa o ambiente de realização do procedimento.

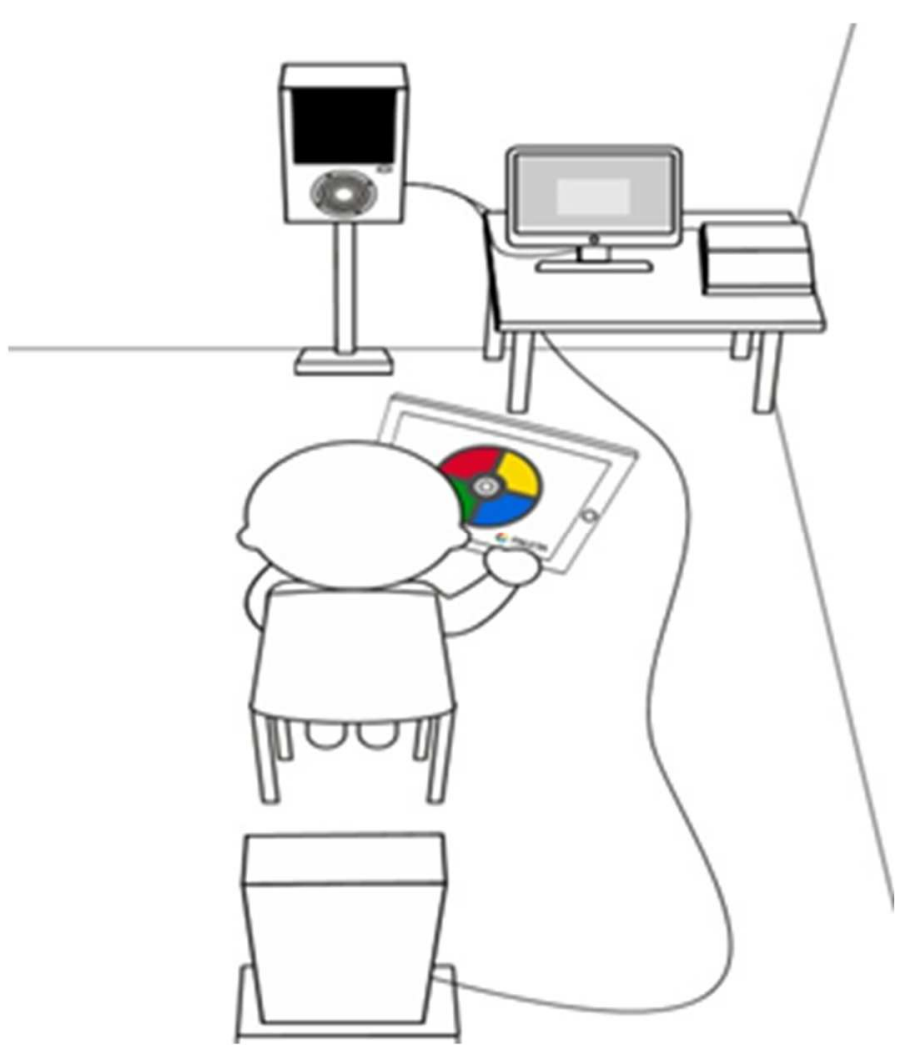

Figura 3 - Ambiente do procedimento 
A TP foi administrada para os participantes do $\mathrm{G} 1$ e do $\mathrm{G} 2$ em duas condições de amplificação: AASI (G2 $\mathrm{AASI}$ ) e AASI + sistema FM (G2FM) (Tabela 4). O design do quadrado latino foi adotado para determinar a ordem das condições em que a TP, a TS e DT foram administradas (Quadro 1 e 2). O período da avaliação das tarefas durou entre 40 minutos a 1 hora e 30 minutos, para cada participante.

Tabela 4 - Condições de apresentações das tarefas

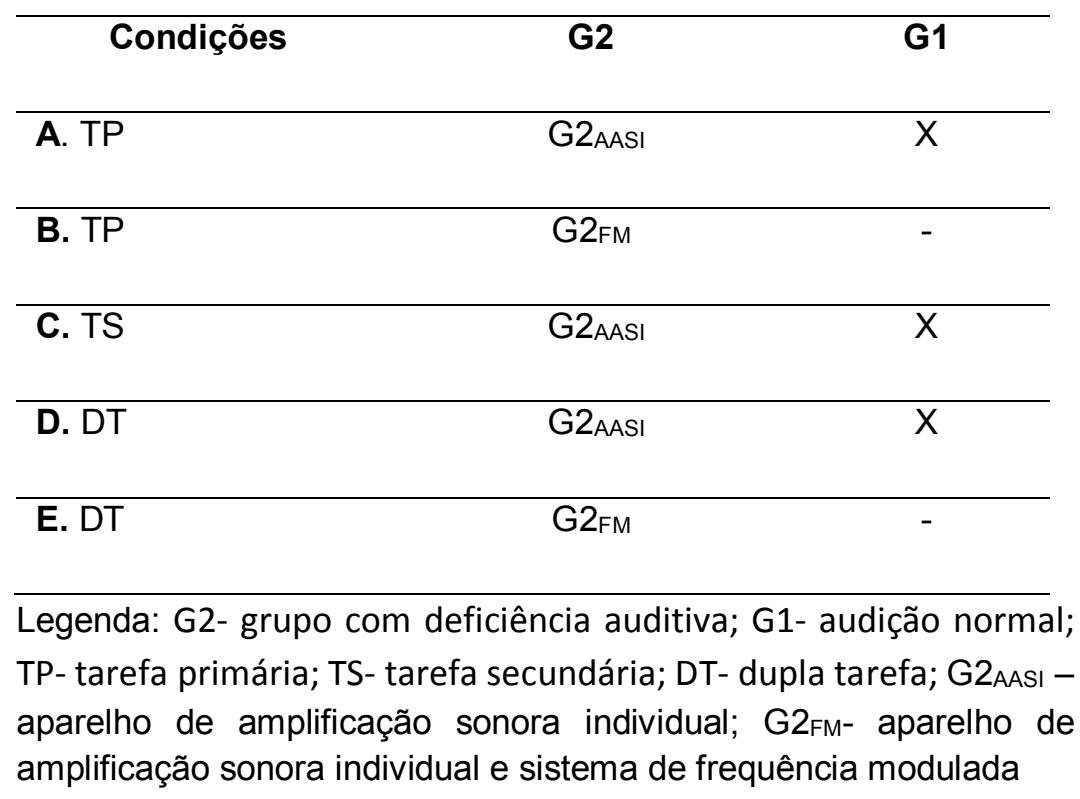

Por meio do design do quadrado latino, as condições das tarefas de $A$ a $E$ foram administradas de forma aleatória no G2, conforme apresenta o Quadro 1. O Quadro 2 apresenta as condições das tarefas $A, C$ e $D$ que foram administradas no $G 1$.

\begin{tabular}{|cccccccc|}
\hline & & Participantes & \multicolumn{5}{c|}{ Condições de apresentações } \\
\hline 1 & 6 & 11 & A & B & C & D & E \\
\hline 2 & 7 & 12 & B & C & D & E & A \\
\hline 3 & 8 & 13 & C & D & E & A & B \\
\hline 4 & 9 & - & D & E & A & B & C \\
\hline 5 & 10 & - & E & A & B & C & D \\
\hline
\end{tabular}

Quadro 1 - Design do Quadrado Latino - G2 


\begin{tabular}{|cccccccccc|}
\hline & \multicolumn{3}{c}{ Participantes } & \multicolumn{5}{c|}{ Condições de apresentações } \\
\hline 1 & 4 & 7 & 10 & 13 & 16 & A & C & D \\
\hline 2 & 5 & 8 & 11 & 14 & 17 & C & D & A \\
\hline 3 & 6 & 9 & 12 & 15 & 18 & D & A & C \\
\hline
\end{tabular}

Quadro 2 - Design do Quadrado Latino- G1

\subsubsection{Fadiga}

Para avaliação da fadiga, foi realizada a tradução para o português brasileiro da Fatigue Scale que foi retirada do "Informal Assessment of Fatigue and Learning" (FUKUDA et al., 2010; Anexo B). Também foi realizada a tradução da primeira questão da escala Learning Effort-Reward Imbalance (LERI) que envolve o impacto do ruído na aprendizagem (Anexo B).

O instrumento "Fatigue Scale" na versão original foi distribuído para dois tradutores-intérpretes de inglês, fluentes nesse idioma, que não se conheciam e não conheciam o questionário, visando elaborar individual e sigilosamente a primeira versão para o Português. Este procedimento foi realizado com o intuito de gerar duas traduções independentes do questionário. $\mathrm{Na}$ fase de adaptação linguística, o grupo revisor foi constituído por duas fonoaudiólogas (brasileiras, com fluência da língua inglesa), que analisaram os dois documentos resultantes e reduziram as diferenças encontradas nas traduções, adaptando o texto à cultura brasileira. Desta forma, foi obtido um novo inventário denominado "Avaliação Informal de Fadiga" (Apêndice C). A versão final permaneceu com os mesmos itens da versão original. A primeira questão da escala Learning Effort-Reward Imbalance (LERI) foi traduzida e foi mantido o título original em inglês (LERI - Apêndice C).

A versão traduzida para o português brasileiro (Apêndice $C$ ) foi aplicada na forma de entrevista. Foi entregue um papel impresso a cada participante, foram orientados a assinalar a alternativa que melhor correspondesse a sua realidade. A escala foi aplicada em ambos os grupos, uma vez para o $\mathrm{G} 1$ e duas vezes para o G2 considerando duas situações de escuta: $\mathrm{G}_{\mathrm{AASI}}$ e G2 $2_{\mathrm{FM}}$. 


\subsubsection{Questionário}

Foi elaborado e aplicado um questionário (Apêndice D) para obter a opinião dos adolescentes DA sobre o sistema FM. O questionário teve como finalidade compreender a realidade de seus ambientes educacionais. As questões foram baseadas nos principais relatos de pacientes atendidos na Clínica de Fonoaudiologia da FOB/USP.

\subsubsection{Análise dos resultados}

Todos os procedimentos estatísticos foram executados no programa IBM SPSS Statistics 24. A análise considerou os dados obtidos em diferentes condições: nas comparações entre os adolescentes do G1 e do G2 (G2AAsı e G2FM), e na comparação do $\mathrm{G} 2$ sob as condições G2AASı e G2FM. Quando a análise estatística envolveu comparar os resultados obtidos dos participantes do $\mathrm{G} 1 \mathrm{com}$ os resultados obtidos pelos participantes do G2 (G2AASI ou G2FM), foi utilizado o Teste T. Para essas análises, foi adotado o nível de significância de $p<0,01$ (com base nos ajustes de Bonferroni) para determinar se as diferenças entre os grupos eram significantes. Quando a análise estatística envolveu as duas condições de amplificação (G2AASı e G2 $F M$ ), utilizou-se o teste ANOVA de medidas repetidas e adotou-se $p<0,05$. Nos casos em que os resultados utilizando o teste ANOVA revelaram significância, as comparações utilizando o Teste T pareado foram utilizadas para descrever a natureza da interação. Na questão 1 da escala LERI foi utilizado o teste qui-quadrado de Pearson para comparação entre os grupos $(p<0,05)$. 
5 Resultados 



\section{RESULTADOS}

Serão apresentados os resultados em três subseções a fim de facilitar a exposição. A primeira irá apresentar os dados referentes ao esforço auditivo (criação da TS e dados coletados na aplicação das tarefas). A segunda parte irá apresentar os dados referentes a escala de fadiga e do impacto do ruído na aprendizagem, e a terceira parte irá apresentar os resultados obtidos no questionário sobre a percepção dos adolescentes quanto ao uso do sistema FM em ambiente educacional.

\subsection{ESFORÇO AUDITIVO}

\subsubsection{Medida comportamental}

Para a execução do PDT foi desenvolvida uma plataforma com uma TS, que é composta por um teste de memória de reconhecimento de cores denominado PALETA. A ferramenta ainda está em processo de ajustes e registro, a fim de futuramente ser disponibilizada aos fonoaudiólogos por meio de endereço eletrônico: http://www.paleta.fob.usp.br/. O Apêndice E mostra as interfaces da plataforma PALETA e a sua forma de aplicação.

\section{Resultados envolvendo a TP (HINT) nas situações de TU e DT}

A média da relação S/R obtida no HINT nas condições de TU e DT para os participantes do G1 e para os participantes do G2 nas condições de amplificação AASI (G2 $\left.{ }_{\text {AASI }}\right)$ e AASI + sistema FM (G2 FM) são exibidas na Figura 4.

Os resultados obtidos no HINT sob a condição de TU foram analisados (Figura 4) utilizando o teste $T$ (para amostras não relacionadas - valor p adotado <0,01) e revelaram uma diferença significativa entre o G1 e o G2 ${ }_{\text {AASI }}\left(t(14)=-5,044, p=0,001^{*}\right)$ mas não entre os participantes do $\mathrm{G} 1$ e o $\mathrm{G} 2 \mathrm{FM}(\mathrm{t}(13)=-2.182, \mathrm{p}=0.047)$. 


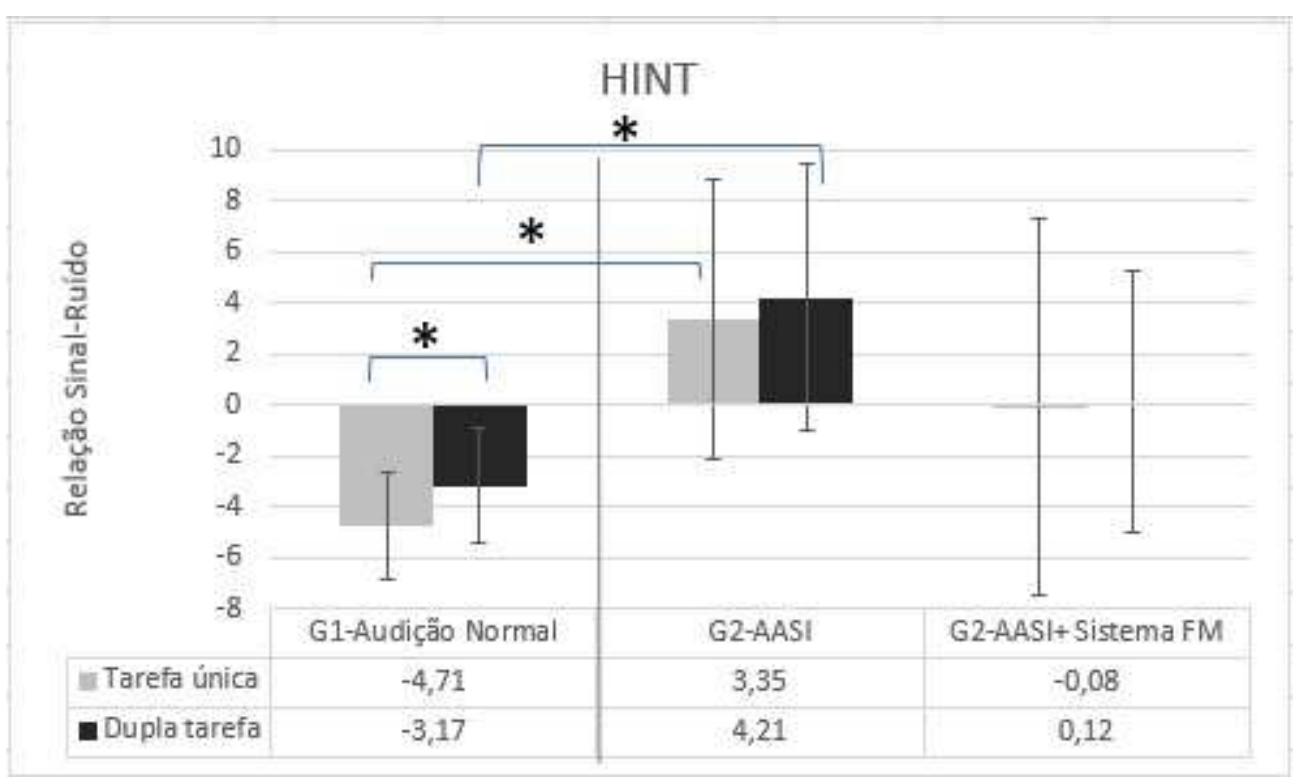

Legenda: * diferença estatisticamente significativa

Figura 4 - As médias das relações sinal/ruído no teste HINT ( \pm 1 SD) para a tarefa única (barras cinza) e dupla tarefa (barra preta) são plotadas como função das condições experimentais para o grupo com audição normal (G1) e o grupo com deficiência auditiva (G2) sob as condições de amplificação (AASI e AASI + sistema FM)

Sob a condição de DT, utilizando o teste $T$ (para amostras não relacionadas) houve diferença significativa no desempenho no HINT entre os participantes do G1 e os participantes do G2 $\mathrm{AASI}$ ( $\left.\mathrm{t}(15)=-4.767, \mathrm{p}=0.001^{*}\right)$, mas não entre $\circ \mathrm{G} 1$ e os participantes do $\mathrm{G}_{\mathrm{FM}}$ ( $\mathrm{t}(29)=-2.437, \mathrm{p}=0.021$ ). $\mathrm{O} \mathrm{G} 1$ apresentou uma diferença significativa no resultado obtido no HINT entre a TU e a condição de DT (t (17) = 5,491, $\left.p=0,001^{*}\right)$.

Para comparação estatística dos resultados dos participantes do $G 2$ nas condições G2 $2_{A A S I}$ e G2 $2_{F M}$ foi utilizado o teste ANOVA para medidas repetidas. A comparação entre a TU e a DT não foi significativa $(F(1,12)=0,978, p=0,342)$. Os resultados revelaram diferença significativa entre as condições de amplificação ( $F$ $\left.(1,12)=14,781, p=0,002^{*}\right)$, e nenhuma interação significativa entre a condição de amplificação e a tarefa: $F(1,12)=0,493, p=0,496)$. 


\section{Resultados envolvendo a TS (tarefa de memória de reconhecimento de cores) nas situações de TU e DT}

Para os participantes do $G 2$ na condição de TU a TS foi medida apenas para a condição de amplificação em que os participantes usavam seus AASI. Este resultado foi utilizado para calcular o esforço auditivo para ambas as condições de amplificação (G2 $2_{A A S I}$ e G2 $2_{F M}$ ).

O TR obtido na TS para cada participante foi calculado da seguinte forma: duração total do tempo das 20 apresentações dividido pelo número total de apresentações (20). A Figura 5 apresenta a média do TR (em segundos) necessária para executar a tarefa de memória de reconhecimento de cores denominada PALETA, obtida sob a condição de TU e DT para os participantes do G1 e para o G2 sob as duas condições de amplificação (G2AASI e G2FM).

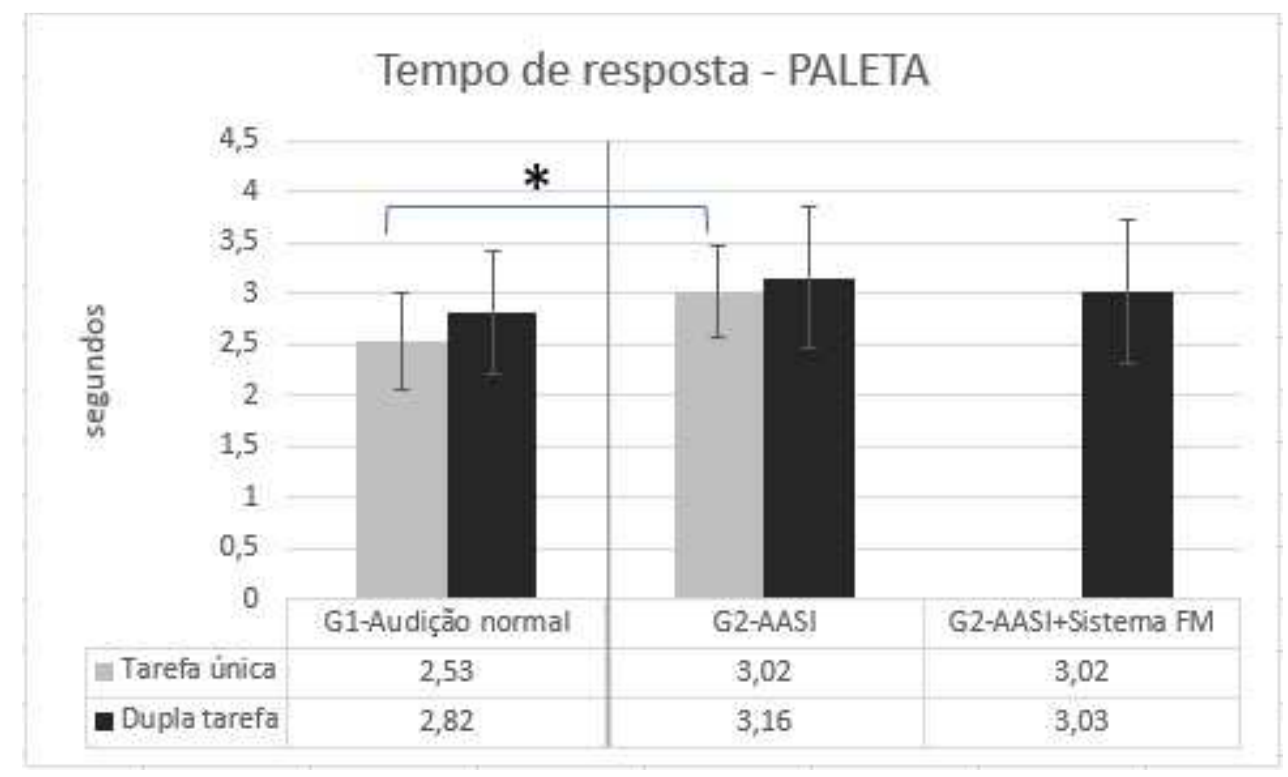

Legenda: * diferença estatisticamente significativa

Figura 5 - As médias dos tempos de respostas em segundos ( \pm 1 SD) para a tarefa de memória de reconhecimento de cores para as condições de tarefa única (barras cinza) e de dupla tarefa (barra preta) são plotadas para as condições de escuta para o grupo com audição normal (G1) e o grupo com deficiência auditiva (G2) nas condições de amplificação (AASI e AASI + sistema FM) 
Os resultados avaliados utilizando o teste $T(p<0,01)$ indicaram que, na condição de TU, o TR dos participantes do G1 foi significativamente menor do que o TR obtido pelos participantes do $\mathrm{G}_{\mathrm{AASI}}\left(\mathrm{t}(29)=-2.90, \mathrm{p}=0,007^{*}\right)$. Destaca-se que, para os participantes do G2, o TR para a TS administrada sob a condição de TU foi obtido apenas sob a condição com AASI. Assim, a comparação entre os participantes do G1 e os participantes do G2FM não foi realizada.

Na condição de DT para a tarefa de memória de reconhecimento de cores, o teste T não demonstrou diferença significativa entre o TR para os participantes do G1 e os participantes do G2 em ambas as condições de amplificação (G1 comparado ao G2 AASI (t $(29)=-1.461, p=0.155)$, para $G 1$ comparado ao $G 2_{F M}(t)(29)=-0.909$, $p=0,371$, e para G2AASI comparado ao $2_{F M}(t(29)=-0.849, p=0,412$ ). Para os participantes do G1 não houve diferença significativa no TR entre a condição de TU e DT $(\mathrm{t}(17)=-1.662, \mathrm{p}=0.115)$. Da mesma forma, para os participantes do G2AASI, não houve diferença significativa no TR entre a TU e na DT ( $t(12)=-0.689, p=0.504)$.

O esforço auditivo foi determinado subtraindo o TR da TS (tarefa de memória de reconhecimento de cores) obtida para a condição de DT subtraindo a condição de TU (Esforço auditivo = TS TR sob condição de DT - TS TR sob condição de TU). O esforço auditivo dos participantes do G1 e G2 nas situações G2AAsI e G2FM são apresentados na Figura 6. O teste $T$ (para amostras não relacionadas) não revelou diferença entre os participantes do G1 e o G2 em ambas as situações de amplificação (G1 comparado ao G2AASI (t (29) =0,583, p = 0,564), e G1 comparado ao G2FM (t $(29)=1,283, p=$ 0,225). Da mesma forma, o teste $T$ (para amostras relacionadas) não revelou diferença significativa entre para os participantes do G2 sob as duas condições de amplificação G2AASI e G2FM (t (12) = 0,994, $p=0,340)$. 


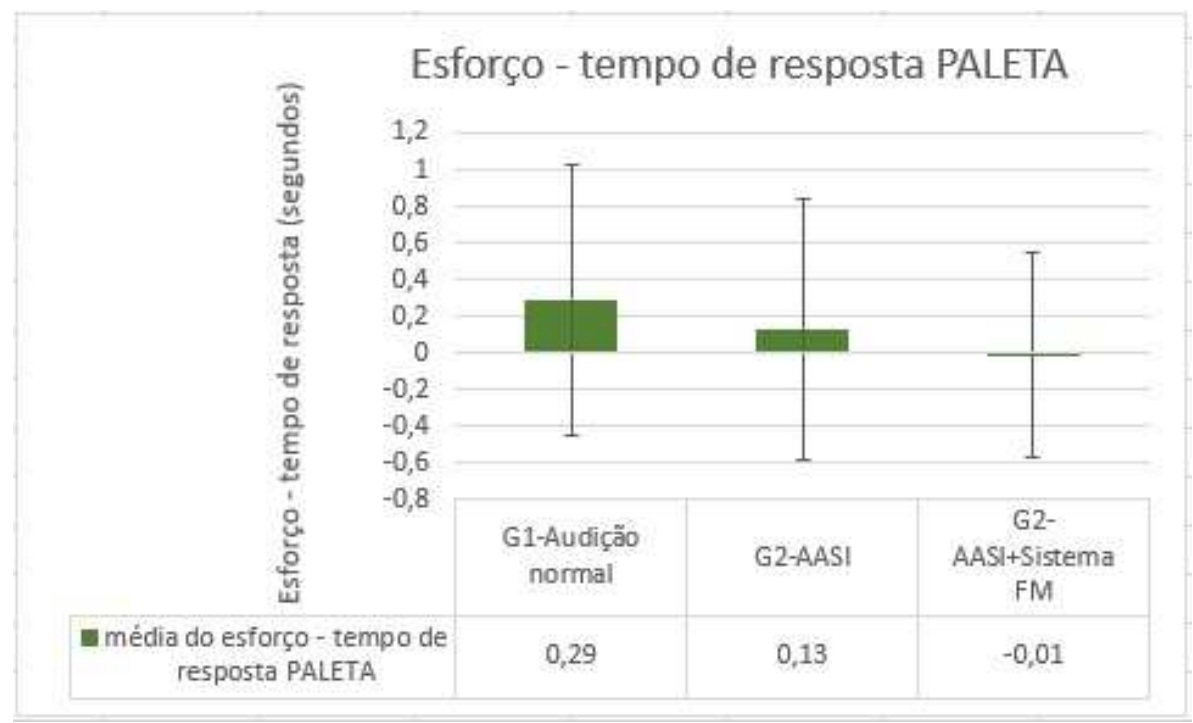

Figura 6 - Média do esforço auditivo com base nos dados dos tempos de respostas em segundos $( \pm 1$ $\mathrm{SD})$ para a tarefa de memória de reconhecimento de cores para o grupo com audição normal (G1) e o grupo com deficiência auditiva (G2- AASI e G2- AASI + sistema FM)

Além do TR, a plataforma PALETA fornece o NRC obtido em cada apresentação do teste, e, com base no NRC na TS, foram verificados estatisticamente os resultados nas condições de TU e DT, por meio do teste T. O NRC na tarefa de memória de reconhecimento de cores, sob a TU e DT dos participantes do G1 e os participantes do G2AAsı e do G2FM são apresentados na Figura 7.

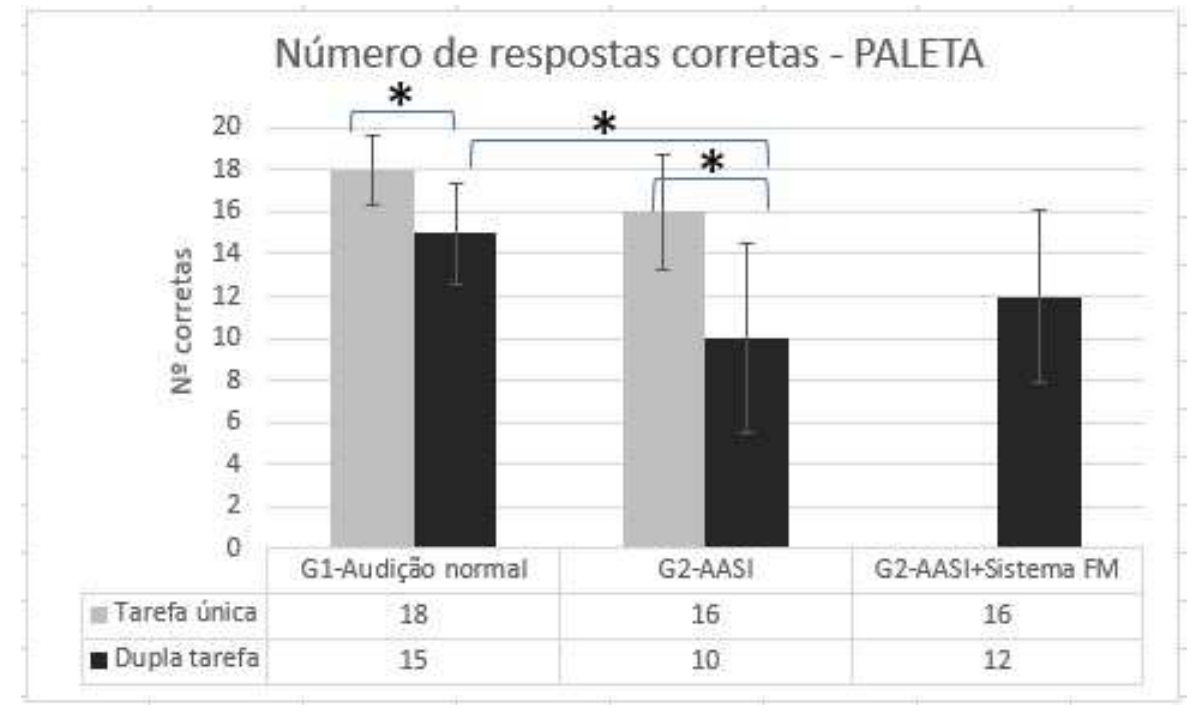

Legenda: * diferença estatisticamente significativa

Figura 7 - Média do número de respostas corretas na tarefa de memória de reconhecimento de cores ( \pm 1 SD) para o grupo com audição normal (G1) e o grupo com deficiência auditiva (G2) em ambas as condições de amplificação (AASI e AASI + sistema FM) 
Os resultados indicaram que, sob a condição de TU, o NRC obtidas dos participantes do $\mathrm{G} 1$ não é significativamente diferente do NRC obtidas pelo G2AASI ( $t$ $(29)=1,894, p=0,068)$. Lembrando que, para os participantes do $G 2$, o NRC para a TS administrada isoladamente só foi obtido sob a condição de AASI. Por isso, não foi apropriado e possível testar estatisticamente se existia diferença na TU entre os grupos de participantes do $\mathrm{G} 1$ e o $\mathrm{G} 2_{\mathrm{FM}}$.

Sob a condição de DT, os resultados revelaram que os participantes do G1 obtiveram valores significativamente maiores que os participantes do G2 AASI $(\mathrm{t}$ (16) = 3.653, $p=0,004^{*}$ ), mas não na condição em que os participantes usavam sistema FM - $G 2_{F M}(t(17)=1,853, p=0,081)$. Para os participantes do $G 2$, sob a condição de DT, não houve diferença significativa entre $\mathrm{G}_{\mathrm{AASI}}$ e $\mathrm{G}_{\mathrm{FM}}(\mathrm{t}(12)=-2,48$, $p=0,029)$.

Uma comparação entre o NRC na condição de TU comparada a DT revelou diferença significativa para os participantes do $\mathrm{G} 1\left(\mathrm{t}(17)=5,581, \mathrm{p}=0,000^{*}\right)$. Da mesma forma, para os participantes do G2AAsI houve uma diferença significativa entre o desempenho obtido sob a condição de TU e DT ( $\left.(12)=5,612, p=0,000^{*}\right)$.

Para os dados com base no NRC, o esforço auditivo foi definido como: Esforço auditivo = TS NRC sob condição de DT - TS NRC sob condição de TU). O esforço auditivo dos participantes do $\mathrm{G} 1$, bem como o esforço auditivo dos participantes do $\mathrm{G} 2 \mathrm{em}$ ambas as condições de amplificação (G2AASI e G2FM) são exibidos na Figura 8.

$O$ teste $T$ para amostras não relacionadas revelou que houve diferença significativa entre os participantes do $\mathrm{G} 1$ e os participantes do G2AASI (t $(29)=2,658$, $\left.p=0,013^{*}\right)$. Não houve diferença significativa entre os participantes do $G 1$ e os participantes do $\mathrm{G}_{\mathrm{FM}}(\mathrm{t}(29)=0,817, \mathrm{p}=0,420)$. $\mathrm{O}$ teste $\mathrm{T}$ para amostras relacionadas revelou que, para os participantes do $G 2$ (G2AASI e G2FM), não houve diferença significativa entre as duas condições de amplificação $(t(12)=-2.480, p=0.029)$. 


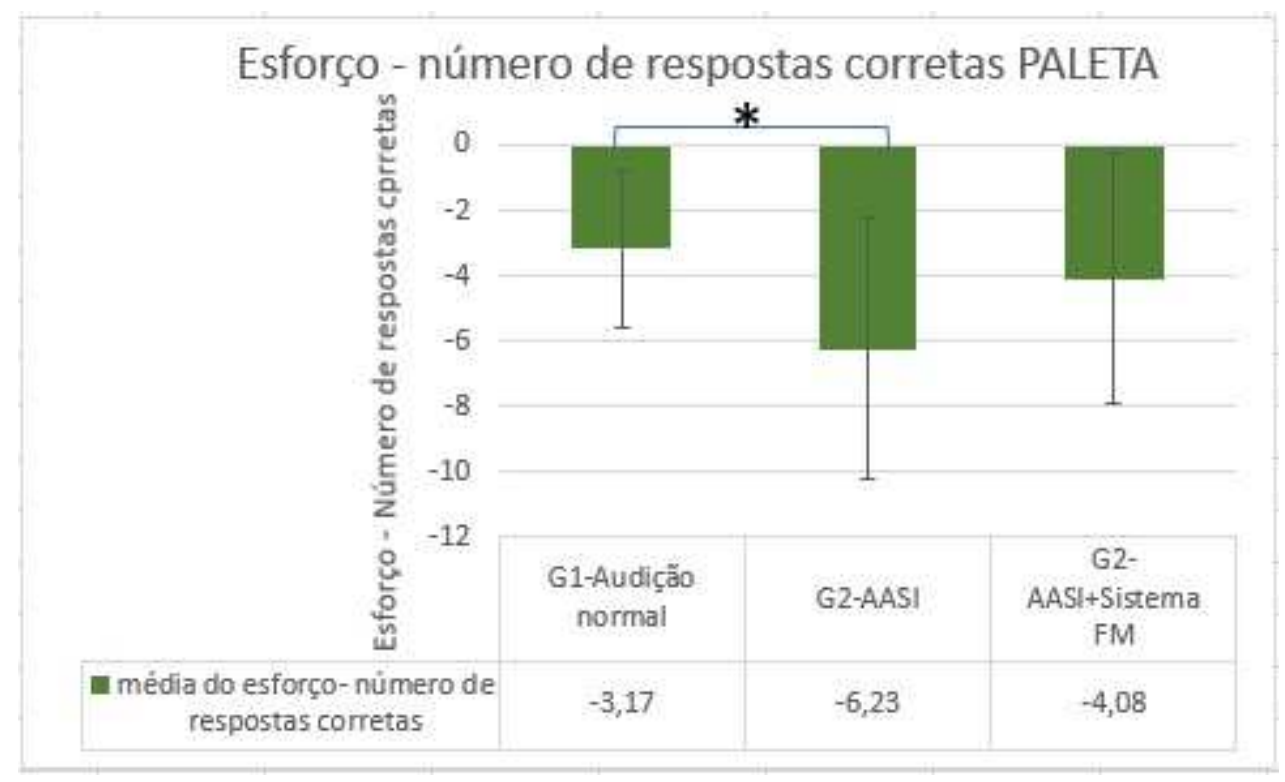

Legenda: * diferença estatisticamente significativa

Figura 8 - Média do esforço auditivo com base no número de respostas corretas na tarefa de memória de reconhecimento de cores $( \pm 1 \mathrm{SD})$ para o grupo com audição normal (G1) e o grupo com deficiência (G2) em ambas as condições de amplificação (AASI e AASI + sistema FM)

Os resultados com diferenças estatisticamente significantes encontradas na comparação entre os grupos são sintetizados no Quadro 3.

\begin{tabular}{|c|c|c|c|c|}
\hline & \multirow[t]{2}{*}{ Análise } & \multicolumn{3}{|c|}{ Resultados* } \\
\hline & & TU & DT & TU x DT \\
\hline Figura 4 & HINT & G1 x G2AASI & G1 x G2AASI & G1 \\
\hline Figura 5 & TR & G1 x G2AASI & ------------ & \\
\hline \multirow[t]{3}{*}{ Figura 7} & NRC & ----------- & G1 x G2AASI & G1 e G2 AASI \\
\hline & & Análise & & Resultados $^{*}$ \\
\hline & \multicolumn{3}{|c|}{ TS sob condição de DT - TS sob condição de TU } & \\
\hline Figura 6 & \multicolumn{3}{|c|}{ Esforço auditivo -TR } & ------------- \\
\hline Figura 8 & \multicolumn{3}{|c|}{ Esforço auditivo -NRC } & $\mathrm{G} 1 \times \mathrm{G} 2_{\mathrm{AASI}}$ \\
\hline
\end{tabular}

Legenda: * diferença estatisticamente significativa; TU- tarefa única; DT- dupla tarefa; TU x DTcomparação entre as tarefas; HINT - Hearing in Noise Test; TR- tempo de resposta; NRC- número de resposta corretas; G1xG2 - comparação entre os grupos

Quadro 3 - Síntese dos resultados significativos entre os grupos 


\subsection{FADIGA}

Para avaliação da fadiga, foi utilizada a "Avaliação Informal de Fadiga", que consiste em 11 questões que abordam a fadiga. Para cada pergunta, é fornecida para a resposta uma escala de 4 pontos. As opções de resposta variam de (0) não é um problema para minha idade a (3) muito mais do que o esperado para a idade (Apêndice C).

A versão traduzida para o Português Brasileiro foi aplicada para ambos os grupos, uma vez para o G1 e duas vezes para o G2 considerando as situações de G2 AASI e G2FM. O teste T foi utilizado para comparar os resultados obtidos para os participantes do G1 e G2.

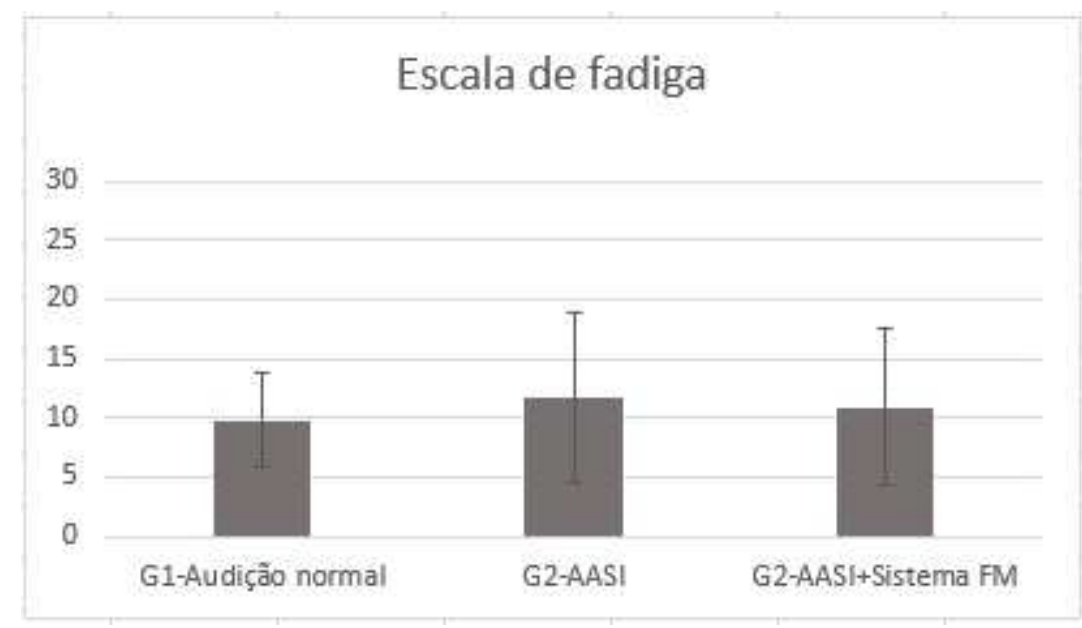

Figura 9 - Escores médios obtidos para a escala de fadiga ( \pm 1 SD) para o grupo com audição normal (G1) e o grupo de participantes com deficiência auditiva (G2) que preencheram o questionário para duas condições de audição: AASI e AASI + sistema FM

A fadiga relatada pelos participantes do G1 e pelos participantes do G2 em ambas as condições de amplificação são exibidas na Figura 9. O teste T (para amostras não relacionadas) não revelou qualquer diferença entre os participantes do G1 e do G2 em ambas as condições de amplificação (G1 comparado ao G2 AASI (t (29) $=0,948, p=0,351) ; G 1$ comparado ao G2FM (t $(29)=-0,597, p=0,555)$. De forma similar, o teste $\mathrm{T}$ (para amostras relacionadas) não revelou qualquer diferença para os participantes do G2 sob as duas condições de amplificação (t (12) = 1,477, p = $0,165)$. 
Os resultados obtidos na questão 1 da Escala LERI (Apêndice C) sobre impacto do ruído na aprendizagem ("Quando eu estou na escola ou durante a aula, muitas vezes tenho que parar minhas tarefas porque as ações ou barulhos de outros estudantes me atrapalham") são apresentados na Figura 10.

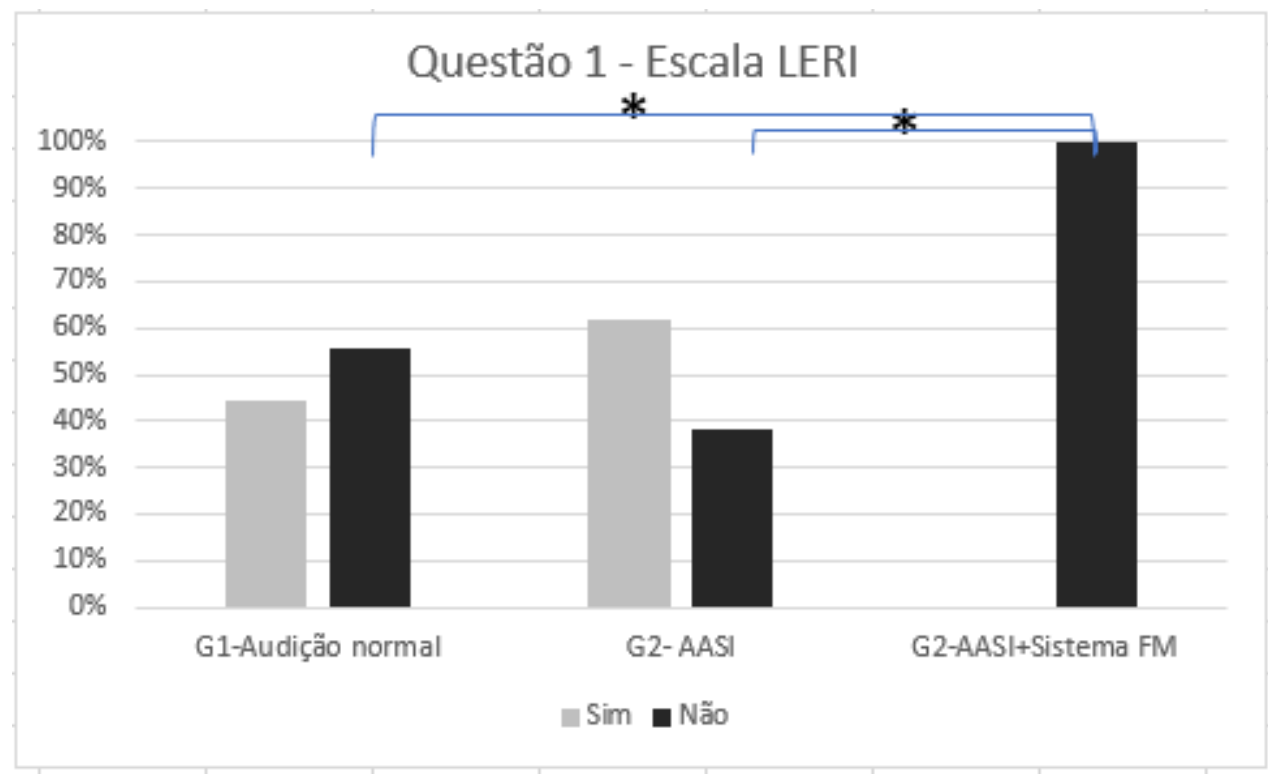

Figura 10 - Percentual das respostas obtidas na questão 1 (escala LERI) para o grupo com audição normal (G1) e o grupo com deficiência auditiva (G2) que responderam a questão para duas condições de audição: AASI e AASI + Sistema FM

O impacto do ruído na aprendizagem relatado pelos participantes do G1 e pelos participantes do G2 em ambas as condições de amplificação são exibidas na Figura 10. O teste qui-quadrado de Pearson não revelou diferença entre os participantes do G1 e do G2AAsI ( $p=0,374$ ), porém os resultados revelaram que os participantes do G2FM apresentaram ocorrência significativamente maior da resposta "Não" quando comparado aos participantes do G1 $\left(p=0,005^{*}\right)$ e do G2AASI $\left(p=0,001^{*}\right)$.

\subsection{QUESTIONÁRIO}

O questionário desenvolvido para pesquisar a opinião dos participantes com DA sobre o impacto do uso do sistema FM pessoal na sala de aula, denominado "Questionário de Avaliação do Sistema FM: Perspectiva do Usuário" (Apêndice D). O questionário foi administrado em 13 adolescentes (11 do sexo masculino e 2 do sexo 
feminino) que usavam AASI e sistema FM na escola. A idade média dos participantes foi de 14 anos e 11 meses, e adaptados ao sistema FM há aproximadamente 2 anos. Os modelos de sistema FM estão listados na Tabela 2 e 3 . Os resultados do questionário são apresentados na Tabela 5.

Tabela 5 - Questionário de Avaliação do Sistema FM: Perspectiva do Usuário

\begin{tabular}{|c|c|}
\hline Questões & Resposta $(n=13)$ \\
\hline 1. Horas de uso por dia & 5 horas (média) \\
\hline 2. Apoio prestado pela escola & $84,6 \%-\operatorname{Sim}$ \\
\hline 3. Todos os professores usam o sistema FM & $61,5 \%-\operatorname{Sim}$ \\
\hline $\begin{array}{l}\text { 4. Sente-se desconfortável em pedir aos professores que usem } \\
\text { o sistema FM }\end{array}$ & $77,0 \%$ - Não \\
\hline 5. Gostar de usar o sistema FM & $84,6 \%-\operatorname{Sim}$ \\
\hline 6. Gosta da aparência do sistema FM & $100 \%-\operatorname{Sim}$ \\
\hline 7. Aspectos positivos do sistema FM & $\begin{array}{c}\text { O sistema FM ajudou a ouvir melhor o } \\
\text { professor }(100 \%)\end{array}$ \\
\hline 8. Aspectos negativos do sistema FM & $\begin{array}{l}\text { 38,5\% - quando o professor grita; } \\
\text { 15,3\% - preconceito e vergonha; } \\
\text { 7,7\% - sente-se desconfortável em } \\
\text { pedir aos professores que usem o } \\
\text { sistema FM; } \\
38,5 \% \text { - sem aspectos negativos }\end{array}$ \\
\hline 9. Outros locais onde o sistema FM é usado & $\begin{array}{c}\text { 7,7\% Igreja; } \\
\text { 7,7\% Computador-celular; } \\
30,8 \% \text { TV / Música; } \\
53,8 \% \text { usam apenas sala de aula. }\end{array}$ \\
\hline
\end{tabular}


6 DIscussÃo 



\section{DISCUSSÃO}

A discussão foi constituída pelos seguintes tópicos: esforço auditivo (criação da TS e dados coletados na aplicação das tarefas); escala de fadiga e a questão sobre o impacto do ruído na aprendizagem; e por último o questionário sobre a percepção dos adolescentes quanto ao uso do Sistema FM em ambiente educacional.

Cabe antes discorrer sobre a opção pela tradução do termo em inglês "listening effort" para o termo em português brasileiro "esforço auditivo". Segundo Barbosa (1990) existem dois tipos de tradução: palavra-por-palavra ou literal.

\footnotetext{
[...] A tradução palavra-por-palavra é uma tradução em que a palavra ou frase mantém a mesma categoria numa mesma ordem sintática por meio do uso de vocábulos idênticos. A tradução literal mantém a semântica da escrita, entretanto são realizadas adequações para as normas gramaticais da língua traduzida. Quando há divergências relacionadas às organizações diversas dos sistemas linguísticos envolvidos na tradução, pode-se usar a transposição, modulação ou equivalência (Barbosa, 1990).
}

No caso do termo "listening effort" a tradução literal é "esforço de escuta", mas nessa pesquisa optou-se pela modulação, que consiste em reproduzir a mensagem original na tradução sob um ponto de vista. A modulação pode ser obrigatória ou por estilo, que é considerada facultativa (Barbosa, 1990). Assim, adotou-se a modulação por estilo, sendo considerada a tradução para o termo em português brasileiro "esforço auditivo", por estar relacionado à audição. Esta terminologia também já foi citada em outra pesquisa nacional (Oliveira et al, 2014).

\subsection{ESFORÇO AUDITIVO}

Os achados dos estudos apresentados no capítulo da revisão de literatura mostram que os problemas relacionados ao esforço auditivo e fadiga em indivíduos com DA podem ou não ser minimizados por meio da utilização do AASI e/ou IC. Observa-se que há uma escassez de estudos que investigaram o esforço auditivo e 
fadiga em crianças e adolescentes com DA. Além disso, nos poucos estudos encontrados é possível observar que existe um alto nível de heterogeneidade clínica e que não há consenso sobre qual ou quais procedimentos são válidos e devem ser adotados para medir o esforço auditivo nessa população. Os estudos que existem sugerem que os indivíduos com DA apresentam mais esforço auditivo do que seus pares com AN ao realizar uma tarefa de compreensão do discurso em ambiente ruidoso. Embora ainda não seja conclusivo, o uso do PDT tem sido indicado como um teste promissor para investigar o esforço auditivo.

\subsubsection{Medida comportamental}

O esforço auditivo foi avaliado por meio do PDT, no qual a tarefa principal consistiu em um teste de percepção da fala no ruído (HINT), e a TS por uma tarefa de memória de reconhecimento de cores. Para esta última foi elaborada uma plataforma específica, denominada PALETA (Apêndice E).

A ferramenta PALETA ainda está em processo de ajustes e registro, a ser disponibilizada aos fonoaudiólogos por meio de endereço eletrônico: http://www.paleta.fob.usp.br/. Sua utilização poderá ser por meio de celular, tablet e/ou computador, com suporte para sistema operacional IOS e Android. Vale lembrar que os profissionais de saúde têm aderido ao uso de aplicativos para auxiliar na consulta, diagnóstico e acompanhamento de pacientes (BURDETTE; HERCHLINE; OEHLER, 2008).

Os resultados de investigações com o PDT apontam que o desempenho pode ser influenciado pela complexidade da TS. Em alguns casos, é difícil determinar se essas tarefas realmente avaliam o esforço auditivo e se os resultados são confiáveis ou estão comprometidos pelas limitações impostas pela DA. No teste de DT, se a tarefa de percepção de fala for muito difícil, os indivíduos com DA podem se concentrar mais na TS, permitindo que o desempenho do reconhecimento de fala diminua (MCFADDEN; PITTMAN, 2008). Portanto, a escolha da metodologia é importante, porque se houver mudança nos recursos cognitivos do reconhecimento de fala para a TS o esforço auditivo não está mais sendo avaliado.

$\mathrm{Na}$ literatura, diferentes tipos de tarefas secundárias já foram utilizados para mensurar o esforço auditivo (GAGNÉ et al., 2017; MCGARRIGLE et al., 2014). Este 
tipo de manipulação experimental do PDT pode levar a resultados diferentes, e, diante da limitação de padronização e complexidade da TS, este estudo propôs desenvolver e disponibilizar uma plataforma para auxiliar na execução da TS e na análise dos dados por ela gerados, visto que na literatura não foi encontrado nenhum material específico para este fim. Autores já apontaram a necessidade e a importância da criação de padronização da avaliação da TS para o PDT (GAGNÉ et al., 2017).

Estudos que utilizaram o PDT para avaliar o esforço auditivo em crianças produziram resultados não conclusivos (MCFADDEN; PITTMAN, 2008; STELMACHOWICZ et al., 2007). Isso pode sugerir que as condições experimentais escolhidas para a TP (ou seja, o teste de percepção de fala no ruído) podem não ter sido suficientemente desafiantes para causar um aumento significativo no esforço de audição (GAGNÉ et al., 2017), ou também, os resultados podem ser influenciados pela complexidade da TS e a heterogeneidade dos tipos de tarefas poderiam levar a resultados diferentes.

A literatura confirma essa crítica à falta de padronização das TS utilizadas para avaliar o esforço auditivo em crianças com DA. Estas podem envolver: solicitar que a criança pressione um botão de resposta o mais rápido possível sempre que um sinal de luz posicionado na parte superior do alto-falante (usado para a tarefa principal) é mostrado (HICK; THARPE, 2002); tarefa de memorização de dígitos (STELMACHOWICZ et al., 2007) e conclusão de desenhos de ligar ponto-a-ponto (MCFADDEN; PITTMAN, 2008).

Vale ressaltar que por meio da PALETA é possível realizar o cadastro do participante e elaboração das tarefas. Todas as respostas das tarefas executadas pelos participantes são salvas na plataforma e disponibilizadas para visualização do administrador, fornecendo informação sobre o TR e o NRC (Apêndice E).

\section{Resultados envolvendo a TP (HINT) nas situações de TU e DT}

A Figura 4 indica que a média da relação S/R obtida no HINT na condição de TU e DT revelou diferença significativa entre o G1 e o G2 $2_{A A S I}$. Porém, pode-se também observar que todos os grupos tiveram piora no desempenho na condição de DT quando comparados a TU. Na condição de TU e na DT o G2 FM apresenta melhor 
desempenho do que o $\mathrm{G} 2 \mathrm{AASI}$, revelando uma diferença significativa entre as condições de amplificação.

Os estudos que utilizaram a DT para avaliar crianças e jovens adultos com DA (HICKS; THARPE, 2002; STELMACHOWICZ et al., 2007; MCFADDEN; PITTMAN, 2008; HUGHES; GALVIN, 2013), adotaram testes de percepção da fala (TP) com diferentes relações $S / R$ fixas, o que difere do presente estudo que utilizou a relação S/R adaptativa. As TP utilizadas nestas investigações foram: tarefa de reconhecimento de palavras administrada em três relações $S / R$ diferentes $(+20 \mathrm{~dB}$, +15 dB e +10 dB; HICK; THARPE, 2002); palavras apresentadas na relação S/R de +8dB (STELMACHOWICZ et al., 2007); palavras apresentadas no silêncio e ruído, nas relações S/R + $6 \mathrm{~dB}$ e $0 \mathrm{~dB}$ (MCFADDEN; PITTMAN, 2008). Observa-se que a TP, embora apresentada utilizando relação fixa, diferia em intensidade entre os trabalhos. Ainda assim, esses dados mostram que a TP com relação fixa é mais adequada para mensurar o esforço auditivo, visto que esta é a única forma possível de realizar a comparação entre a TP e a TS por meio da porcentagem de acertos entre as tarefas como sugere Gagné et al. (2017), o que não foi realizado neste estudo.

Entretanto, o teste de percepção de fala (HINT) com relação adaptativa também foi utilizado na pesquisa de Jacob et al. (2012), que citam não terem encontrado estudos em pacientes com DA na faixa etária entre sete a 17 anos que utilizassem o HINTPro com a aplicação de forma adaptativa, e sim, apenas pesquisas que adotaram as sentenças do HINT como material de avaliação de fala por meio de gravação em $C D$, e utilizando relação fixa com resultados em porcentagem. Isto pode ser justificado pelo fato das listas de sentença e do ruído do HINT Brasil estarem disponíveis apenas por meio da interface do HINTPro, que não oferece a opção de relação SR fixa, sendo este equipamento encontrado em poucas instituições de pesquisa do país.

Os autores citados acima avaliaram a percepção de fala no ruído por meio do HINT em jovens entre 13 a 17 anos com DA usuários de AASI e Sistema FM. O sistema FM mostrou benefício na percepção de fala. Outro estudo que comprova a eficácia do Sistema FM é o de Lewis et al. (2004), cujos resultados revelaram que a percepção da fala no ruído foi significativamente melhor com a utilização do AASI em conjunto com o Sistema FM, assim como indicado na revisão de Bertachini et al. (2015). 
Em relação a abordagem adaptativa, de acordo com o guia da AAA (2008, 2011), apesar de ser utilizada em pesquisas com o sistema FM, essa abordagem não foi padronizada para o uso na verificação clínica do desempenho do sistema FM (LEWIS et al., 2004; SCHAFER; THIBODEAU, 2006; JACOB et al., 2012). Os guias para avaliação de microfones remotos da ASHA (2002) e AAA $(2008,2011)$ sugerem relação $S / R$ fixa de 0 ou $+5 \mathrm{~dB}$. O ruído interfere negativamente no reconhecimento de fala e pode prejudicar a aprendizagem no ambiente escolar para todos os alunos (CRUZ et al., 2016). Os achados desta investigação reforçam a importância do uso do Sistema FM para melhorar a compreensão do sinal de fala no ruído (Figura 4), e confirmam a hipótese de que também auxiliam na redução do esforço auditivo (Figura 8) diante do declínio na TS em situação de DT ser maior sem o sistema FM, conforme apresentado na Figura 7.

\section{Resultados envolvendo a TS (tarefa de memória de reconhecimento de cores) nas situações de TU e DT}

A média do TR (em segundos) necessária para executar a tarefa de memória de reconhecimento de cores da PALETA (Figura 5), revela que na condição de TU, o TR dos participantes do G1 foi significativamente menor do que o TR obtido pelos participantes do G2AASI. A análise descritiva dos resultados mostrou que houve um aumento do TR quando comparadas as situações de TU e DT para o G1 e G2AASI, porém na condição G2FM a média do TR da TU e da DT foram próximos. Os autores Hicks e Tharpe (2002) e Stelmachowicz et al. (2007) também não observaram diferença entre os grupos de DA e seus pares com AN quando analisaram a TR para mensurar o esforço auditivo.

Questiona-se se o TR pode ser considerado uma boa métrica, visto que o paciente pode obter um tempo mais rápido, ou seja, um tempo menor na execução da tarefa, mas a quantidade de acertos na TS ser menor, ou apresentar um TR maior só que com uma quantidade de NRC maiores (Figuras 5 e 7).

O esforço auditivo é quantificado quando existe uma queda do desempenho da TS na condição de DT (GAGNÉ et al., 2017). O esforço auditivo obtido pelo TR não revelou qualquer diferença significativa entre os grupos (Figura 6). Por meio da análise descritiva observa-se que o G1 apresenta um esforço auditivo maior do que o G2 em 
ambas condições G2AASI e G2FM. Na comparação entre o G2, observa-se que G2AASI apresenta maior esforço do que quando comparado a condição G2FM.

$\mathrm{Na}$ Figura 7, os resultados apresentados demonstram que, sob a condição de TU, o NRC obtidas dos participantes do G1 não é significativamente diferente do NRC do G2 AASI. Sob a condição de DT, os resultados revelaram que os participantes do G1 obtiveram valores significativamente maiores do número de acertos do que os participantes do G2 AASI. Uma comparação entre o NRC na condição de TU com a DT revelou diferença significativa para os participantes do G1 e do G2AAsI. Por meio de análise descritiva, observa-se que o NRC reduziu para todos os grupos na condição de DT quando comparado à condição de TU.

Para a avaliação do esforço auditivo por meio dos dados do NRC (Figura 8), observou-se que houve diferença significativa entre os participantes do G1 e os participantes do G2AASI. Embora não ter acontecido o mesmo no G2 entre as duas condições de amplificação, é possível observar que na situação AASI e sistema FM o esforço auditivo foi menor, e não há diferença entre o G1 e G2 $2_{\mathrm{FM}}$ (Figura 8), o que sugere que os adolescentes usuários de sistema FM ficam em condições de escuta próximas aos seus pares ouvintes, reforçando novamente a tese de que o uso do sistema FM auxilia na redução do esforço auditivo.

O tema desta investigação é pioneiro quanto à avaliação do esforço auditivo em adolescentes usuários de AASI e Sistema FM, entretanto os estudos encontrados na população infantil com DA que utilizam o PDT para mensuração do esforço auditivo discutem seu impacto nesta população (HICKS; THARPE, 2002; STELMACHOWICZ et al., 2007; MCFADDEN; PITTMAN, 2008).

Hick e Tharpe (2002) não observaram diferença entre os dois grupos de participantes nas tarefas de reconhecimento de fala. Com relação à TS, embora não significativa, os TR obtidos sob a condição de DT sugerem que as crianças com DA apresentaram um esforço auditivo maior quando comparada aos seus pares com AN. Os achados encontrados pelos autores não foram os mesmos observados na presente investigação. Quanto à TP na condição de DT observou-se diferença significativa entre o G1 e o G2AASI, revelando que o G2 $2_{A A S I}$ teve um desempenho pior no teste de percepção de fala no ruído, e necessitou de uma relação $S / R$ positiva, sendo a média de $+4,21 \mathrm{~dB}$ (Figura 4). Já na TS, os TR obtidos pelo G1 sugerem que esses apresentaram um esforço auditivo maior do que o $\mathrm{G} 2 \mathrm{em}$ ambas condições 
(G2 $2_{A A S I}$ e G2FM). Na comparação entre as duas condições de escuta do G2, observase que G2AASI apresenta maior esforço quando comparado à condição G2FM(Figura $5)$.

Os resultados da investigação de McFadden e Pittman (2008) sugeriram que as crianças com DA leve experimentaram maior esforço auditivo sob a condição de DT em ruído do que as crianças com AN. Os autores concluíram que ambos os grupos apresentaram melhor desempenho na TS quando foi administrado sob a condição de TU do que quando apresentado em DT. Esses achados também foram observados nos adolescentes do G1 e G2 (Figura 7), assim como o G2AASI apresentou um esforço auditivo estatisticamente maior quando comparado ao G1 (Figura 8).

$\mathrm{Na}$ condição de DT, a métrica para quantificar o esforço auditivo é baseada no declínio da performance na TS na condição de DT (GAGNÉ et al., 2017). Nessa avaliação pode ser considerado os valores do NRC ou o TR na TS (GOSSELIN; GAGNÉ, 2011; FRASER et al., 2010; GAGNÉ et al., 2017). Diante dos dados encontrados na presente investigação e na ausência de resultados significativos no TR obtido na TS nos estudos de Hicks e Tharpe (2002) e Stelmachowicz et al. (2007), sugere-se que, para a avaliação do esforço auditivo, deve-se investir no NRC como métrica (Figuras 7 e 8). Picou (2013) refere que o TR tende a ser sensível aos efeitos de aprendizagem e fadiga, referindo que no início da tarefa as pessoas podem ser mais lentas, e ao longo do tempo, se tornarem mais rápidas e à medida que estão cansadas podem desacelerar novamente, o que pode ter acontecido neste estudo (Figuras 5 e 6 ), apesar de ter sido utilizado o Design do Quadrado Latino para evitar estes efeitos da ordem de aplicação das tarefas.

Os resultados encontrados sugerem que a PALETA é um método confiável para medir o TR e o NRC, sendo uma TS fácil de usar e efetiva para avaliar o esforço auditivo, assim como observou-se que o uso do sistema FM auxiliou na redução do esforço auditivo dos adolescentes com DA quando comparado à condição com AASI e os seus pares. 


\subsection{FADIGA}

A fadiga relatada pelos participantes dos $\mathrm{G} 1$ e $\mathrm{G} 2$ não revelou qualquer diferença significativa entre os grupos (Figura 9), corroborando com os achados de Hick e Tharpe (2002), que avaliaram a fadiga em dez crianças com DA e dez com AN por meio da escala COOP (WASSON et al., 1994). Já Hornsby et al. (2014) avaliaram a fadiga em 20 crianças divididas igualmente em dois grupos (com DA e AN), por meio do relato dos pais. Sete destas crianças usavam o sistema FM na sala de aula. A fadiga foi avaliada por meio da escala PedsQL MFS (VARNI et al., 2002), e os resultados revelaram um aumento da fadiga em crianças com DA quando comparada aos seus pares. Os autores ressaltam que a evidência preliminar indicou que as crianças com DA estão em maior risco de fadiga em comparação aos seus pares com AN.

Os estudos citados que avaliaram a fadiga por meio de questionários e escalas apontam que essas ferramentas não foram projetadas especificamente para indivíduos com DA, assim como a escala de fadiga (Apêndice $C$ ) utilizada na presente pesquisa. Na literatura não são encontrados estudos que investigam a fadiga auditiva em adolescentes com DA.

O esforço auditivo é considerado como o processo para compreender a fala durante situações diárias adversas, enquanto a fadiga é a consequência desse processo de escuta cansativo. Na prática clínica também há vários relatos anedóticos de que os indivíduos com DA se queixam de fadiga, que pode causar consequências negativas na qualidade de vida desses indivíduos (HORNSBY; KIPP, 2016).

Pode-se inferir que, ao longo do dia, o aluno com DA poderá apresentar sintomas de fadiga e estresse resultante do esforço auditivo que teve que realizar para conseguir compreender a fala do seu professor e dos seus colegas em um ambiente escolar ruidoso e reverberante.

Dessa forma, destaca-se a importância do desenvolvimento de ferramentas, escalas ou questionários para avaliar e investigar o impacto da fadiga auditiva relacionada à DA, podendo assim auxiliar em uma maior compreensão das dificuldades específicas do paciente, no melhor ajuste dos dispositivos usados e no acompanhamento dessa população. 
Os resultados apresentados na Figura 10 representam o quanto o ruído em sala de aula muitas vezes atrapalha não só os adolescentes com DA quando estão usando apenas o AASI como os seus pares com AN (Figura 10). A queixa destes adolescentes com DA diminui significativamente com o uso do Sistema FM, relatando melhor desempenho até que seus pares ouvintes. Thibodeau e Shaper (2014) já vislumbraram uma situação como essa quando, ao investigarem os benefícios da tecnologia digital sem fio, por observarem resultados tão promissores, imaginaram ser possível que adolescentes com DA utilizando este tipo de dispositivo poderiam explicar aos seus colegas ouvintes o que estaria sendo dito em situações escolares que envolvessem ruído.

Pichora-Fuller (2003) relata que em uma situação que é difícil para ouvir, o indivíduo terá que fazer um esforço maior para compreender a mensagem, ocasionando cansaço, podendo deixar o indivíduo frustrado e levá-lo a desistir de compreender a mensagem. O estudo de Cruz (2014) ilustra essa situação por meio de um depoimento de um estudante sobre o ambiente acústico da sua sala de aula, que considera barulhenta. Refere que quando não consegue prestar atenção na fala do professor, desiste de acompanhar e começa a conversar com os amigos. Essa atitude pode trazer impactos negativos para o processo de aprendizagem do aluno em sala de aula.

\subsection{QUESTIONÁRIO}

O "Questionário de Avaliação do Sistema FM: Perspectiva do Usuário" (Apêndice D) teve como objetivo coletar informações e compreender a realidade dos adolescentes usuários de sistema FM no ambiente educacional.

A média de idade dos participantes foi de 14 anos e 11 meses. Em média, os participantes usavam o sistema FM por aproximadamente dois anos, cinco horas por dia (Tabela 5). A maioria dizia receber apoio da escola. Embora mais da metade dos relatos apontam que os professores usam o sistema FM, seria imprescindível que $100 \%$ dos professores usassem. É sabido que, embora os professores sejam favoráveis à inclusão, os mesmos ainda não têm conhecimentos suficientes sobre o assunto (LIBARDI, 2012). Portanto, torna-se importante a realização de programas de apoio aos professores que 
atendam às necessidades dos alunos com DA, contribuindo em uma melhor relação professor-aluno.

A maioria dos participantes informou utilizar o sistema FM em todas as aulas, e três relataram que não usavam sempre. Quando questionados sobre o motivo, relataram que "alguns professores não usam e não querem usar; um adolescente relatou que um professor disse que já tem tarefas demais e que não tem tempo"; outro relatou que "não faz uso constante na escola, porque tem vergonha de levar o sistema FM, pois, não quer que os amigos vejam e nem ser questionado sobre o sistema FM", e outro adolescente também relatou que "sente vergonha de pedir para o professor, usa as vezes em algumas aulas, mas que vai parar de usar porque sente vergonha".

Esses achados corroboram com os dados encontrados na pesquisa de Spósito (2017) que avaliou 185 prontuários de adolescentes usuários de Sistema FM, com 12 a 18 anos de idade. A autora referiu que muitos adolescentes informaram que não enfrentam obstáculos em sala de aula quanto ao uso do dispositivo, entretanto, dentre os que se queixaram, os motivos relatados foram: vergonha de usá-lo, constrangimento de solicitar para o professor que utilize o dispositivo; e a falta de incentivo e disposição do professor em aprender a usar de modo correto o dispositivo.

Dentre os 13 adolescentes, a maioria se sente confortável em pedir aos professores que usem o sistema FM, gosta de usá-lo e da aparência do equipamento. $\mathrm{Na}$ questão aberta sobre os aspectos positivos do sistema FM, todas as repostas foram relatos relacionados a melhora na percepção da fala do professor. Quanto aos aspectos negativos, destacaram-se: o grito do professor; preconceito e vergonha e desconforto em pedir aos professores que usem o sistema FM.

A maioria dos adolescentes relatou que usa o sistema FM apenas na sala de aula. Outros lugares citados foram: igreja; computador-celular; e TV/Música. Spósito (2017) destaca que essa possiblidade de uso além da sala de aula pode servir de estratégia para a maior adesão ao uso do sistema FM, visto que os jovens nasceram numa época em que a ciência avança a passos largos. Portanto, oferecer dispositivos que se conectam com os mais diversos aparelhos tecnológicos torna-se mais atrativo ao adolescente.

Estes dados vão ao encontro dos achados de Gustafson et al. (2013). Os autores observaram que as crianças com DA usuárias de AASI e sistema FM pessoal entre sete a dez anos de idade são usuárias mais consistentes dos AASI e sistema 
FM no ambiente escolar do que as crianças entre 11 a 12 anos, independentemente da severidade da perda auditiva. Apesar da importância do uso efetivo do sistema de FM, Johnson (2014) destaca que, no caso dos adolescentes, mesmo quando o sistema FM está bem adaptado e são conhecidos os benefícios que pode proporcionar aos usuários, o estigma social e o desejo de serem como seus pares podem influenciar o uso adequado desta TA.

Segundo Spósito (2017) o uso consistente do sistema FM por adolescentes envolve diversos fatores que precisam ser considerados por toda a equipe multiprofissional durante o processo de adaptação e acompanhamento, para buscar fortalecê-lo e incentivá-lo, mostrando as vantagens que alcançarão a médio e longo prazos.

Os resultados aqui apresentados são importantes para reforçar o uso efetivo do sistema FM e evitar a problemática citada no estudo de Spósito (2017), que foi a falta desses pacientes no momento após adaptação da TA e até mesmo a desistência e devolução do sistema FM. Os resultados obtidos por meio da DT (Figura 4 a 7; Quadro 3) na avaliação do impacto do sistema FM no esforço auditivo (Figura 8) contribuem como evidências para mostrar e quantificar o benefício do uso do dispositivo em ambiente ruidoso.

\subsection{LIMITAÇÕES E SUGESTÕES}

Vale destacar que esta é a primeira pesquisa a utilizar a PALETA. Portanto, há necessidade da ampliação da casuística, investigando diferentes faixas etárias, tipos e graus de perda auditiva e dispositivos utilizados (AASI e/ou IC, unilateral e bilateral) para a validação deste instrumento.

Por meio dos resultados obtidos, sugere-se que a TP seja composta por lista de sentenças ou palavras com relação fixa, e a TS (PALETA) seja testada em todas as condições de escuta avaliadas, para que seja realizada a comparação entre as tarefas.

$\mathrm{Na}$ literatura observa-se a ausência de questionários ou escalas específicas que avaliem a fadiga auditiva em adolescentes com DA, tornando esse um importante campo a ser investigado. 

7 CONCLUSÕES 



\section{CONCLUSÕES}

A partir do estudo para avaliar o esforço auditivo em adolescentes com deficiência auditiva foi possível concluir que:

- A PALETA foi considerada uma tarefa secundária de fácil aplicação e execução, sendo efetiva para auxiliar nos testes de dupla tarefa;

- Os adolescentes com deficiência auditiva apresentam mais risco de esforço auditivo do que seus pares com audição normal;

- O uso do sistema de frequência modulada foi efetivo para reduzir o esforço auditivo quando comparado com os resultados apenas com o uso do aparelho de amplificação sonora individual e com os seus pares com audição normal;

- Não foram observadas diferenças significantes quanto à fadiga entre os grupos avaliados;

- Quanto ao impacto do ruído na aprendizagem, a queixa dos adolescentes com deficiência auditiva diminui significativamente com o uso do sistema FM, relatando melhor desempenho até que seus pares ouvintes;

- A maioria dos adolescentes usuários de sistema FM encontravam-se satisfeitos e faziam o uso efetivo de seus dispositivos em sala de aula. 




\section{REFERÊNCIAS}

American Academy of Audiology. Clinical Practice Guidelines: Remote Microphone Hearing Assistance Technologies for Children and Youth from Birth to 21 Years. 2011.

American National Standard Institute - ANSI S12.60.2010. Acoustical Performance Criteria, Design Requirements, and Guidelines for Schools, Part 1: Permanent Schools. 2010.

American Speech-Language-Hearing Association. Guidelines for fitting and monitoring FM systems. 2002.

Associação Brasileira de Normas Técnicas. NBR 10152: Níveis de ruído para conforto acústico- procedimentos. Rio de Janeiro, 1987. 4p.

Barbosa HG. Procedimentos técnicos da tradução: Uma nova proposta. Campinas: Pontes, 1990.

Bernarding C, Strauss DJ, Hannemann R, Seidler H, Corona-Strauss FI. Neural correlates of listening effort related factors: Influence of age and hearing impairment. Brain Res Bull. 2013;91:21-30.

Bertachini ALL, Pupo AC, Morettin M, Martinez MAN, Bevilacqua MC, Moret ALM, et al. Frequency Modulation System and speech perception in the classroom: a systematic literature review. CoDAS. 2015;27(3):292-300.

Bess FH, Gustafson SJ, Corbett BA, Lambert EW, Camarata SM, Hornsby BW. Salivary Cortisol Profiles of Children with Hearing Loss. Ear Hear. 2016;37(3):334-44.

Bess FH, Gustafson SJ, Hornsby BW. How hard can it be to listen? Fatigue in schoolage children with hearing loss. JEA. 2014;20:1-14.

Bess FH, Hornsby BWY. The complexities of fatigue in children with hearing loss. SIG 9 Perspectives on Hearing and Hearing Disorders in Childhood. 2014;24(2):25-39.

Bevilacqua MC, Banhara MR, Costa EA, Vignoly AB, Alvarenga KF. The Brazilian Portuguese Hearing In Noise Test (HINT). Int J Audiol. 2008;47(6):364-65. 
Boksem M, Tops M. Mental fatigue: costs and benefits. Brain Res Rev. 2008;59(1):125-39.

Brasil. Lei 8.069, de 13 de Julho de 1990. Estatuto da Criança e do Adolescente. Brasília: Ministério da Justiça, 1990.

Brasil. Portaria $\mathrm{n}^{\circ} 1.274$ de 25 de junho de 2013. Inclui o Procedimento de Sistema de Frequência Modulada Pessoal (FM) na Tabela de Procedimentos, Medicamentos, Órteses, Próteses e Materiais Especiais (OPM) do Sistema Único de Saúde. 2013.

Burdette SD, Herchline TE, Oehler R. Practicing medicine in a technological age: using smartphones in clinical practice. Clin Infect Dis. 2008;47(1):117-22

Crandell CC, Smaldino JJ. Classroom acoustics for children with normal hearing and with hearing impairment. Lang Speech Hear Serv Sch. 2000;31(4):362-70.

Cruz AD, Alves Silvério KC, Costa AR, Moret AL, Lauris JR, de Souza Jacob RT. Evaluating effectiveness of dynamic soundfield system in the classroom. Noise Health. $2016 ; 18(80): 42-9$.

Cruz AD. Sistema de campo livre digital: avaliação da efetividade em ambiente educacional [Dissertação]. Bauru (SP): Faculdade de Odontologia de Bauru, Universidade de São Paulo; 2014.

Desjardins JL, Doherty KA. Age-related changes in listening effort for various types of masker noises. Ear Hear. 2013;34(3):261-72.

Desjardins JL, Doherty KA. The effect of hearing aid noise reduction on listening effort in hearing-impaired adults. Ear Hear. 2014;35(6):600-10.

Downs DW. Effects of hearing aid use on speech discrimination and listening effort. J Speech Hear Disord. 1982; 47(2):189-93.

Fidêncio VLD, Moret ALM, Jacob RTS. Measuring noise in classrooms: A systematic review. Codas. 2014;26(2):155-8.

Fonseca VRJRM. Surdez e deficiência auditiva: a trajetória da infância à idade adulta. São Paulo: Casa do Psicólogo, 2001. 
Fraser S, Gagné JP, Alepins M, Dubois P. Evaluating the Effort Expended to Understand Speech in Noise Using a Dual-Task Paradigm: The Effects of Providing Visual Speech Cues. J Speech Lang Hear Res. 2010;53(1):18-33.

Fukuda S, Yamano E, Joudoi T, Mizuno K, Tanaka M, Kawatani J, et al. Effort-reward imbalance for learning is associated with fatigue in school children. Behav Med. 2010;36(2):53-62.

Gagné JP, Besser J, Lemke U. Behavioral Assessment of Listening Effort Using a Dual-Task Paradigm: A Review. Trends Hear. 2017;21:2331216516687287.

Gatehouse S, Noble W. The Speech, Spatial and Qualities of Hearing Scale (SSQ). IJA. 2004;43(2): 85-99.

Gonsalez ECM, Almeida K. Adaptação cultural do questionário Speech, Spatial and Qualities of Hearing Scale (SSQ) para o Português Brasileiro. Audiol Commun Res. 2015; 20(3):215-224.

Gosselin PA, Gagné JP. Older adults expend more listening effort than young adults recognizing speech in noise. J Speech Lang Hear Res. 2011;54(3):944-58.

Gustafson S, Delong A, Werfel K, Bess FH. Classroom Noise and Fatigue in Children with Normal Hearing and Children with Hearing Loss. Paper presented at the American Speech -Language-Hearing Association, Chicago II. 2013.

Hicks CB, Tharpe AM. Listening effort and fatigue in school age children with and without hearing loss. J Speech Lang Hear Res. 2002: 45(3); 573-84.

Higgins JPT, Green S. Cochrane Handbook for Systematic Reviews of Interventions Version 5.1.0. The Cochrane Collaboration, 2011.

Hornsby BW, Kipp AM. Subjective ratings of fatigue and vigor in adults with hearing loss are driven by perceived hearing difficulties not degree of hearing loss. Ear Hear. 2016;37(1):e1-e10.

Hornsby BW, Werfel K, Camarata S, Bess FH. Subjective fatigue in children with hearing loss: Some preliminary findings. Am J Audiol. 2014;23(1):129-34.

Hornsby BW. The effects of hearing aid use on listening effort and mental fatigue associated with sustained speech processing demands. Ear Hear. 2013;34(5):52334. 
Houben R, Doorn-Bierman M, Dreschler WA. Using response time to speak as a measure for listening effort. IJA. 2015;52(11): 753-61.

Howard CS, Munro KJ, Plack CJ. Listening effort at signal-to-noise ratios that are typical of the school classroom. Int J Audiol. 2010;49(12):928-32.

Hughes KC, Galvin KL. Measuring listening effort expended by adolescents and young adults with unilateral or bilateral cochlear implants or normal hearing. Cochlear Implants Int. 2013;14(3):121-9.

Jacob RTS, Bevilacqua MC, Molina SV, Queiroz M, Hoshii LA, Lauris JRP, et al. Sistema de frequência modulada em crianças com deficiência auditiva: avaliação de resultados. Rev Soc Bras Fonoaudiol. 2012;17(4):417-21.

Jacob RTS, Queiroz-Zattoni M. Sistemas de frequência modulada. IN: Boéchat EM et al. (Ed). Tratado de audiologia. $2^{a}$ ed. São Paulo: Santos, 2015. Cap. 43, p. 290-309.

Johnson CD. Hearing Assistance Technology: Collaborating with Teens to Get It Right. Semin Hear. 2014; 35(3): 257-66.

Kochkin S. MarkeTrak VIII Patients report improved quality of life with hearing aid usage. Hear J. 2011;64(6):25-32.

Kramer SE, Teunissen CE, Zekveld AA. Cortisol, Chromogranin A, and Pupillary Responses Evoked by Speech Recognition Tasks in Normally Hearing and Hard-ofHearing Listeners: A Pilot Study. Ear Hear. 2016;37(1):126S-35S.

Levitt $\mathrm{H}$, Rabiner LR. Use of a sequential strategy in intelligibility testing. J Acoust Soc Am. 1967; 42(3): 609-12.

Lewis MS, Crandell CC, Valente M, Horn JE. Speech perception in noise: directional microphones versus frequency modulation (FM) systems. Am J Audiol. 2004; 15(6):426-39.

Libardi AL. Avaliação do site "Curso de sistema de frequência modulada para professores" [Dissertação]. Bauru (SP): Faculdade de Odontologia de Bauru, Universidade de São Paulo; 2012.

Lobo MC. Adolescente surdo e os conflitos da idade: o olhar da Psicologia. REVISTA NEP. 2016; 2(5): 132-43. 
Mackersie CL, Cones H. Subjective and psychophysiological indexes of listening effort in a competing-talker task. J Am Acad Audiol. 2011;22(2):113-22.

MacPherson A, Akeroyd MA. The Glasgow Monitoring of Uninterrupted Speech Task (GMUST): A naturalistic measure of speech intelligibility in noise. POMA. 2013; 19(1):050068.

McFadden B, Pittman A. Effect of minimal hearing loss on children's ability to multitask in quiet and in noise. Lang Speech Hear Serv Sch. 2008;39(3):342-351.

McGarrigle R, Munro KJ, Dawes P, Stewart AJ, Moore DR, Barry JG, et al. Listening effort and fatigue: what exactly are we measuring? A British Society of Audiology Cognition in Hearing Special Interest Group 'white paper'. Int J Audiol. 2014;53(7):43340.

Miguel JHDS, Novaes BCDAC. Hearing rehabilitation in children: adhesion to treatment and use of hearing aids. Audiology-Communication Research. 2013;18(3): 171-78.

Neher T, Grimm G, Hohmann V. Perceptual consequences of different signal changes due to binaural noise reduction: do hearing loss and working memory capacity play a role?. Ear Hear. 2014;35(5):e213-e27.

Obleser J, Wöstmann M, Hellbernd N, Wilsch A, Maess B. Adverse listening conditions and memory load drive a common a oscillatory network. J Neurosci. 2012;32(36):12376-83.

Oliveira IS, Etcheverria AK, Olchik MB, Gonçalves AK, Seimetz BM, Flores LS, et al. Audição em adultos e idosos: associação com sexo, idade e cognição. Rev CEFAC. 2014;16(5):1463-70.

Oxford Centre for Evidence-Based Medicine. Levels of Evidence. 2009. Available from:

Pichora-Fuller MK. Cognitive aging and auditory information processing. IJA. 2003;42(2):S26-S32.

Picou EM, Aspell E, Ricketts TA. Potential benefits and limitations of three types of directional processing in hearing aids. Ear Hear. 2014;35(3):339-52.

Picou EM, Ricketts TA, Hornsby BW. How hearing aids, background noise, and visual cues influence objective listening effort. Ear Hear. 2013;34(5):52-64. 
Picou EM, Ricketts TA. The Effect of Changing the Secondary Task in Dual-Task Paradigms for Measuring Listening Effort. Ear and Hearing. 2014;35(6):611-22.

Picou EM. 20Q: Listening effort - we know it's a problem but how do you measure it? AudiologyOnline. 2013. Article 12032.

Rudner M, Lunner T, Behrens T, Thorén ES, Rönnberg J. Working memory capacity may influence perceived effort during aided speech recognition in noise. J Am Acad Audiol. 2012;23(8):577-89.

Rudner M, Rönnberg J, Lunner T. Working memory supports listening in noise for persons with hearing impairment. J Am Acad Audiol. 2011;22(3):156-67.

Sarampalis A, Kalluri S, Edwards B, Hafter E. Objective measures of listening effort: effects of background noise and noise reduction. J Speech Lang Hear Res, 2009; 52(5):1230-40.

Shield BM, Dockrell JE. The effects of noise on children at school: a review. Building Acoustics. 2003;10(2),97-116.

Soli SD, Wong LLN. Assessment of speech intelligibility in noise with the hearing in noise test. Int J Audiol. 2008;47(6):356-61.

Spósito C. Resistência ao uso do sistema FM por adolescentes em um serviço público de saúde auditiva: fato ou mito? [Dissertação]. Bauru (SP): Faculdade de Odontologia de Bauru, Universidade de São Paulo; 2017.

Steel MM, Papsin BC, Gordon KA. Binaural fusion and listening effort in children who use bilateral cochlear implants: A psychoacoustic and pupillometric study. PLoS One. 2015;10:e0117611.

Stelmachowicz PG Lewis DE, Choi S, Hoover B. Effect of stimulus bandwidth on auditory skills in normal-hearing and hearing-impairment children. Ear Hear. 2007; 28(4):483-494.

Thibodeau LM, Schaper L. Benefits of Digital Wireless Technology for Persons with Hearing Aids. Semin Hear. 2014;35(3):168-76.

Thibodeau LM., Wallace S. Guidelines and Standards for Wireless Technology for Individuals with Hearing Loss. Semin Hear. 2014;35(3):159-67. 
Tun PA, McCoy S, Wingfield A. Aging, hearing acuity, and the attentional costs of effortful listening. Psychol Aging 2009;24(3):761-6.

Varni JW, Burwinkle TM, Katz ER, Meeske K, Dickinson P. The PedsQL ${ }^{\mathrm{TM}}$ in pediatric cancer. Cancer. 2002;94(7):2090-2106.

Wasson JW, Kairys SW, Nelson EC, Kalishman N, Baribeau P. A short survey for assessing health and social problems of adolescents. J Fam Pract.1994;38(5):489-95.

Weiss D, Dempsey JJ. Performance of bilingual speakers on the English and Spanish versions of the Hearing in Noise Test (HINT). J Am Acad Audiol. 2008;19(1): 5-17.

Wu YH, Aksan N, Rizzo M, Stangl E, Zhang X, Bentler R. Measuring listening effort: driving simulator versus simple dual-task paradigm. Ear Hear 2014;35(6):623-32.

Zekveld AA, Kramer SE, Festen JM. Cognitive load during speech perception in noise: the influence of age, hearing loss, and cognition on the pupil response. Ear Hear. 2011;32(4):498-510.

Zugliani AP, Motti TFG, Castanho RM. O autoconceito do adolescente deficiente auditivo e sua relação com o uso do aparelho de amplificação sonora individual. Rev Bras Educ Espec. 2007;13(1): 95-110. 

APÊNDICES 



\section{APÊNDICE A - TERMO DE CONSENTIMENTO LIVRE E ESCLARECIDO}

\section{TERMO DE CONSENTIMENTO LIVRE E ESCLARECIDO}

\section{Projeto de Pesquisa: Esforço auditivo e fadiga em adolescentes com deficiência auditiva - Uso do Sistema FM}

\section{Prezados Pais,}

Esta pesquisa refere-se ao estudo da avaliação do esforço em escutar em ambiente ruidoso, nas situações sem e com o Sistema de Frequência Modulada (FM). Os resultados desta pesquisa contribuirão para evidências científicas que envolvam adolescentes com deficiência auditiva e o impacto do sistema de frequência modulada para população estudada. Viemos por este documento convidar e solicitar autorização para a participação voluntária do seu(sua) filho(a) nesta pesquisa desenvolvida pela aluna de doutorado do programa de pós-graduação em Fonoaudiologia, Aline Duarte da Cruz, com a supervisão da orientadora Profa. Dra. Regina Tangerino de Souza Jacob.

De acordo com os tópicos da Resolução 466, 12.12.2012, publicada em 13 de junho de 2013, parágrafo IV.3:

a) Caso autorize a participação de seu(sua) filho(a), este passará por algumas avaliações que serão realizadas na Clínica de Fonoaudiologia da Faculdade de Odontologia de Bauru (FOB/USP):

a.I- Umas dessas avaliações será para verificar como algumas estruturas do ouvido estão funcionando, através dos testes de meatoscopia, emissões otoacústicas, timpanometria e pesquisa do reflexo acústico. Para isso ele (a) não precisa responder nada, apenas permanecer quieto(a). Estas avaliações serão realizadas apenas em participantes que não apresentam diagnóstico de perda auditiva. Estima-se em vinte minutos o tempo para conclusão das avaliações.

a.Il- Aplicação do procedimento de "dupla tarefa" composto por uma tarefa primária e outra secundária. A tarefa primária é apresentada em ambiente com barulho/ruído, e trata-se da solicitação de repetição de seis listas de sentenças, com 20 frases cada. Na tarefa secundária o participante deverá apertar um botão toda vez que um estímulo visual (luz) for apresentado. A última tarefa é composta pelas duas tarefas citadas acima apresentadas de forma simultânea. O tempo estimado para esta aplicação é de trinta minutos.

a.III- Aplicação da escala que avalia o aluno em sala de aula, a escala será preenchido pelo(a) seu(sua) filho(a), a escala é composta por 12 questões, e caso ele(a) utilize o Sistema FM também será aplicado um questionário obter a opinião dele(a) sobre o impacto do uso do sistema FM em sala de aula, que contém 9 questões. O participante será orientado a preencher na forma papel e lápis. O tempo estimado para esta aplicação é de dez minutos. 
b) Esses procedimentos não são invasivos, não causam dor e não oferecem risco a saúde do participante, no entanto, durante a pesquisa o participante pode se cansar. Se houver alguma alteração audiológica em algum exame realizado durante a pesquisa o participante será encaminhado para Divisão Regional de Saúde (DRS) IV do município de Bauru, para providenciar as condutas e encaminhamentos.

c) A participação é voluntária, sendo permitida a desistência em qualquer momento, sem qualquer prejuízo.

d) As informações referentes ao seu(sua) filho(a) serão guardadas em sigilo, sendo que somente nós teremos acesso a estas informações. Os resultados da pesquisa serão divulgados com sigilo da identidade dos participantes.

e) O responsável legal receberá uma cópia do Termo de Consentimento Livre e Esclarecido declarando estar de acordo com os procedimentos que serão realizados e autorizar seu(sua) filho(a) a participar da pesquisa. Seu(sua) filho(a), será orientado pela pesquisadora e assinará um Termo de Assentimento concordando em participar ou não da pesquisa.

f) Não será fornecida nenhuma ajuda de custo e nem ressarcimento de despesas com locomoção dos participantes até a Clínica de Fonoaudiologia- FOB/USP.

g) Há garantia de indenização diante de eventuais danos decorrentes da pesquisa por parte dos pesquisadores e dos participantes.

Para esclarecimentos de dúvidas procure a Fonoaudióloga Aline (14)9988-36281, email: aline.d.cruz@hotmail.com.br ou procure Profa. Dra ${ }^{a}$. Regina (14) 3235-8332, email: reginatangerino@usp.br e endereço: Departamento de Fonoaudiologia da Faculdade de Odontologia de Bauru/USP, Alameda Dr. Octávio Pinheiro Brisolla,975. Para denúncias e/ou reclamações entrar em contato com Comitê de Ética em Pesquisa, da Faculdade de Odontologia de Bauru/USP, Alameda Dr. Octávio Pinheiro Brisolla, 9-75, Vila Universitária, pelo telefone (14)3235-8356 ou e-mail: cep@fob.usp.br.

Agradecemos a participação de seu(sua) filho(a) e colocamo-nos à sua disposição para qualquer informação que se faça necessária.

Pelo presente instrumento que atende às exigências legais, o Sr.(a) portador da cédula de identidade , representante legal do menor após leitura minuciosa das informações constantes neste TERMO DE CONSENTIMENTO LIVRE E ESCLARECIDO, devidamente explicada pelos profissionais em seus mínimos detalhes, ciente dos serviços e procedimentos aos quais será submetido, não restando quaisquer dúvidas a respeito do lido e explicado, DECLARA e FIRMA seu CONSENTIMENTO LIVRE E ESCLARECIDO concordando que seu(sua) filho (a) participe da pesquisa proposta. Fica claro que o participante da pesquisa, pode a qualquer momento retirar seu CONSENTIMENTO LIVRE E ESCLARECIDO e deixar de participar desta pesquisa e ciente de que todas as informações prestadas tornar- 
se-ão confidenciais e guardadas por força de sigilo profissional (Art. $13^{\circ}$ do Código de Ética Fonoaudiólogico).

Por fim, como pesquisadora responsável pela pesquisa, DECLARO o cumprimento do disposto na Resolução CNS n 466 de 2012, contidos nos itens IV.3, item IV.5.a e na íntegra com a resolução CNS n 466 de dezembro de 2012.

Por estarmos de acordo com o presente termo o firmamos em duas vias igualmente válidas (uma via para o participante da pesquisa e outra para o pesquisador) que serão rubricadas em todas as suas páginas e assinadas ao seu término, conforme o disposto pela Resolução CNS nº 466 de 2012, itens IV.3.f e IV.5.d.

Bauru- SP, de de pelo Participante da Pesquisa

O Comitê de Ética em Pesquisa - CEP, organizado e criado pela FOB-USP, em 29/06/98 (Portaria GD/0698/FOB), previsto no item VII da Resolução n 466/12 do Conselho Nacional de Saúde do Ministério da Saúde (publicada no DOU de 13/06/2013), é um Colegiado interdisciplinar e independente, de relevância pública, de caráter consultivo, deliberativo e educativo, criado para defender os interesses dos participantes da pesquisa em sua integridade e dignidade e para contribuir no desenvolvimento da pesquisa dentro de padrões éticos.

Qualquer denúncia e/ou reclamação sobre sua participação na pesquisa poderá ser reportada a este CEP:

\section{Horário e local de funcionamento:}

Comitê de Ética em Pesquisa

Faculdade de Odontologia de Bauru-USP - Prédio da Pós-Graduação (bloco E pavimento superior), de segunda à sexta-feira, no horário das $13 \mathrm{~h} 30$ às 17 horas, em dias úteis.

Alameda Dr. Octávio Pinheiro Brisolla, 9-75

Vila Universitária - Bauru - SP - CEP 17012-901

Telefone/FAX(14)3235-8356

e-mail: cep@fob.usp.br 


\section{APÊNDICE B - TERMO DE ASSENTIMENTO}

\section{TERMO DE ASSENTIMENTO}

Projeto de Pesquisa: Esforço auditivo e fadiga em adolescentes com deficiência auditiva - Uso do Sistema FM

\section{Querido Jovem,}

Você está sendo convidado a participar desta pesquisa para testar como escuta quando em ambiente ruidoso. Caso utilize Sistema FM, fará com e sem o mesmo. Vamos realizar os seguintes testes:

Se você NÃO usa Aparelho Auditivo e Sistema FM

Primeiro irei verificar como suas orelhas estäo

funcionando. Estes exames seräo bem rápidos e näo väo
doer. Você precisará apenas ficar parado e fazer estes doer. Você precisará apenas ficar parado e fazer estes
exames antes de começar o teste de "dupla tarefa".

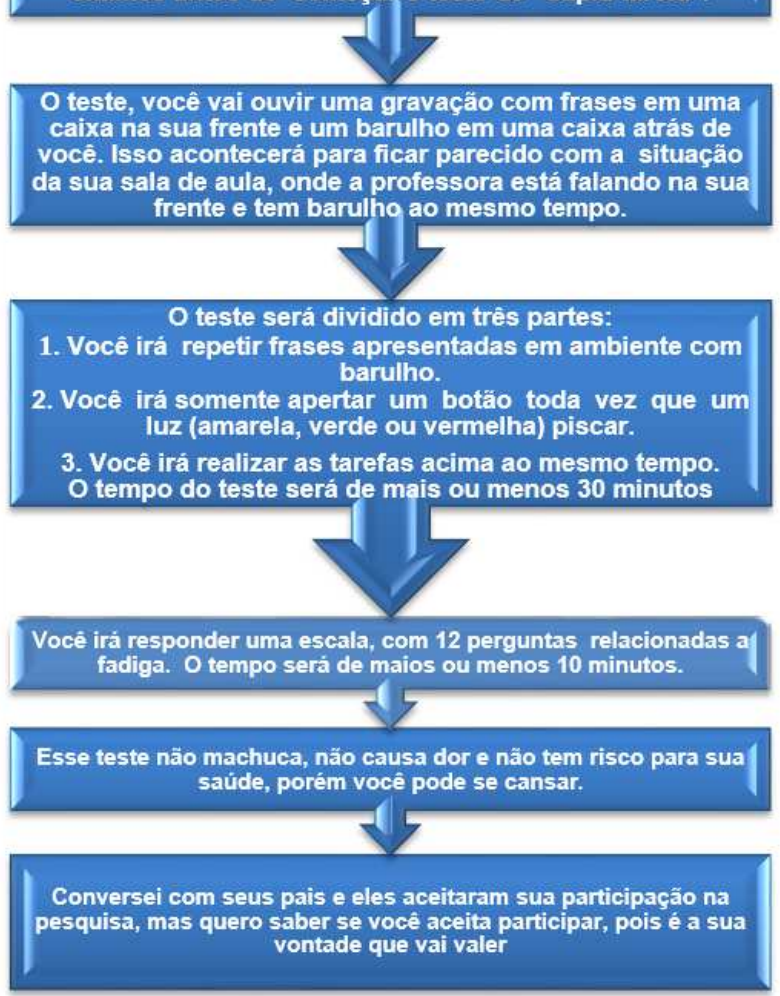

Se você usa Aparelho Auditivo e Sistema FM

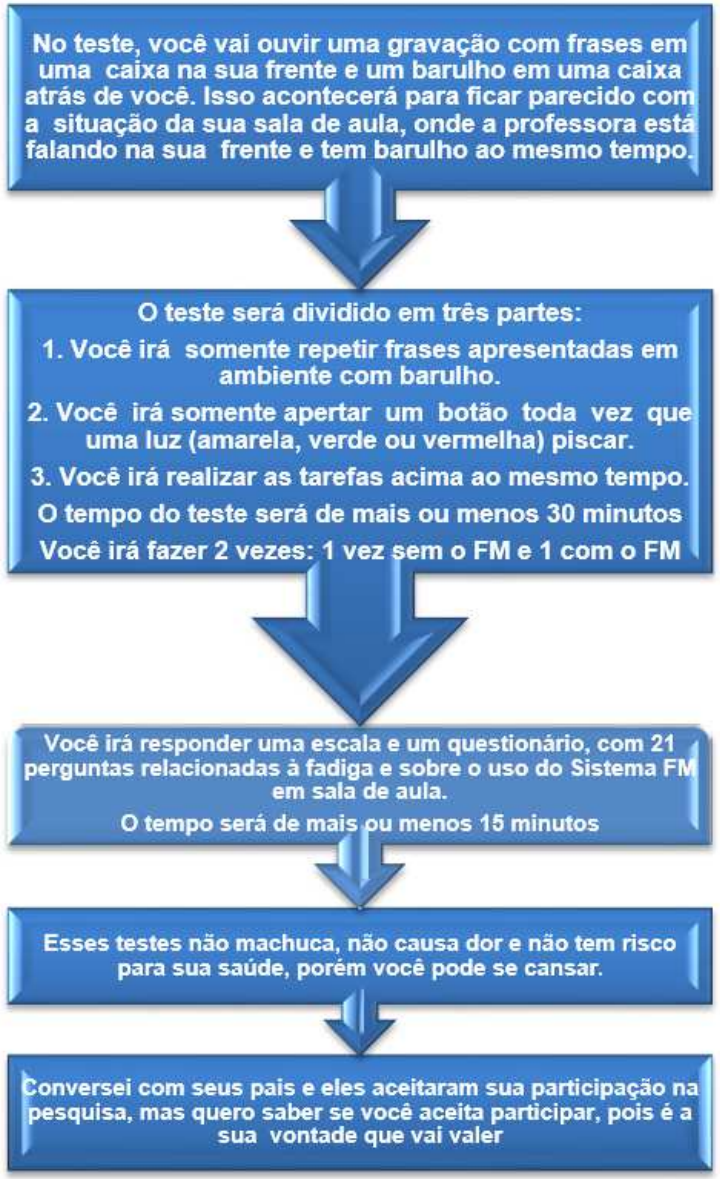




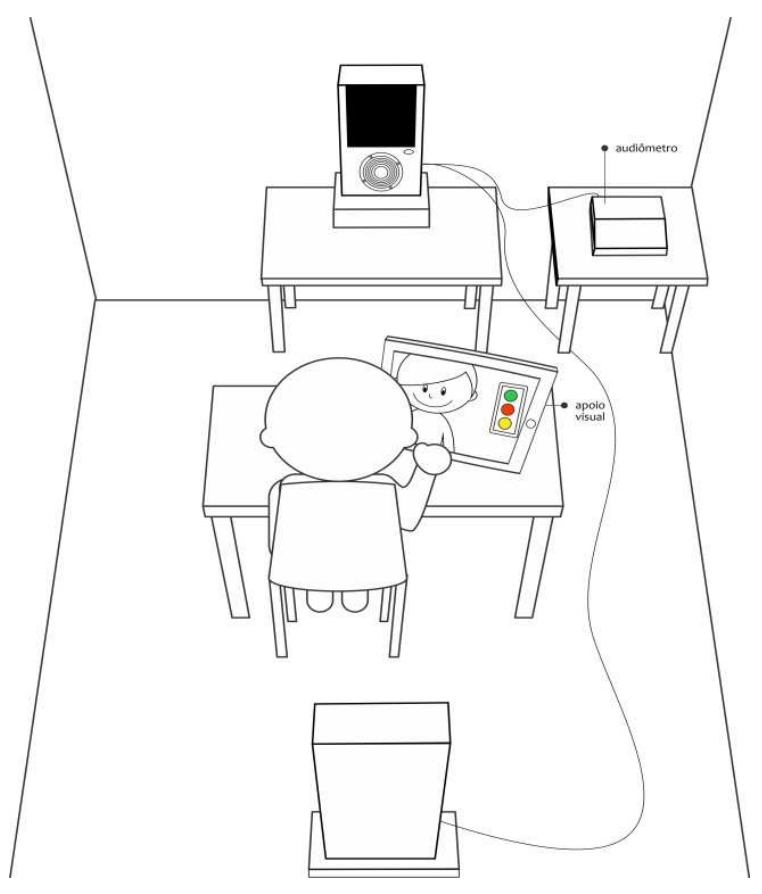

Figura 1 - Ambiente do teste

Você concorda com o que foi explicado e aceita participar? ( ) Sim （ ) Não

Por este documento, eu ,de anos, concordo em participar da pesquisa. Não tenho dúvidas do que irão realizar em mim e autorizo a publicação dos meus resultados.

Bauru, SP, de de

Assinatura do Participante

da Pesquisa
Aline Duarte da Cruz

Pesquisadora Responsável 
APÊNDICE C - Avaliação Informal de Fadiga (Cruz AD; Jacob RTS, 2016)

\section{Avaliação Informal de Fadiga}

Nome do Estudante

Série

Escola

Data

O propósito dessas escalas é avaliar a fadiga do estudante e o seu possível impacto na aprendizagem. Leia os itens desta página para os estudantes ou peça a eles para completarem o breve formulário, independentemente.

\begin{tabular}{|c|c|c|c|c|c|}
\hline \multicolumn{6}{|c|}{ Escala de Fadiga } \\
\hline $\begin{array}{l}0=\text { não é um problema para minha idade } \\
1=\text { um pouco mais do que o comum }\end{array}$ & $\begin{array}{l}2 \text { = mais do que o comum } \\
3=\text { muito mais do que o comum }\end{array}$ & 0 & 1 & 2 & 3 \\
\hline \multicolumn{6}{|l|}{ 1. Você tem problemas com cansaço? } \\
\hline \multicolumn{6}{|c|}{ 2. Você sente a necessidade de descansar mais? } \\
\hline \multicolumn{6}{|c|}{ 3. Você se sente sonolento(a) ou cochila com facilidade? } \\
\hline \multicolumn{6}{|c|}{ 4. Você tem dificuldades para começar a fazer as coisas? } \\
\hline \multicolumn{6}{|l|}{ 5. Você sente falta de energia? } \\
\hline \multicolumn{6}{|c|}{ 6. Você sente seus músculos fracos (fraqueza muscular)? } \\
\hline \multicolumn{6}{|l|}{ 7. Você se sente fraco(a)? } \\
\hline \multicolumn{6}{|c|}{ 8. Você tem problemas de concentração? } \\
\hline \multicolumn{6}{|c|}{ 9. Você se esquece das palavras enquanto fala? } \\
\hline \multicolumn{6}{|c|}{ 10. Você sente mais dificuldade do que os outros em encontrar a palavra certa? } \\
\hline \multicolumn{6}{|l|}{ 11. Como é sua memória? } \\
\hline & Total de $\mathrm{F}$ & & & & \\
\hline
\end{tabular}

\section{Learning Effort-Reward Imbalance (LERI)}

1. Quando eu estou na escola ou durante a aula, muitas vezes tenho que parar minhas tarefas porque as ações ou barulhos de outros estudantes me atrapalham. 


\section{APÊNDICE D - Questionário de avaliação do Sistema FM: perspectiva do usuário}

Questionário de avaliação do Sistema FM: perspectiva do usuário

Nome:

Data de adaptação do sistema FM:

D.N.:

Data:

\section{Questões}

1. Quantas horas por dia você usa o sistema FM?

2. Você recebe apoio da escola para usar o sistema FM?

SIM NÃO

3. Todos os seus professores usam o sistema FM na sala de aula?

SIM NÃO

4. Você se sente incomodado em ter que entregar o sistema FM para

SIM NÃO

o(s) seu(s) professor(es)?

5. Você gosta de usar o sistema FM na sala de aula?

SIM NÃO

6. Você gosta da aparência do sistema FM?

SIM NÃO

7. Quais são os pontos positivos de usar o sistema FM na sala de aula?

8. Quais são os pontos negativos de usar o sistema FM na sala de aula?

9. Além da sala de aula, em qual(is) lugar(es) você usa o sistema FM? 
APÊNDICE E - Tutorial da Plataforma PALETA

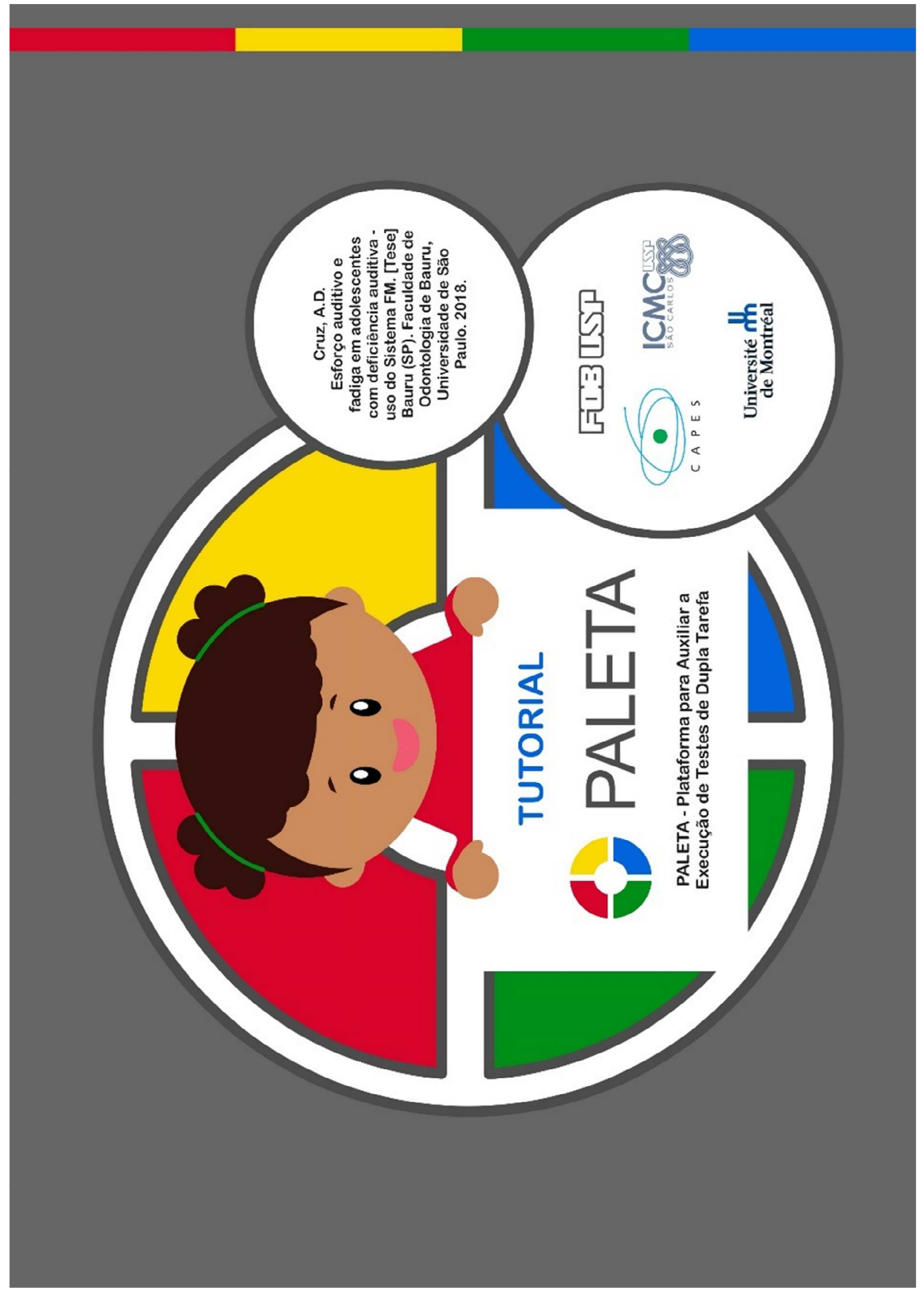



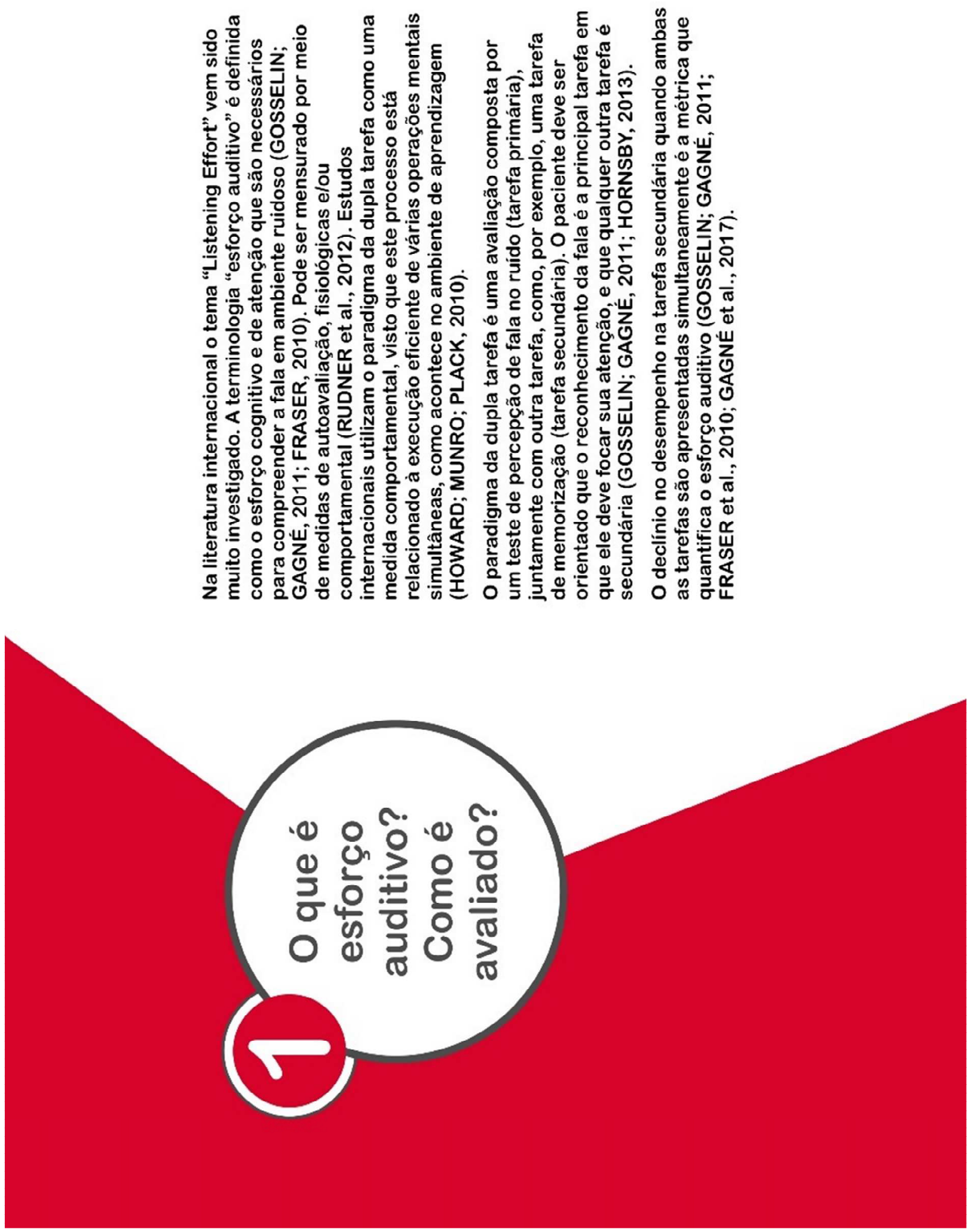


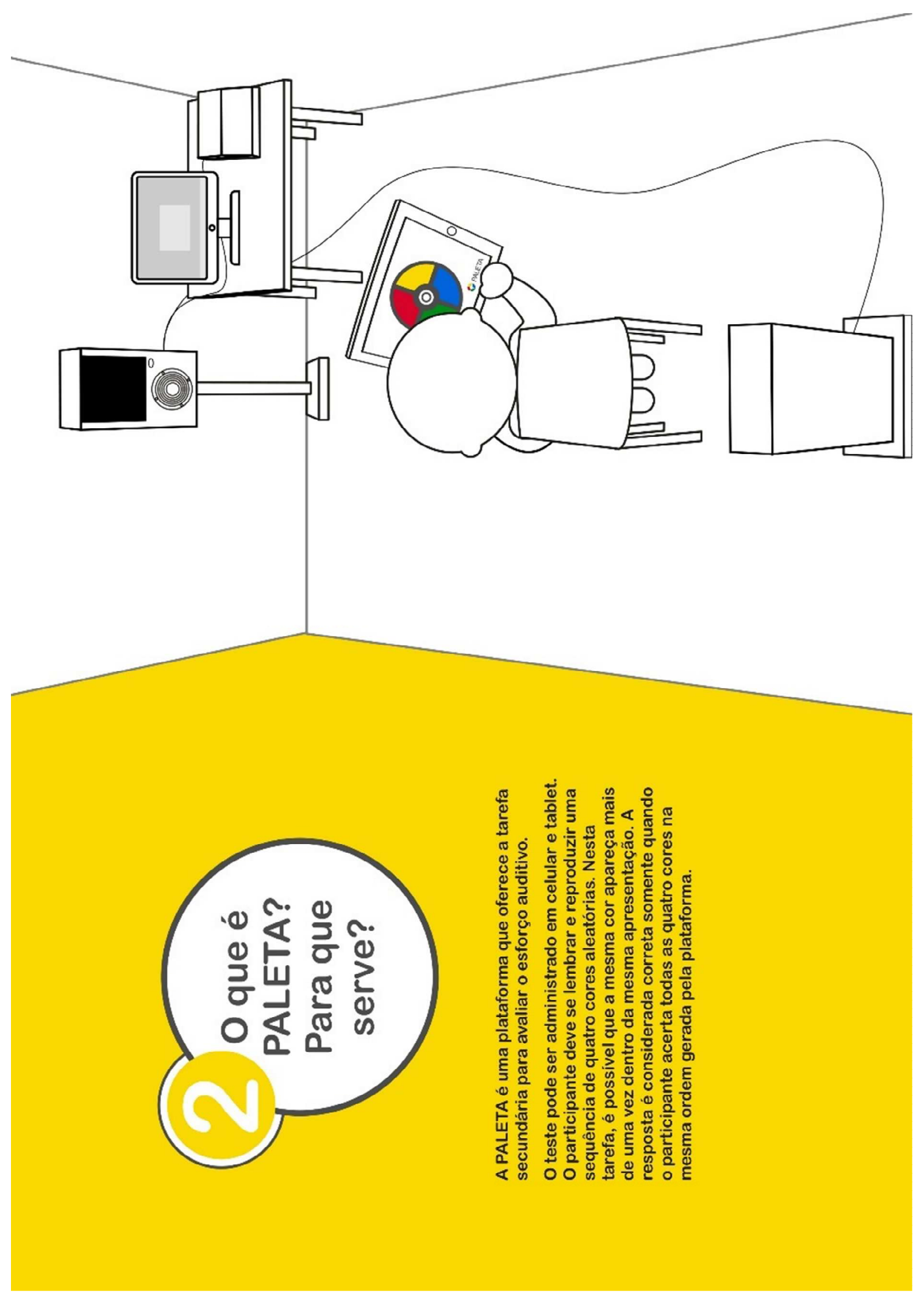



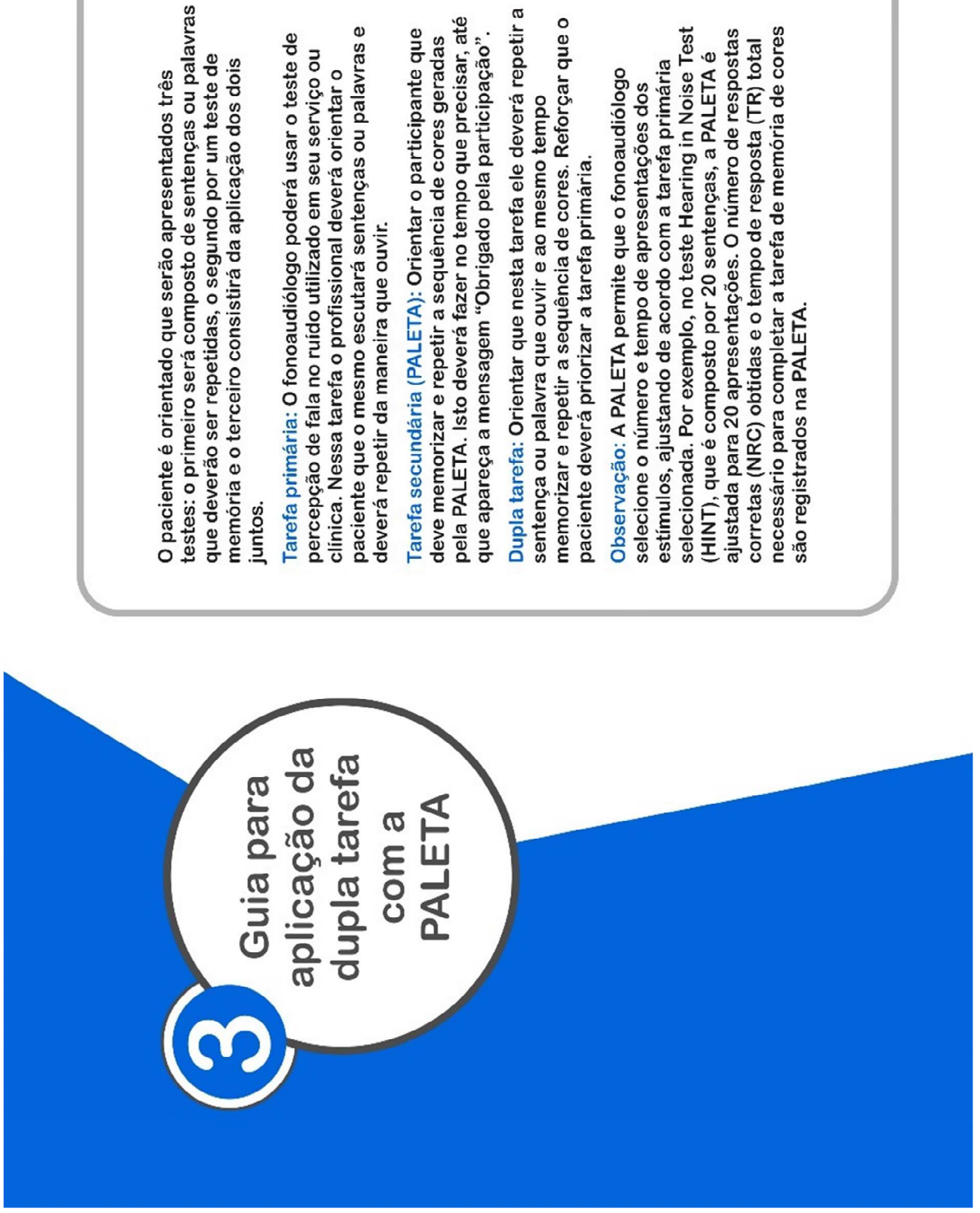


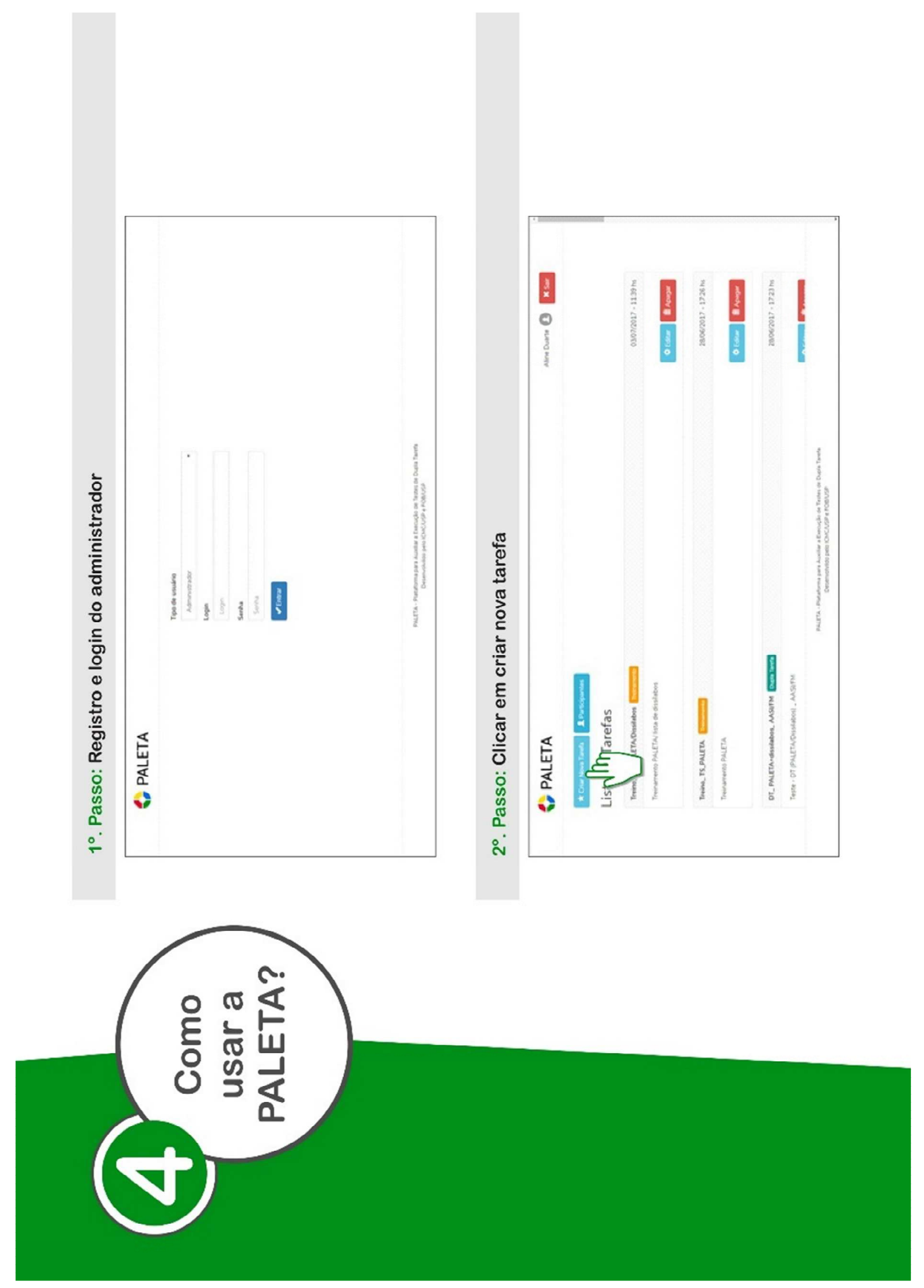




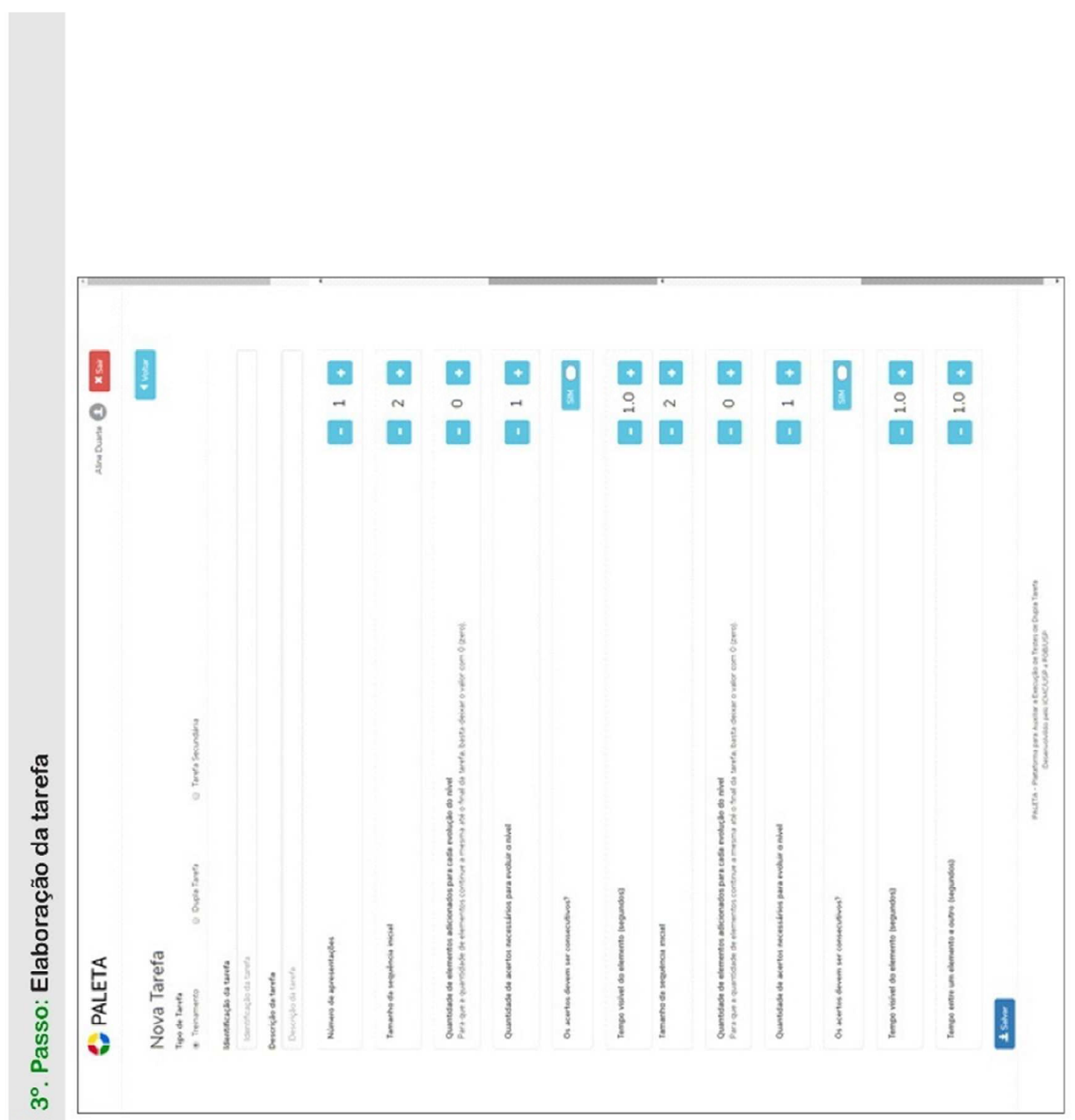




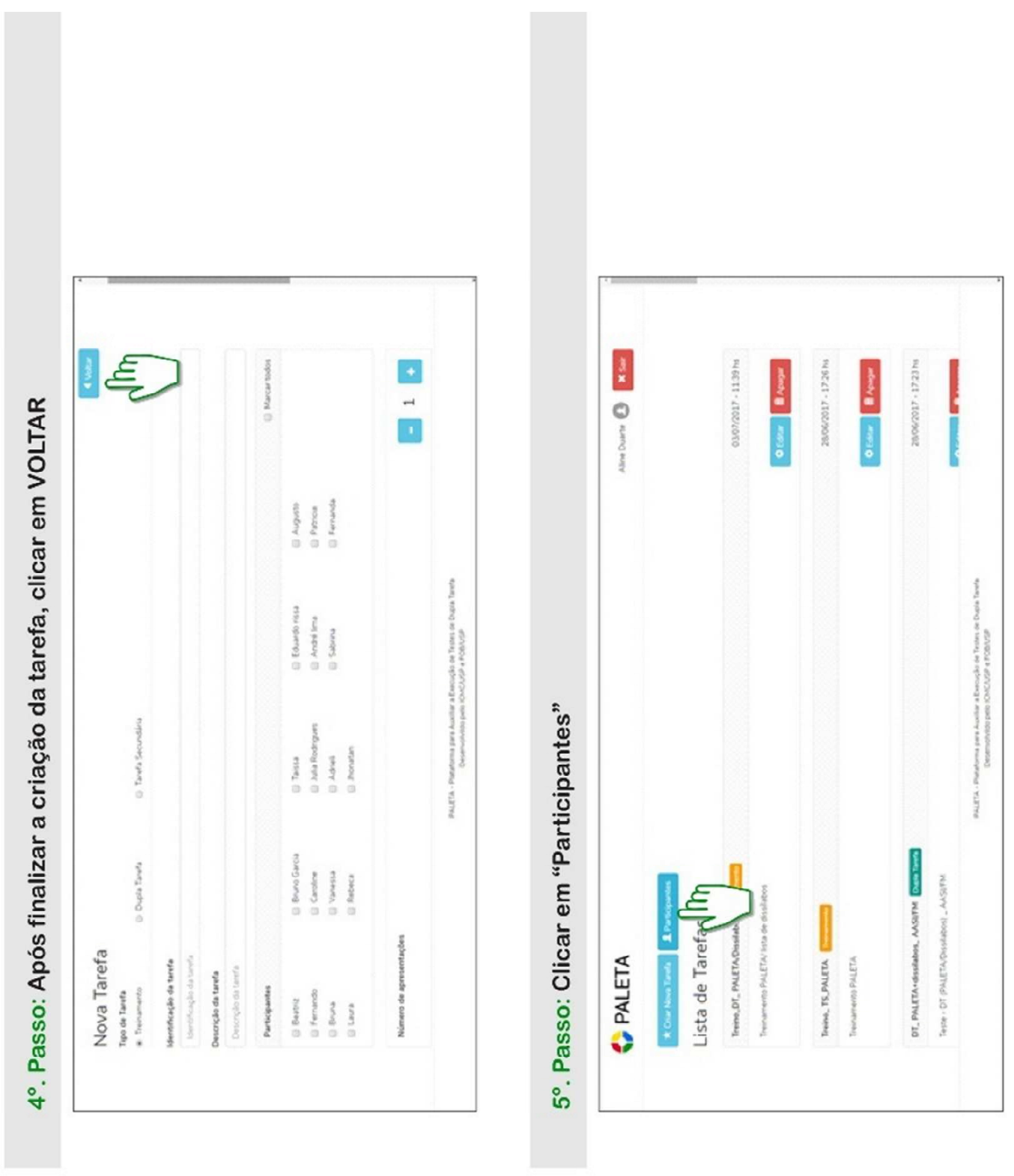



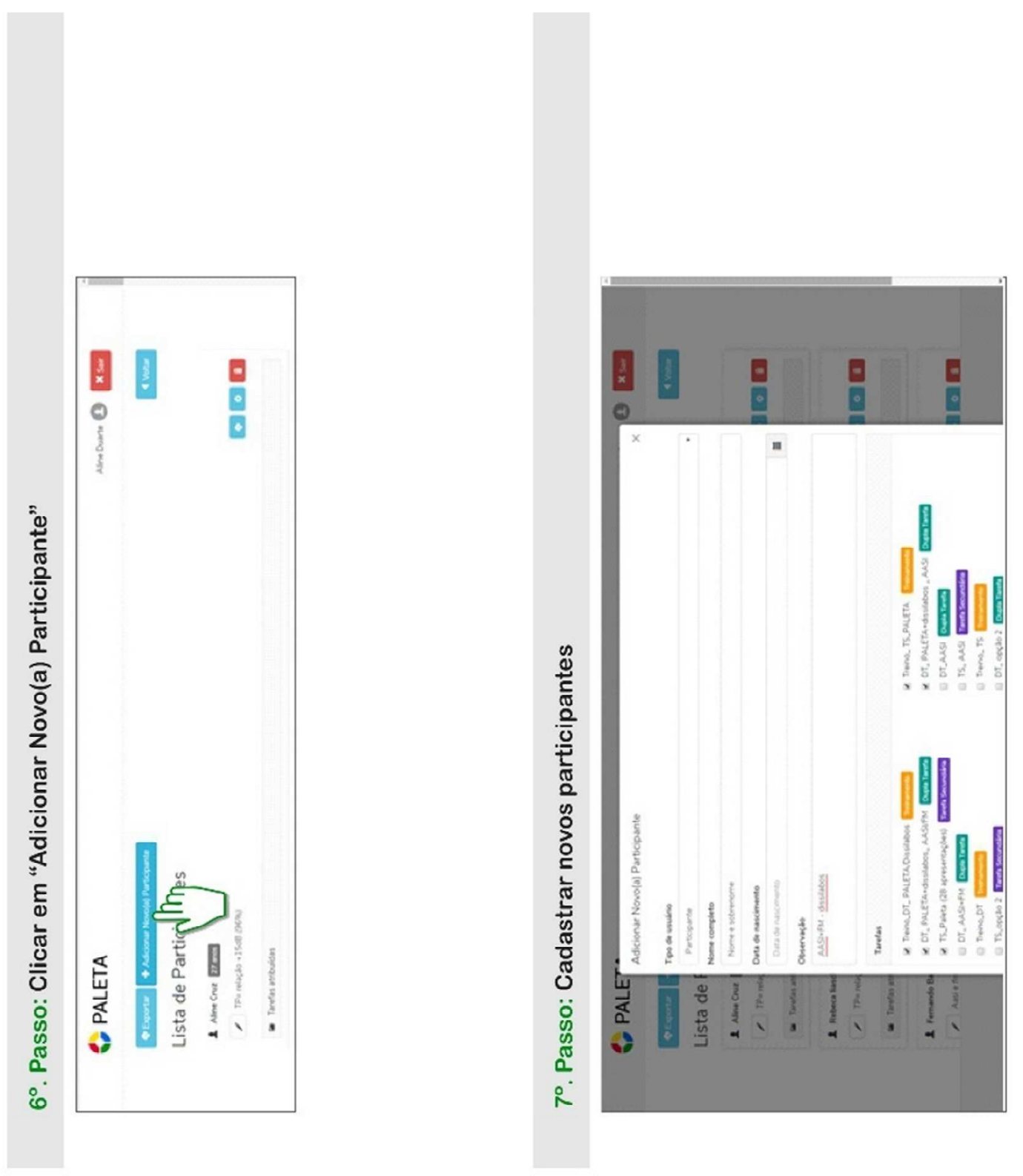


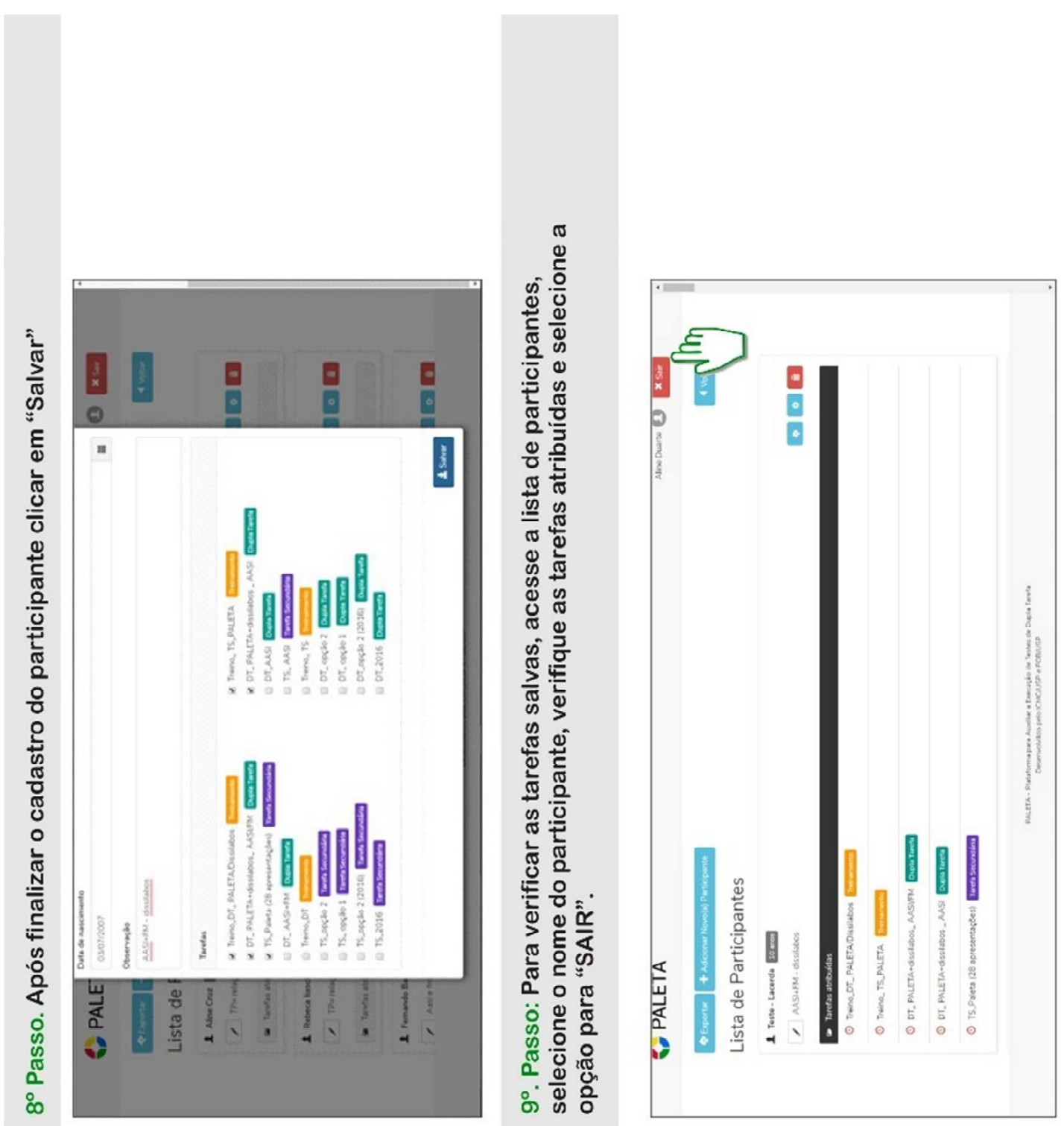




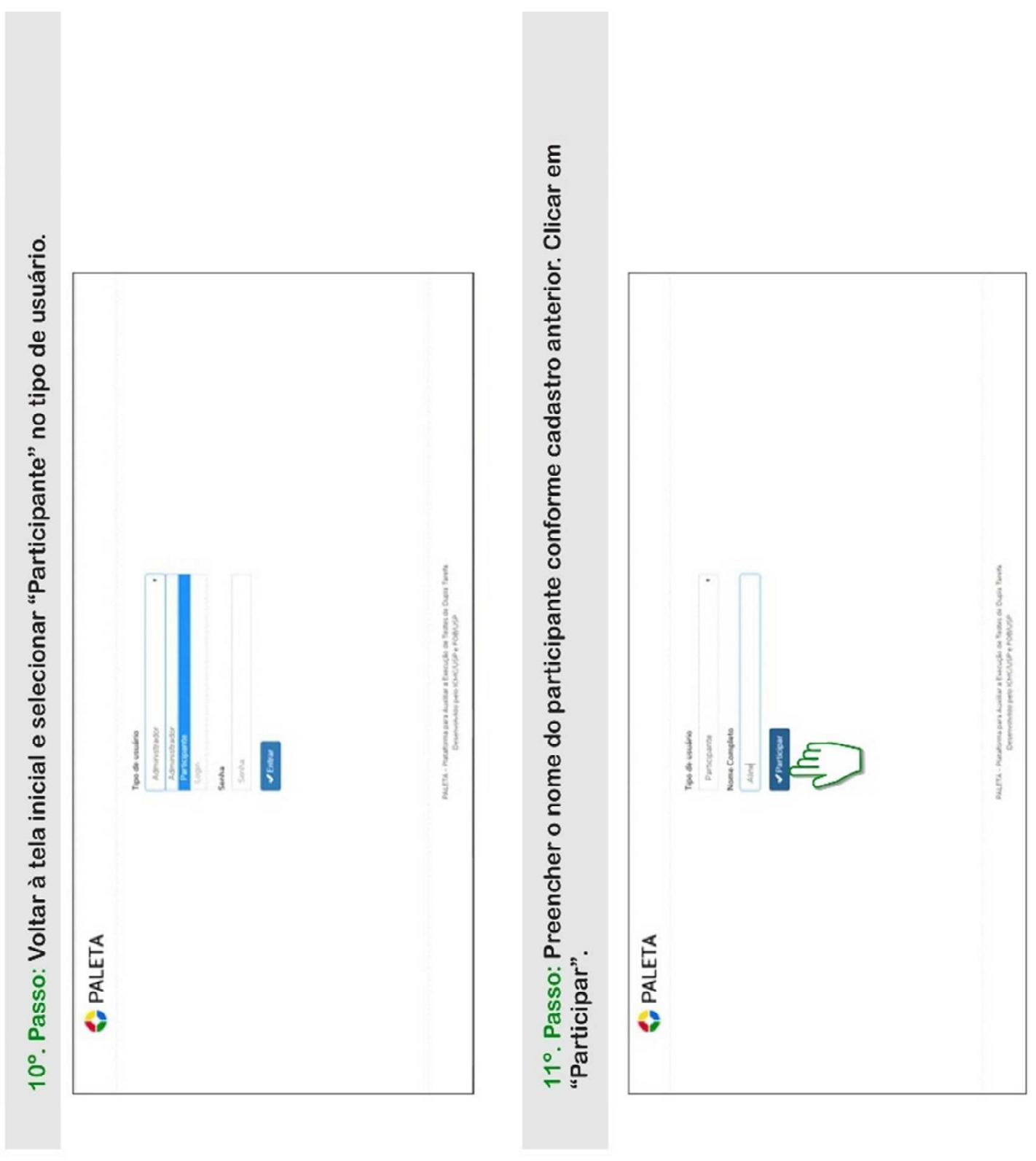




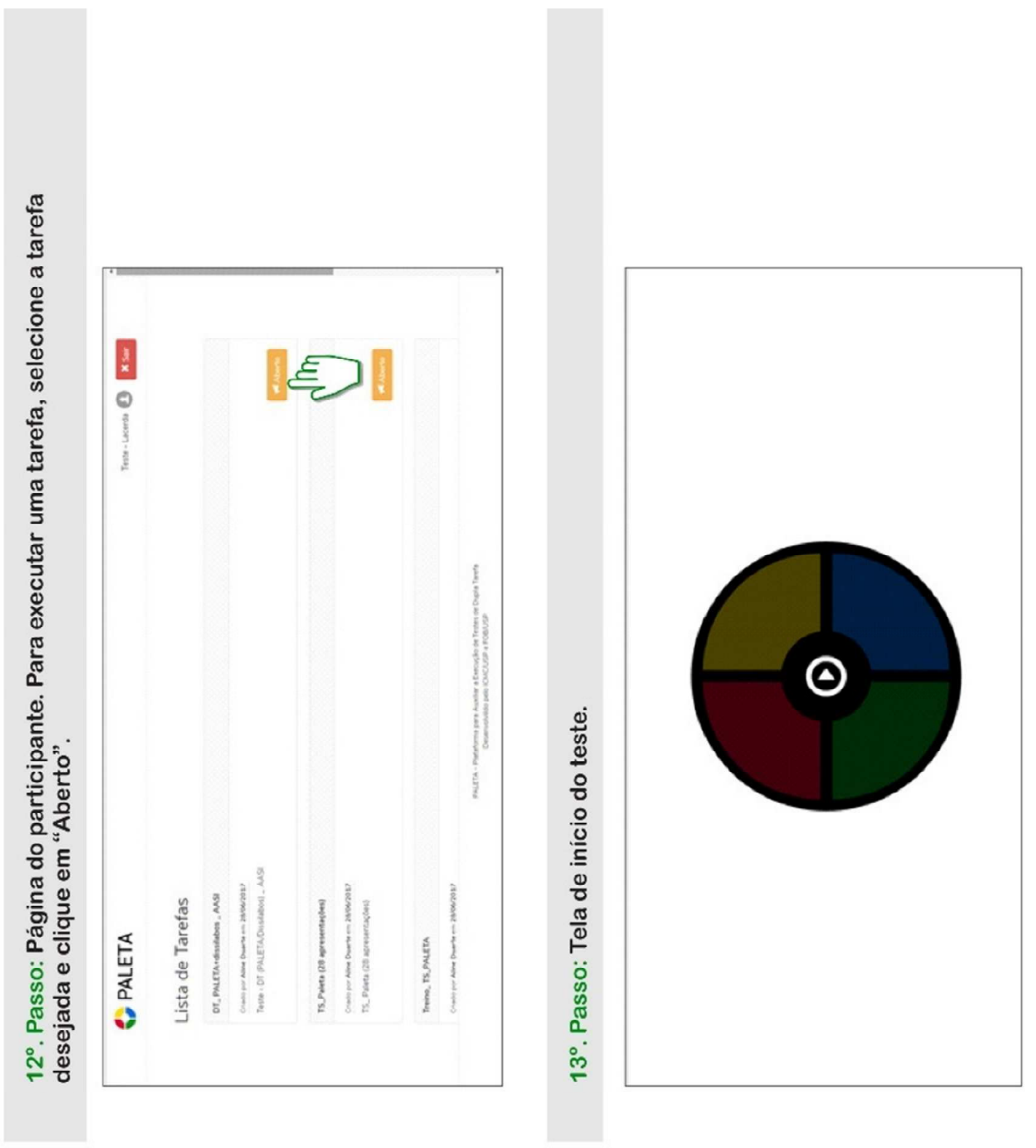



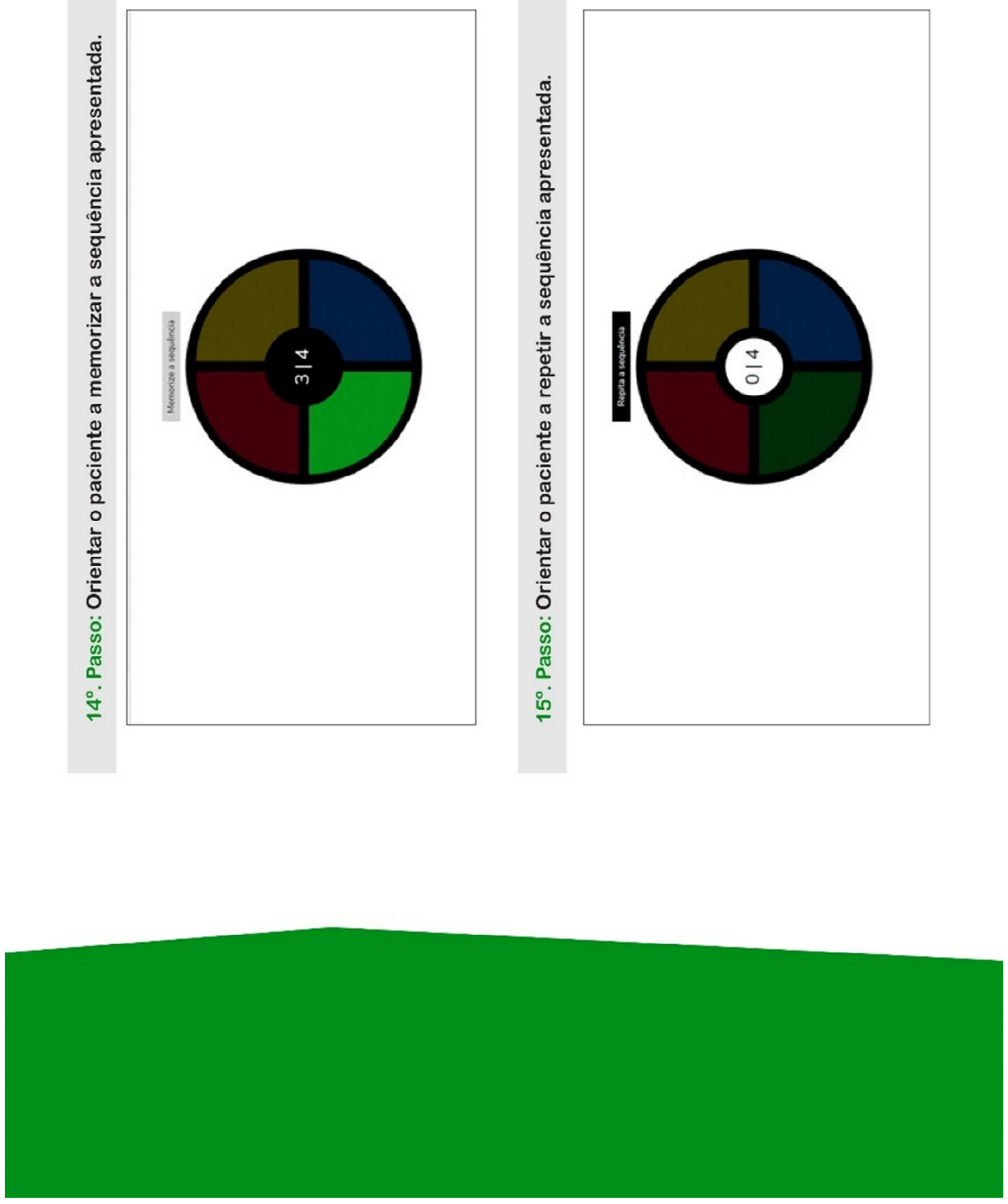

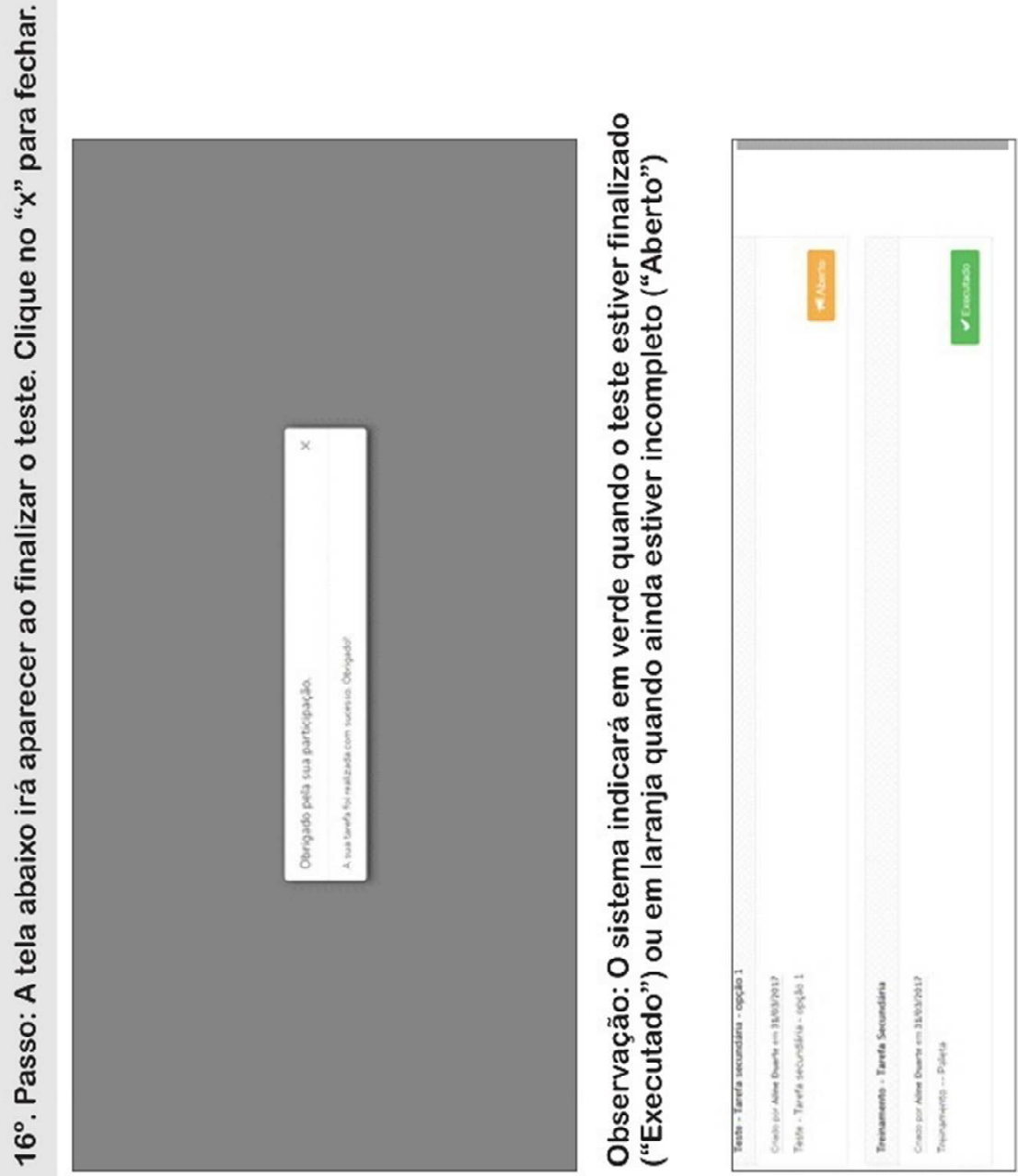

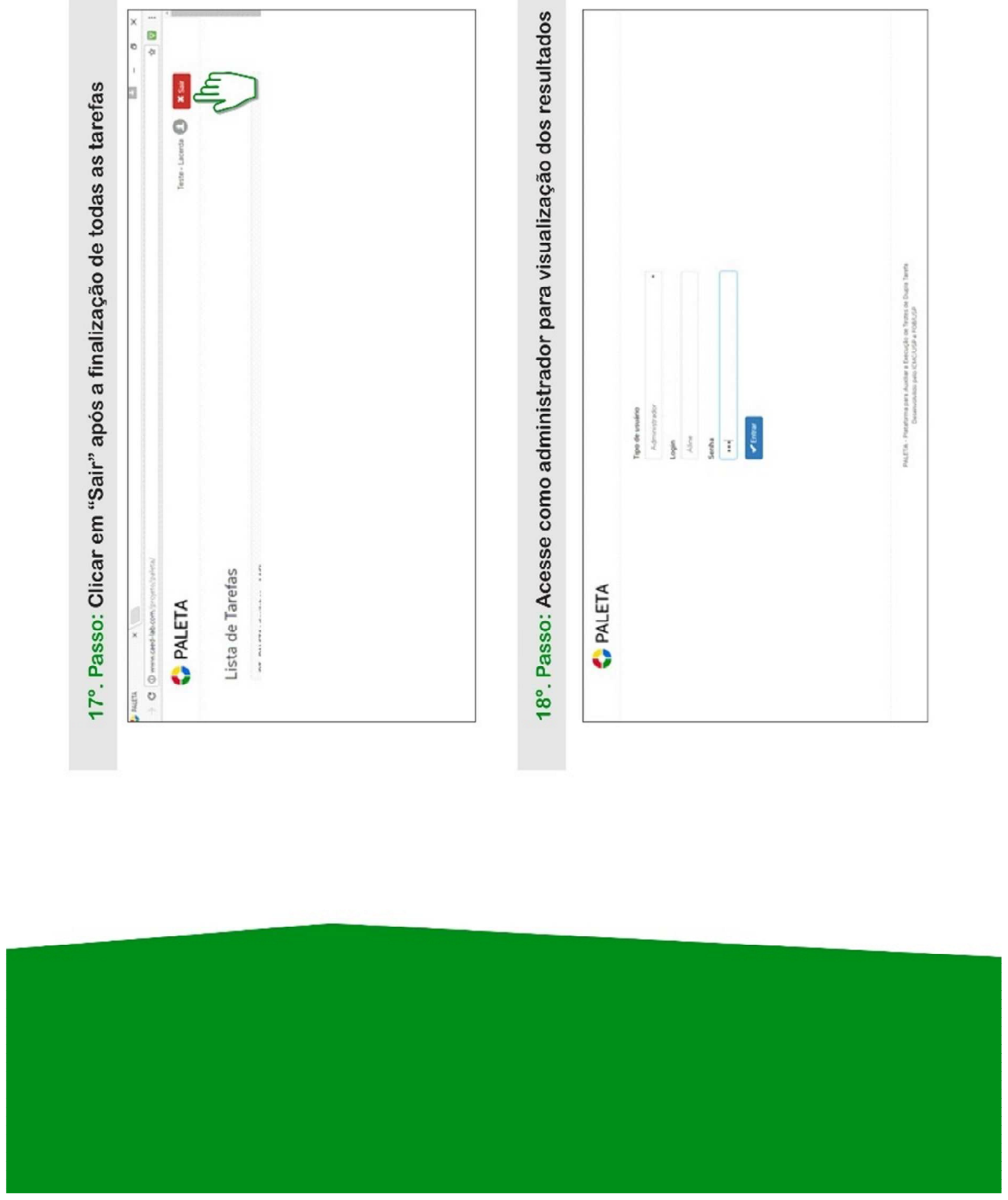

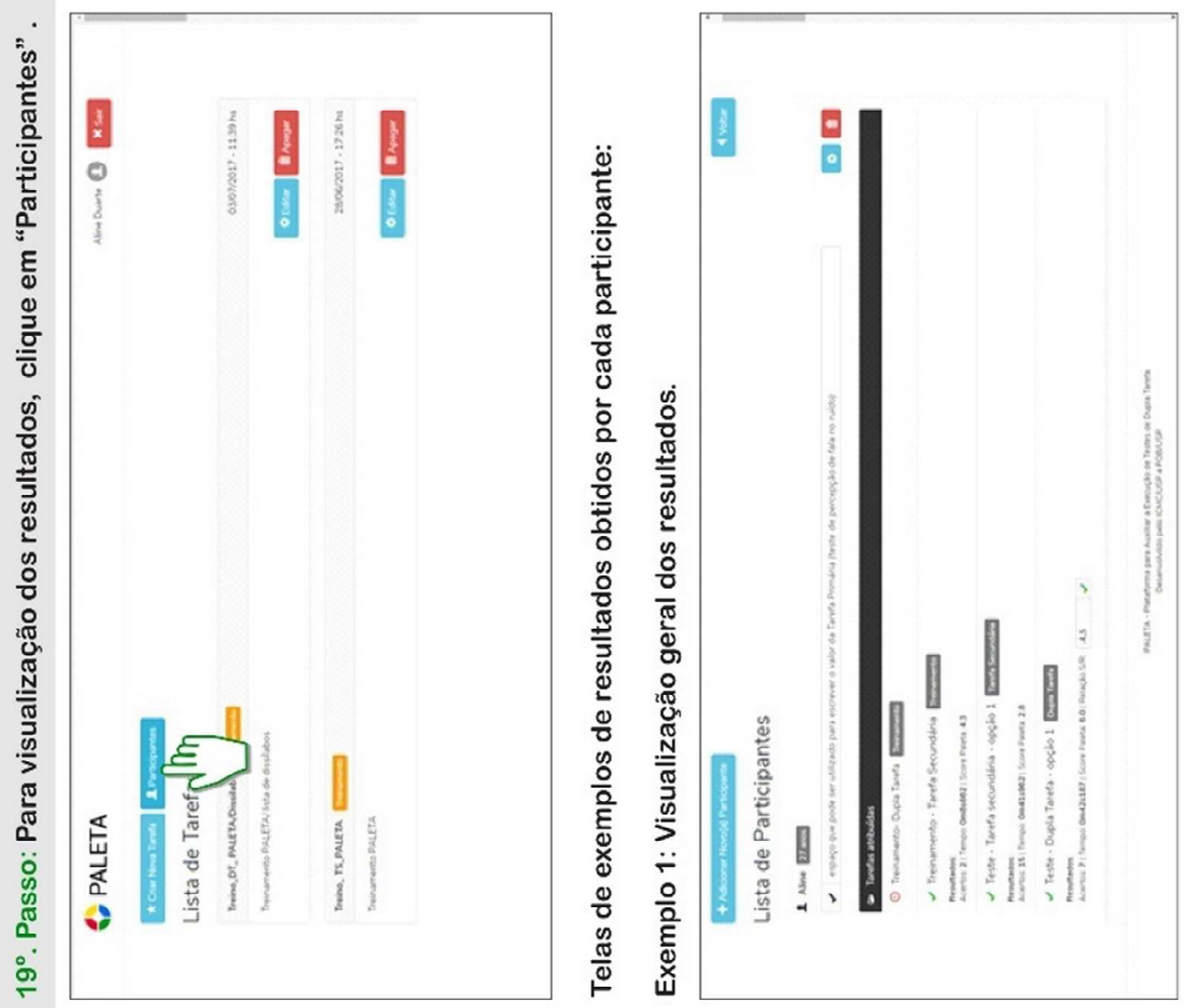

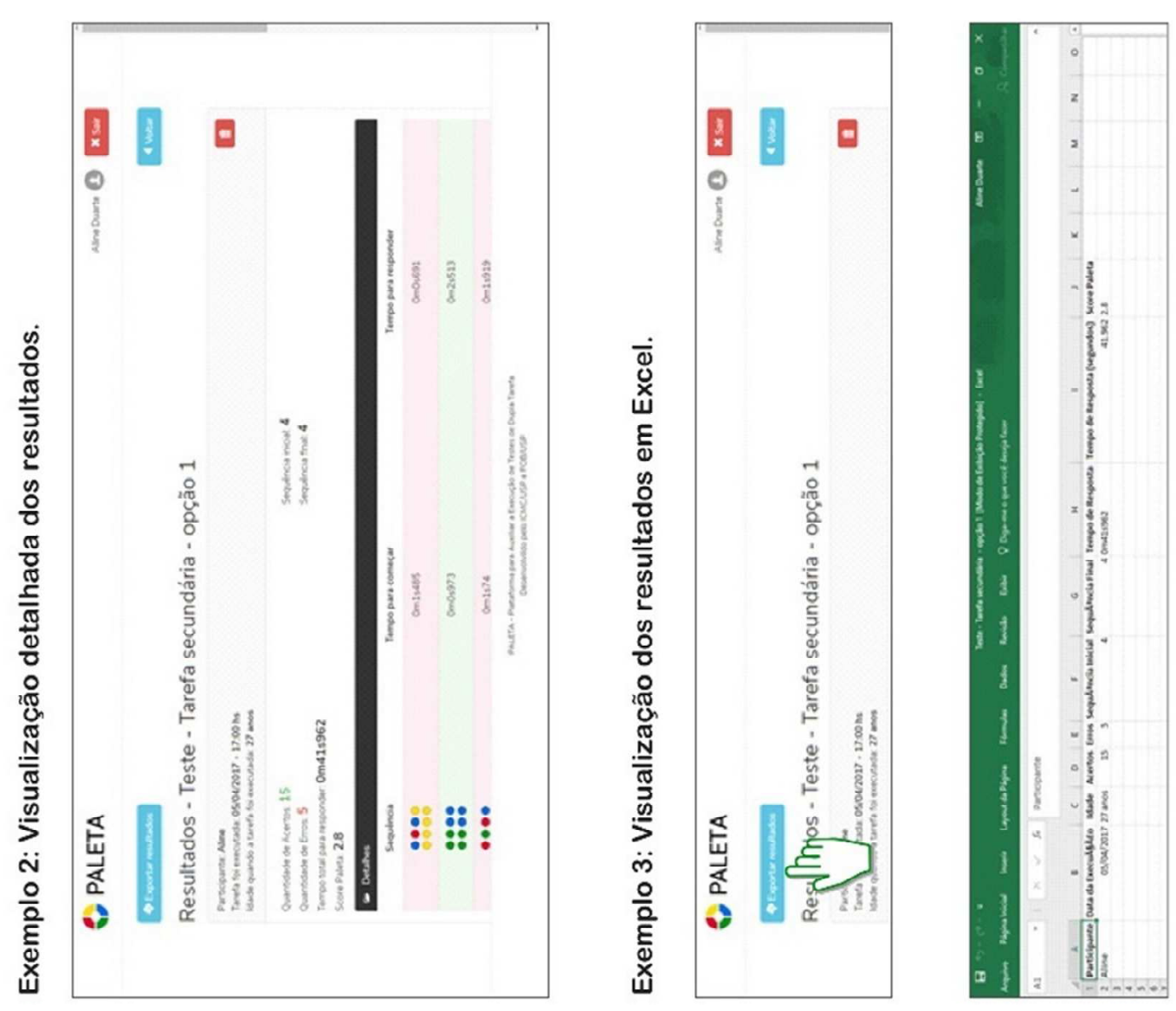

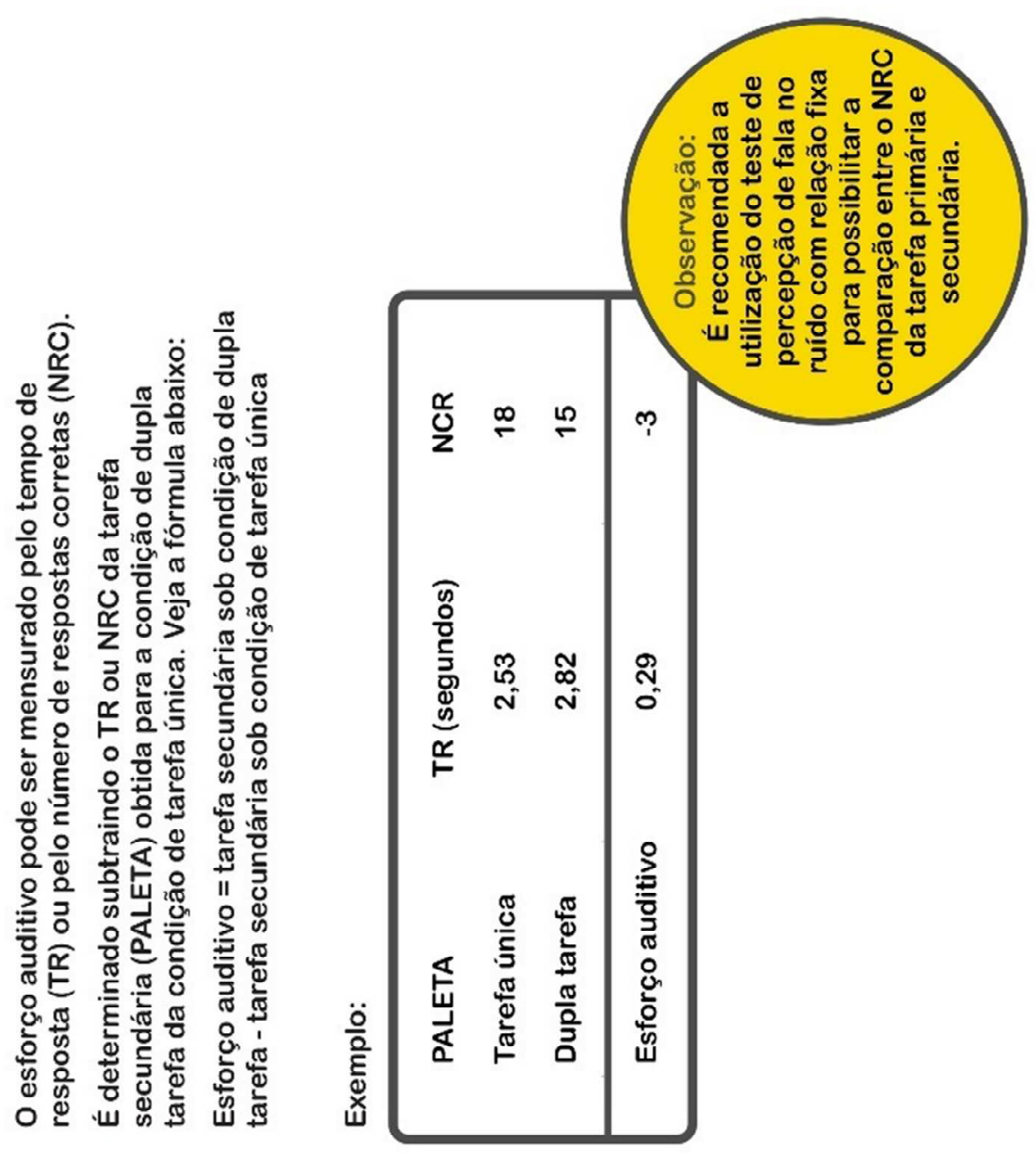

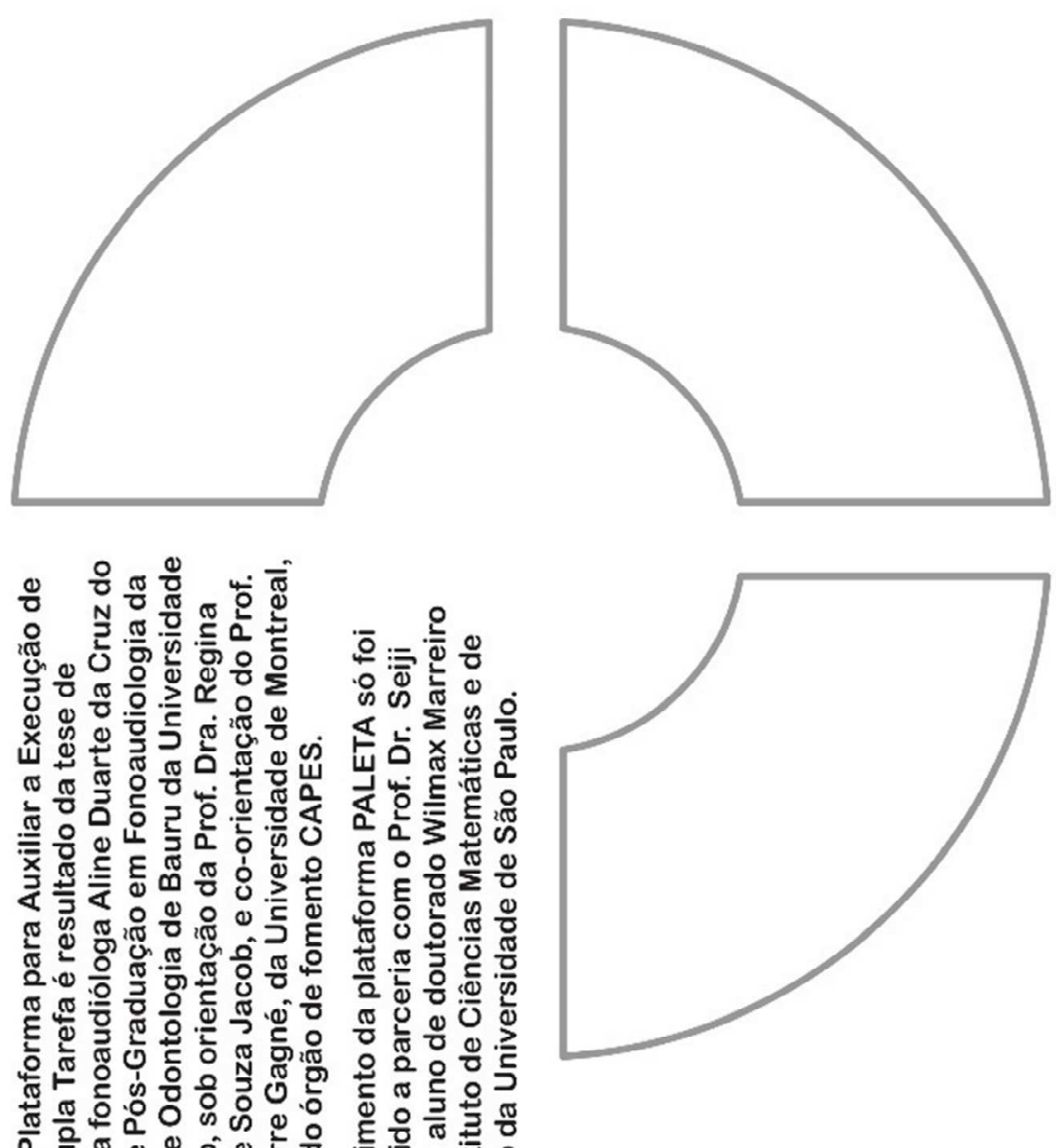

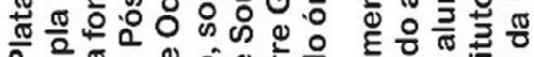

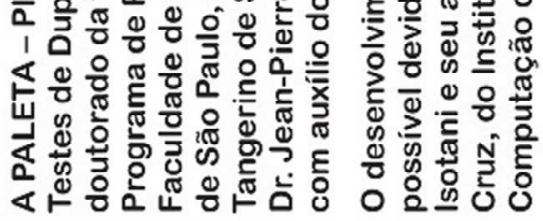
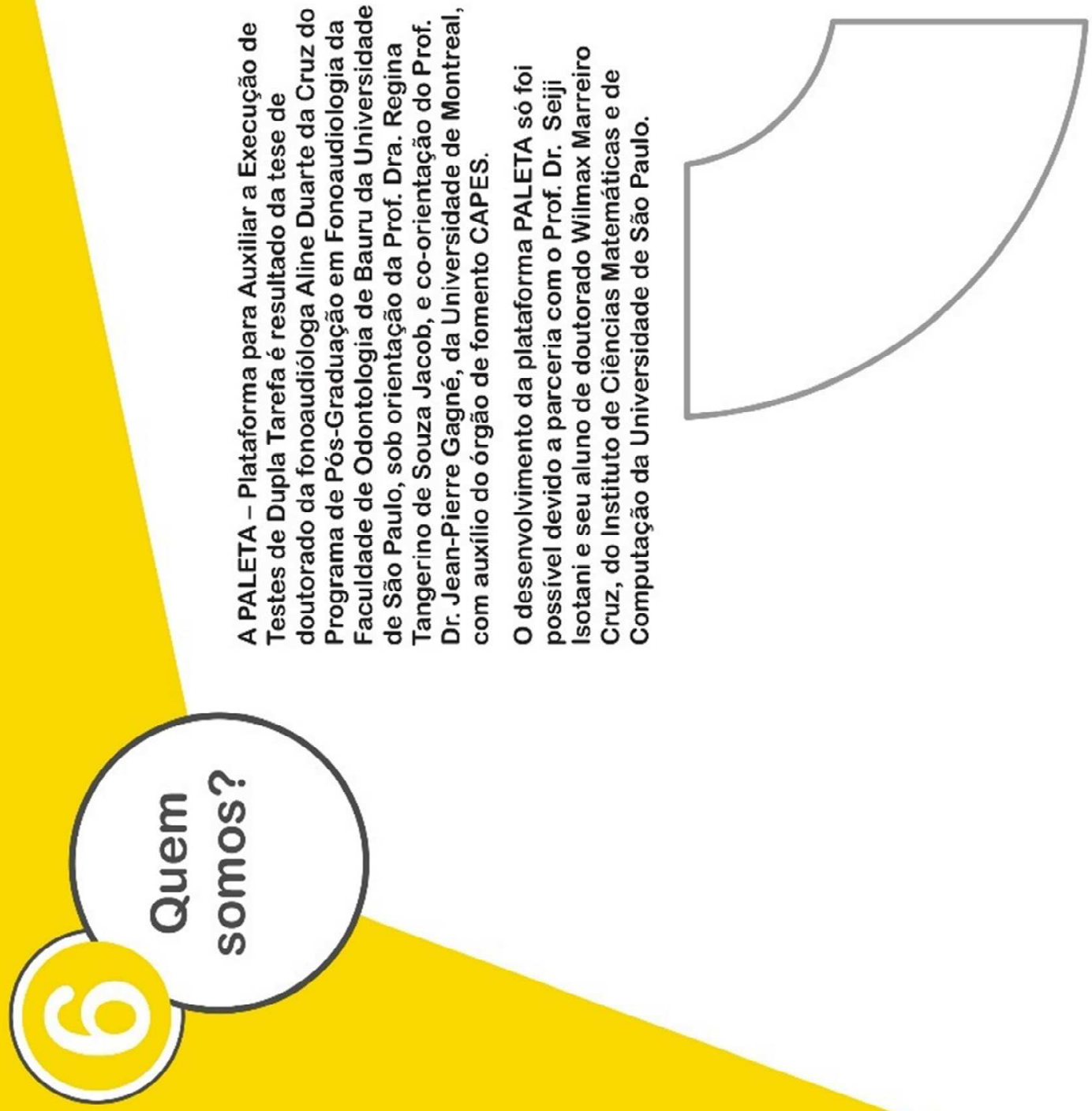


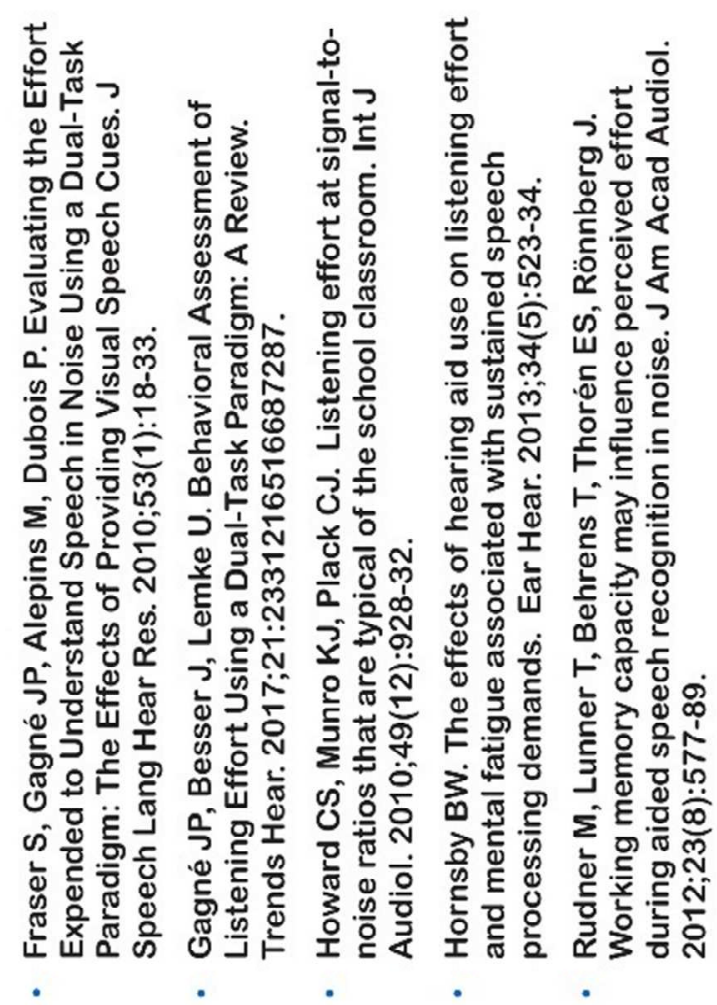




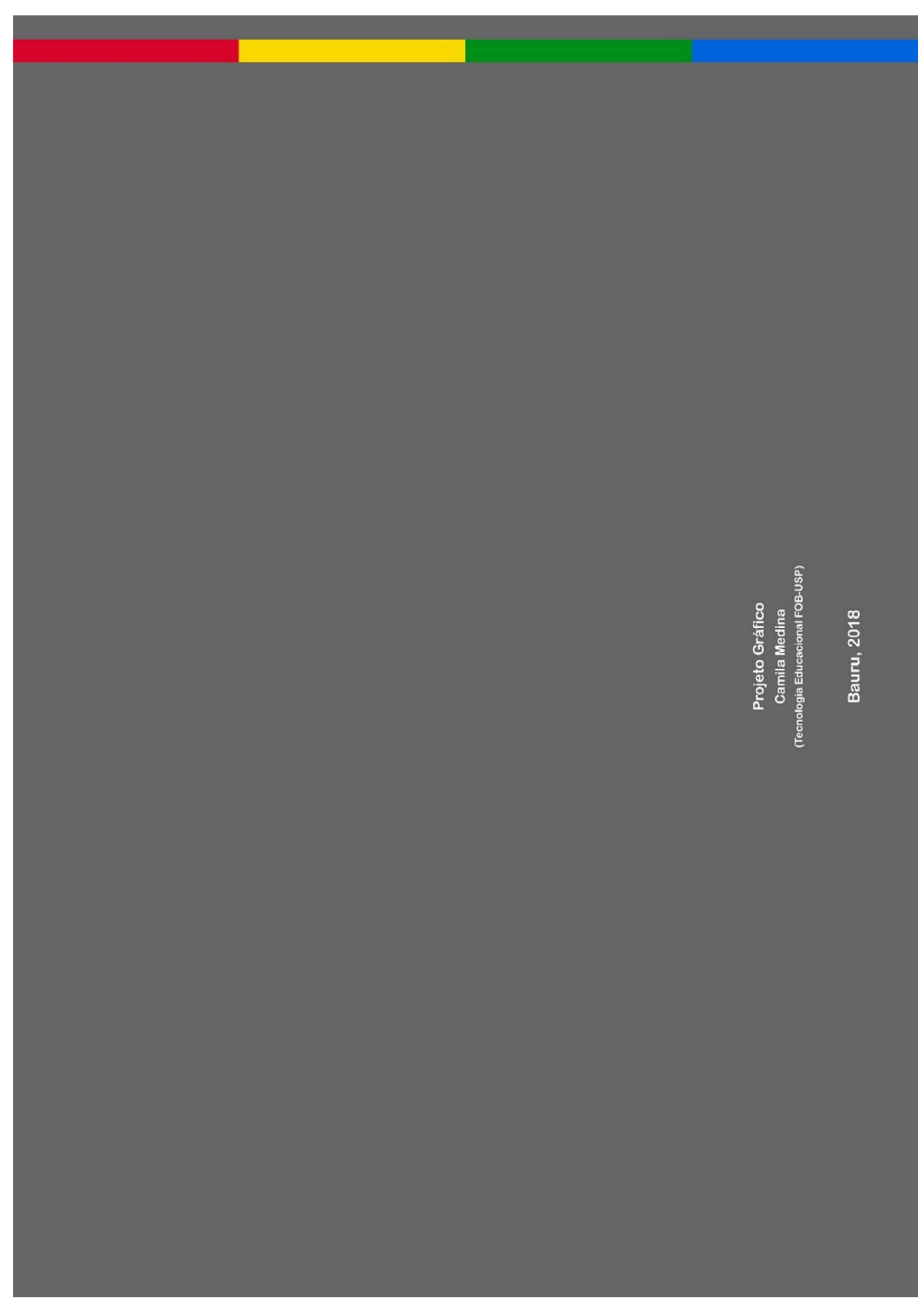



AnEXos 

ANEXO A - Aprovação do CEP

\section{FACULDADE DE ODONTOLOGIA DE BAURU- USP}

Conshugabs do Parecer: 1.074 .623

Consideraçōes Finais a critério do CEP:

Esse projeto foi considerado APROVADO na reunião ordinária do CEP de 20.05.2015. com base nas normas éticas da Resolução CNS 466/12. Ao término da pesquisa o CEP-FOB/USP exige a apresentação de relatório final. Os relatórios parciais deverăo estar de acordo com o cronograma e/ou parecer emitido pelo CEP. Alteraç⿸̄es na metodologia, título, inclusão ou exclusão de autores, cronograma e quaisquer outras mudanças que sejam significativas deverão ser previamente comunicadas a este CEP sob risco de não aprovação do relatório final. Quando da apresentação deste, deverão ser incluídos todos os TCLEs e/ou termos de doaçăo assinados e rubricados, se pertinentes.

BAURU, 22 de Maio de 2015

Assinado por:

Izabel Regina Fischer Rubira Bullen

(Coordenador) 
ANEXO B - Informal Assessment of Fatigue and Learning (Fukuda et al., 2010)

\begin{tabular}{|c|c|c|c|c|c|}
\hline \multicolumn{6}{|c|}{ Fatigue Scale } \\
\hline $\begin{array}{l}0=\text { less of a problem than is usual for my age } \\
1=\text { no more than usual }\end{array}$ & $\begin{array}{l}\mathbf{2}=\text { more than usual } \\
\mathbf{3}=\text { much more than usual }\end{array}$ & 0 & 1 & 2 & 3 \\
\hline \multicolumn{6}{|l|}{ 1. Do you have problems with tiredness? } \\
\hline \multicolumn{6}{|l|}{ 2. Do you need to rest more? } \\
\hline \multicolumn{6}{|l|}{ 3. Do you feel sleepy or drowsy? } \\
\hline \multicolumn{6}{|l|}{ 4. Do you have problems starting things? } \\
\hline \multicolumn{6}{|l|}{ 5. Do you lack energy? } \\
\hline \multicolumn{6}{|l|}{ 6. Do your muscles have less strength (feel weak)? } \\
\hline \multicolumn{6}{|l|}{ 7. Do you feel weak? } \\
\hline \multicolumn{6}{|l|}{ 8. Do you have trouble concentrating? } \\
\hline \multicolumn{6}{|l|}{ 9. Do you make slips of the tongue when speaking? } \\
\hline \multicolumn{6}{|c|}{ 10. Do you find it more difficult than others to find the correct word? } \\
\hline \multicolumn{6}{|l|}{ 11. How is your memory? } \\
\hline & & & & & \\
\hline
\end{tabular}

\section{Learning Effort-Reward Imbalance (LERI) Scale}

1. When I am in school or during class, I must often stop my learning because the actions or noises of other students disturbs me 